
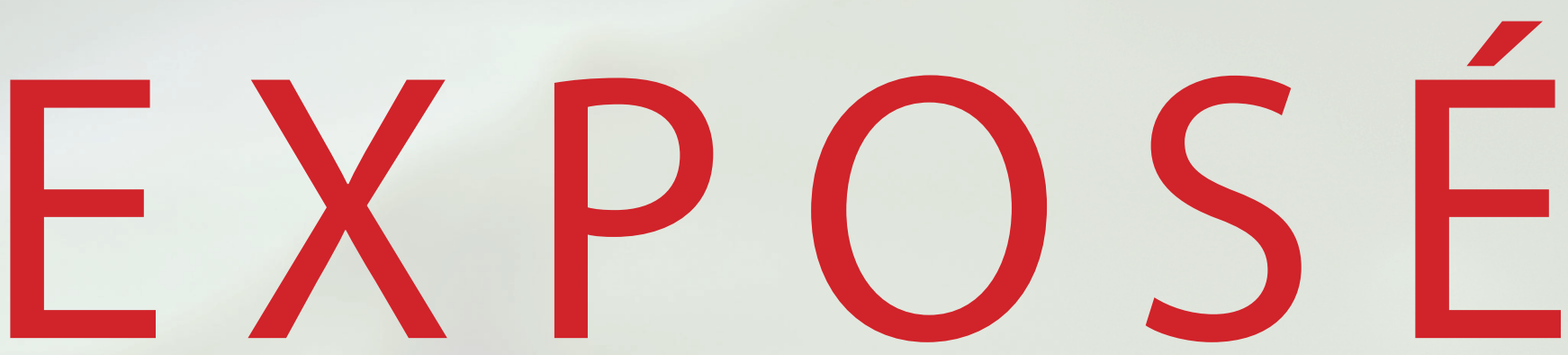

Zeitschrift für wissenschaftliches Schreiben und Publizieren

$1-2021$

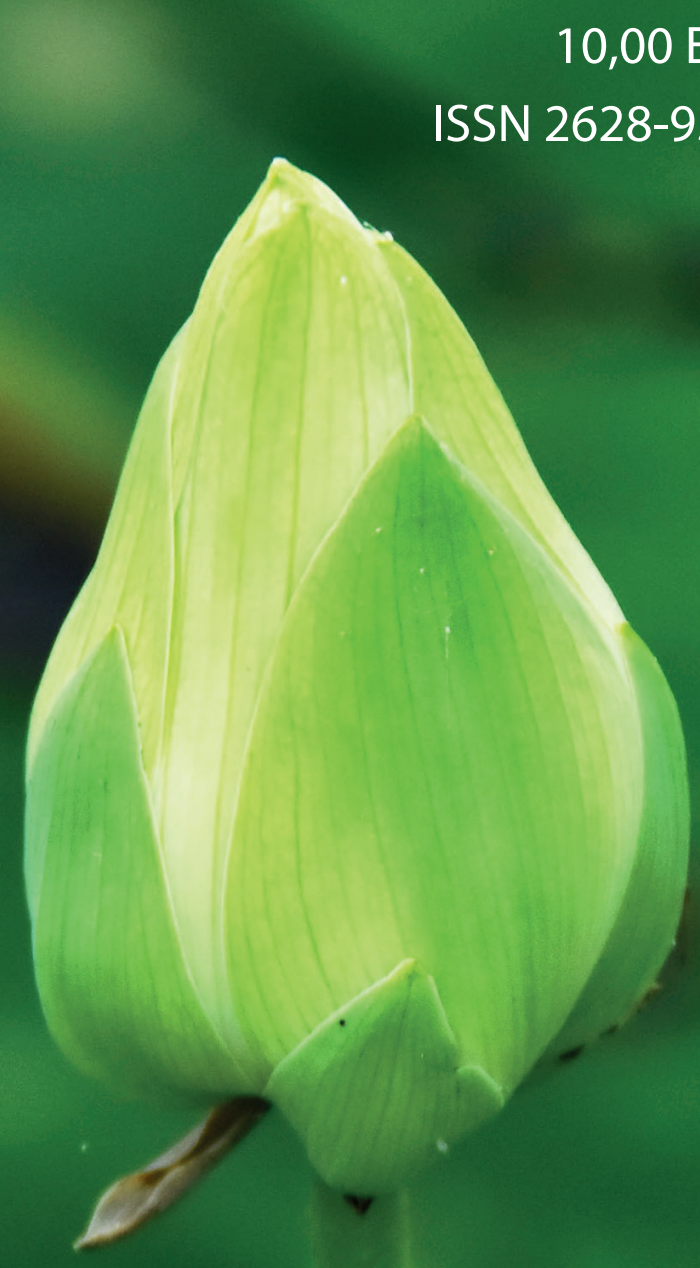

PUBLIZIEREN Die Dissertation veröffentlichen

SCHREIBEN Professioneller Feinschliff der Doktorarbeit PROMOVIEREN Wie Sie den Promotionsalltag meistern NETZWERKEN Schluss mit der Selbstsabotage 


\section{Inhaltsverzeichnis}

Editorial

Magdalena Gromada

Promovieren

Der Promotionsalltag: Zwischen Schweinehund, Pomodoro und zu viel Kaffee

Louise Hoffmann

Die Promotion veröffentlichen

Barbara Budrich

Das Lektorat als wichtiger Bestandteil Ihres Promotionsprojektes

Isabelle Romann

Promovieren als handlungsorientiertes Projekt

Dagmar Knorr

Promovieren mit Kind: Wie lassen sich Dissertation und Familie unter einen Hut bringen?

Majana Beckmann

Der Nutzen von selbstorganisierten Arbeitsgruppen während der Promotion

Alexander Parchow

Die Disputation in Zeiten der Covid-19-Pandemie

Lena Greinke

Netzwerken

Erste leisten Pionierarbeit

Jasmin Döhling-Wölm

\section{Methoden}

Die Auswahl der passenden statistischen Methode

Daniela Keller

Nachwuchstipps

Rezensionen, Auszeichnungen, Veranstaltungen

Autor*innenportraits

\section{Impressum}

Exposé - Zeitschrift für wissenschaftliches Schreiben und Publizieren

herausgegeben von:

Barbara Budrich (Verlag Barbara Budrich) und

Magdalena Gromada (budrich training)

Redaktionelle Betreuung:

Magdalena Gromada

redaktion@expose-zeitschrift.de

Verlag Barbara Budrich GmbH

Stauffenbergstr. 7

D-51379 Leverkusen

Tel. (+49) (0)2171 7949150

Fax (+49) (0)2171 7949169

info@expose-zeitschrift.de

www.expose-zeitschrift.de

www.budrich-journals.de
Die Zeitschrift Exposé erscheint zweimal jährlich. Das Jahresabonnement der Printausgabe kostet im regulären Abonnement 15,00 €, Sonderpreis für Studierende 12,00€ (jeweils zzgl. Zustellgebühr). Ein Einzelheft kostet 10,00€ zzgl. Versandkosten. Abonnements-Kündigungen bitte schriftlich an den Verlag. Die Kündigungsfrist beträgt drei Monate zum Jahresende. Anzeigenverwaltung beim Verlag.

Für die Printausgabe $\odot 2021$ Verlag Barbara Budrich Opladen, Berlin \& Toronto Druck und Verarbeitung: WIRmachenDRUCK GmbH, Backnang Printed in Europe

Für die Printausgabe: Alle Rechte vorbehalten. Kein Teil dieser Zeitschrift darf ohne schriftliche Genehmigung des Verlages vervielfältigt oder verbreitet werden. Unter dieses Verbot fällt insbesondere die gewerbliche Vervielfältigung per Kopie.

Die Online-Ausgabe von Exposé erscheint im goldenen Open Access (CC BY-SA 4.0). https://creativecommons.org/licenses/ by-sa/4.0/. Diese Lizenz erlaubt die Verbreitung, Speicherung, Vervielfältigung und Bearbeitung bei Verwendung der gleichen CC-BY-SA 4.0-Lizenz und unter Angabe der Urheber*innen, Rechte, Änderungen und verwendeten Lizenz. Ausgenommen hiervon sind Abbildungen und Fotos 


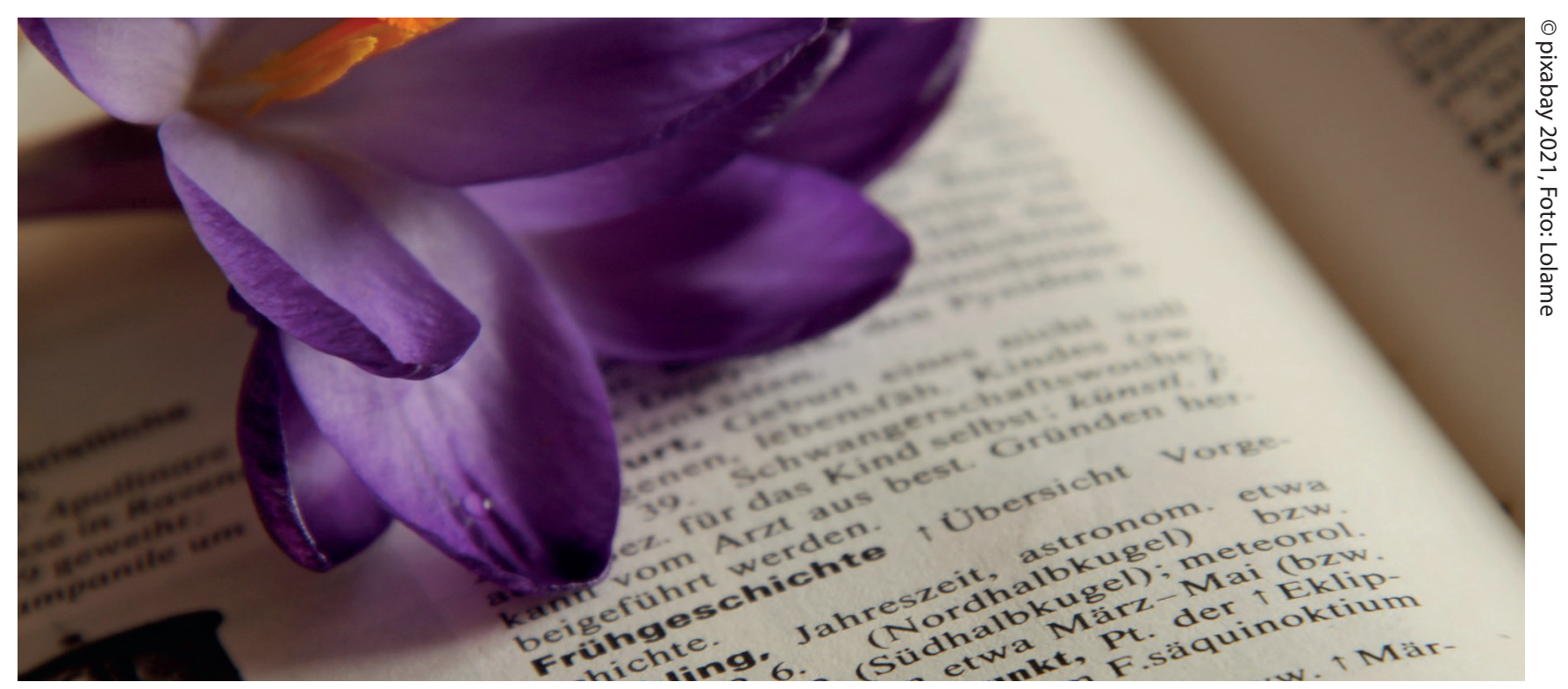

\section{Editorial}

Liebe Leser*innen,

ich freue mich, Ihnen unsere dritte Ausgabe und unser erstes Themenheft mit dem Schwerpunkt Promotion zu präsentieren!

Neben den Beiträgen unserer üblichen Expert*innen haben wir unter der Vielfalt und -zahl an eingesandten Artikeln eine Auswahl getroffen, die aus unterschiedlichen Perspektiven Aspekte rund um die Dissertation beleuchtet: Überschaubar legt Barbara Budrich Ihnen die Möglichkeiten dar, die Ihnen zur Veröffentlichung zur Verfügung stehen. Isabelle Romann erläutert, welche Vorteile ein professionelles Lektorat Ihrer Dissertation Ihnen bietet (auch wenn Sie fit sind in Orthografie und Grammatik). Mit der Vorstellung ihres Kaskadenmodells lädt Dagmar Knorr Sie ein, die Promotion als Projekt zu denken. Wenn Sie promovieren und Kinder haben, hat Majana Beckmann praktische Tipps für Sie. Alexander Parchow berichtet von seinen positiven Erfahrungen mit selbstorganisierten Arbeitsgruppen, die durch Austausch und Verbindlichkeit den eigenen Forschungsund Schreibprozess im Alltag verankern. Auch in Zeiten der Pandemie wird promoviert: Lena Greinke hat unter, auch technisch, besonderen Umständen verteidigt und lässt uns an ihren Erkenntnissen teilhaben.
Der rege und freudige Austausch während der Herstellung dieser Ausgabe ist überschattet von einem traurigen Ereignis: Unsere Autorin Louise Hoffmann ist kurz nach der Fertigstellung ihres Artikels unerwartet verstorben. Nicht nur wissenschaftlich hochengagiert: Informationen zu Frau Hoffmanns Vita finden Sie unterhalb ihres Beitrags und ich empfehle Ihnen einen Blick auf ihre Webseite als Zeugnis ihres inspirierenden Lebens und wissenschaftlichen Wirkens. Der motivierende, leichtfüßige Artikel zum Promotionsalltag bildet unseren Auftakt, Sie finden ihn gleich auf der folgenden Seite. Mit Humor gewürzt gibt er hilfreiche Handreichungen, um in Balance durch die Herausforderungen und Hürden der Promotionszeit zu kommen.

Denn das ist Zweck dieser Ausgabe: Sie gut und mit Anregungen versorgt durch die Promotionszeit zu begleiten, auf die Dissertation vorzubereiten oder Ihre Studierenden mit unseren Inhalten zu unterstützen. Sollte das nicht Ihr Thema sein, haben wir in der 2. Ausgabe 2021 den Schwerpunkt Internationales und mit Sicherheit den ein und anderen Beitrag für Sie - oder wollen Sie selbst einen Artikel verfassen? Schreiben Sie mir gern: redaktion@exposé-zeitschrift.de!

In diesem Sinne: Kommen Sie gut und ausgeglichen durch die Promotion, genießen Sie den Frühling!

Ihre Magdalena Gromada 


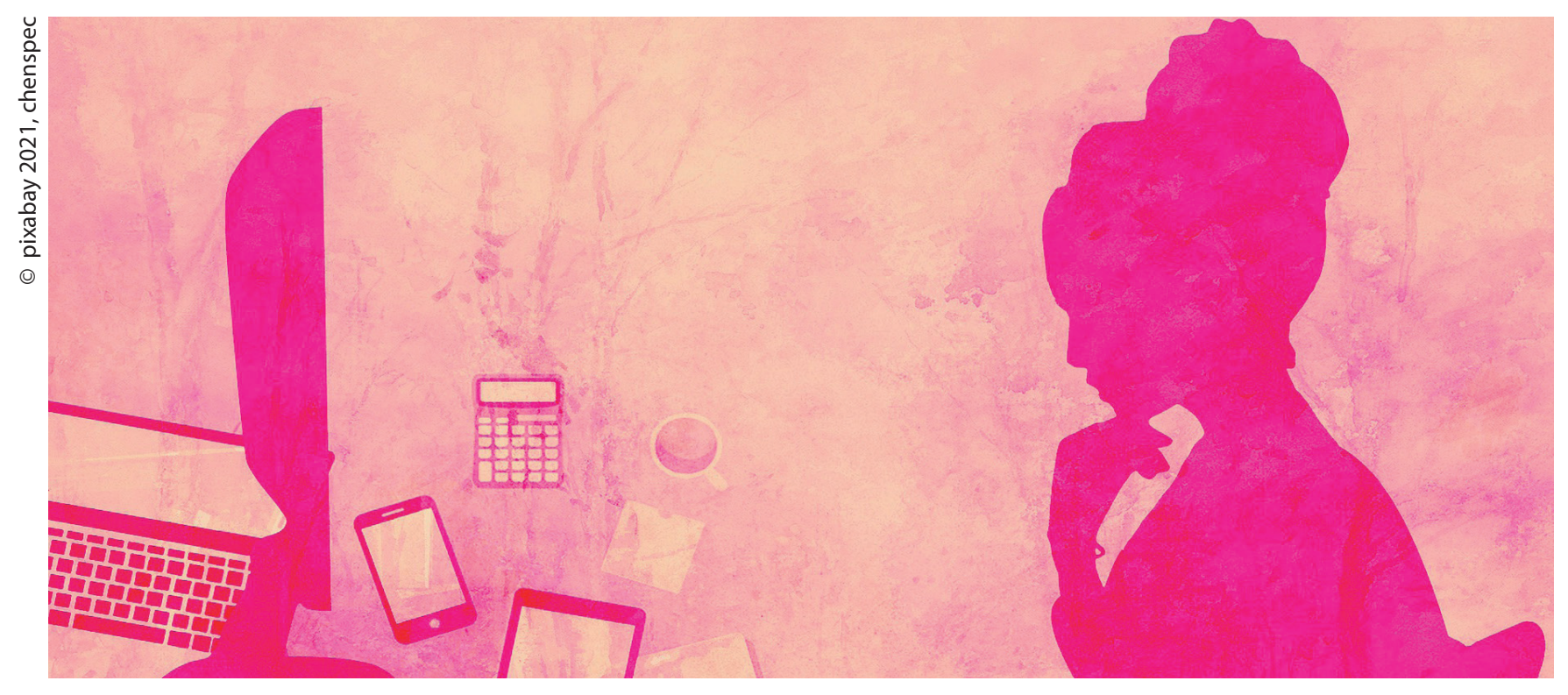

\section{Der Promotionsalltag: Zwischen} Schweinehund, Pomodoro und zu viel Kaffee

\section{von Louise Hoffmann}

Das Verfassen einer Doktorarbeit ist ein langer Prozess, der vor allem viel Selbstorganisation benötigt. Auf den folgenden Seiten erhalten Doktorand*innen verschiedene Anregungen, wie sie ihren Promotionsalltag optimieren können und sich somit besser auf ihr Projekt fokussieren können.

\section{„Warum tue ich mir das eigentlich an?" - Warum Ziele so wichtig sind}

Ein großes Ziel haben Sie sich bereits gesetzt, in dem Sie sich für die Promotion entschieden haben. Sie möchten ein bestimmtes Thema durchdringen und somit neue Forschungsergebnisse erzeugen. Vielleicht haben Sie auch bereits eine bestimmte wissenschaftliche Tätigkeit im Blick, für die ein Doktortitel verlangt wird. Der Weg bis dahin dauert jedoch mehrere Jahre und benötigt viel Durchhaltevermögen. Zwischenziele in Form von Meilensteinen können Sie dabei unterstützen, Ihre großen Ziele (Promotion, Job...) nicht aus den Augen zu verlie- ren. Bei der Erstellung der Meilensteine sollten Sie nicht nur an Ihre Promotion, sondern auch an Ihre berufliche und private Zukunft denken. Wenn Sie also bereits wissen, welchen beruflichen Weg Sie nach der Promotion einschlagen möchten, könnten Sie überlegen, welche Kompetenzen Sie in diesem Bereich während der Promotionszeit vertiefen könnten. Überlegen Sie sich für die gesamte Promotionszeit zunächst größere Meilensteine (z.B. Exposé), die Sie dann weiter unterteilen - nach Jahr oder Semester. Diese können Sie anschließend herunterbrechen in kleinere Ziele, wie z.B. Monats-, Wochen-, oder Tagesziele. Planen Sie stets genügend Puffer mit ein, um Frustration angesichts nicht erreichter Ziele zu vermeiden. Behalten Sie dabei auch Ereignisse im Blick, welche die Meilensteine in irgendeiner Weise beeinflussen könnten, z.B. die Geburt eines Kindes, ein Umzug usw. 
"Ach, das kann ich doch auch übermorgen machen": Planen Sie Diss-Zeiten ein

Nachdem die einzelnen Ziele konkretisiert wurden, ist es wichtig, sich Zeitfenster zu blocken, in denen man ungestört arbeiten kann. Damit Sie Ihre Diss-Zeiten nicht immer vor sich hinschieben, blocken Sie Zeiten in Ihrem Kalender, die ausschließlich für die Promotion reserviert sind. Informieren Sie andere Personen über Ihre Abwesenheit, wie z.B. Familienangehörige oder den Freundeskreis, damit sie wissen, dass Sie in dieser Zeit nicht gestört werden möchten. Nützlich könnte es auch sein, diese Zeiten in Ihrem Arbeitskalender einzutragen (hier können Sie den Termin als "privat" markieren). Sofern auch andere Promovierende Zeit haben, könnten Sie Ihre Diss-Zeit für gemeinsame (Online-) Schreibtreffen nutzen. Der Vorteil: Sie motivieren sich gegenseitig, tauschen sich über Ihre Ziele aus und der "Gruppenzwang" hilft, dass Sie an Ihrer Dissertation arbeiten.

Egal, ob Sie alleine oder gemeinsam mit anderen an diesen Tagen etwas für Ihre Dissertation tun: es ist hilfreich, den Tag in mehrere Arbeitsphasen zu unterteilen und dazwischen genügend Pausen einzuplanen. Dabei können Sie nach der Pomodoro-Methode vorgehen: 25 Minuten arbeiten, dann 5 Minuten Pause und dann wieder $25 \mathrm{Mi}$ nuten arbeiten. Das Ganze wiederholen Sie insgesamt $4 \mathrm{Mal}$ und machen anschließend eine längere Pause. Sie werden erstaunt sein, wie viel Sie in 25 Minuten geschafft bekommen, vorausgesetzt, Sie setzen auch die nächsten Punkte um.

"Ich weiß sowieso nicht, wo ich gerade stehe, da muss ich erst gar nicht anfangen": Das Motivationsjournal Eine weitere Herausforderung von Promovierenden ist es, den Überblick über die verschiedenen Arbeitsschritte zu behalten. Gerade, wenn man nicht täglich an seiner Promotion sitzt, kann es schnell mal passieren, dass man die Orientierung verliert. Ein nützliches Instrument kann das Führen eines Journals sein, das verschiedene Funktionen erfüllen kann. Erstens unterstützt es Sie, den Gesamtüberblick über Ihr Projekt zu behalten, indem Sie einzelne Arbeitsschritte mit Datum knapp zusammenfassen. Zweitens kann es Sie auf lange Sicht unterstützen, fokussierter zu arbeiten, indem Sie zu Beginn einer Arbeitseinheit die Aufgabe konkretisieren und abschlie-
Bend die wichtigsten Ergebnisse notieren. Drittens kann es Sie dabei unterstützen, die nächsten Arbeitsschritte zu planen, indem Sie aus Ihren Notizen Rückschlüsse ziehen, was als Nächstes bei Ihnen ansteht.

"Voll dieTasse, fertig, losschreiben“-Die Aufwärmphase Nicht nur beim Sport, sondern auch bei der Erstellung Ihrer Dissertation benötigen Sie eine "Aufwärmphase". Überlegen Sie sich Rituale, die Ihnen den Beginn der Aufwärmphase erleichtern. Bevor Sie sich an den aufgeräumten Schreibtisch setzen, könnten Sie sich z.B. noch einen Kaffee kochen und diesen in Ihre Lieblingstasse gießen. Oder Sie hören sich noch ein bestimmtes Lied an, welches Sie in die richtige Arbeitsstimmung versetzt ... Seien Sie ruhig kreativ und überlegen Sie, was Ihnen konkret helfen würde. Geschmäcker sind bekanntlich sehr verschieden und was die eine Doktorandin als hilfreich empfindet, mag der nächste Doktorand nicht. Nutzen Sie die Aufwärmphase auch dazu, sich einen Überblick zu verschaffen, wo Sie aktuell stehen. Bevor Sie also einen Aufsatz zu einem bestimmten Teil Ihrer Dissertation lesen, könnten Sie eine Mind-Map erstellen, um herauszufinden was Sie schon zu diesem Thema wissen. Nach der Lektüre können Sie Ihre Visualisierung anschließend mit weiteren Begriffen ergänzen.

"Ich recherchiere das mal schnell, dann arbeite ich weiter" - Fokus im Blick

Einige Anregungen, um fokussiert arbeiten zu können, haben Sie bereits in den letzten Abschnitten gelesen. Sie wissen mittlerweile, wie Sie Ihre Aufgaben in kleine realistische Arbeitspakete packen können und wie Sie die Aufwärmphase nutzen können, um sich gedanklich auf Ihre Promotion vorzubereiten. Das sind schon mal gute Vorrausetzungen für die nächste Phase: die Fokus-Phase. Damit Sie langfristig fokussiert bleiben und nichts dem Zufall überlassen, ist es wichtig, dass Sie allgemein Ihre Bedürfnisse kennen: Zu welchen Zeiten sind Sie am produktivsten? Wie lange am Stück können Sie konzentriert arbeiten? Arbeiten Sie lieber mit Hintergrundgeräuschen, alleine oder in Gesellschaft? Gerade für die Fokuszeit ist es wichtig, dass Sie sich von dem Rest der Welt abschirmen. Schließen Sie dafür alle Programme Ihres Computers, die Sie aktuell nicht benötigen (insbesondere das eMail-Programm!). Versuchen Sie zudem, sich nicht von 
Gedanken ablenken zu lassen, die Ihnen zwischendurch durch den Kopf gehen, egal, ob sie Ihre Promotion oder etwas Anderes betreffen. Notieren Sie sie notfalls kurz auf einem Zettel, damit Sie sie nicht vergessen. Wichtig aber: Behalten Sie den Fokus aufrecht, für alles Weitere ist später auch noch Zeit.

„Tschüss, Schweinehund, hallo Katzenbuckel!“ - Wie Sie die Diss und sich selbst in Einklang bringen

Achten Sie auf regelmäßige Pausen, auch wenn Sie noch so fokussiert sind. Nutzen Sie die Pausen zum Beispiel, um die Waschmaschine laufen zu lassen (die dann passend zur nächsten Pause fertig ist), etwas frische Luft auf dem Balkon zu holen oder sich mit jemandem aus Ihrer Familie zu unterhalten. Vergessen Sie Ihren Körper nicht und nutzen Sie die Pause, um sich etwas zu bewegen. Ein paar Yoga-Übungen lassen sich auch in kurzen Pausen durchführen, wie z. B. die Katzenbuckel-Übung. Gönnen Sie sich neben kleinen Pausen auch regelmäßig längere Auszeiten von der Dissertation. Gerade wenn es mal klemmt, kann dies ein Signal Ihres Körpers sein, dass Sie überlastet sind und etwas zur Ruhe kommen sollten.

\section{„Wo ist denn hier der Kompass?" - Die Promotion als} Reise zu sich selbst

In dem Moment, wo Sie sich entscheiden, den Promotionsweg zu gehen, entscheiden Sie sich zu einer Reise, die mehrere Jahre lang andauern und die Sie auch persönlich verändern wird. Lernen Sie geduldig mit sich selbst zu sein, auch wenn es an der einen oder anderen Stelle mal nicht so funktioniert, wie Sie es sich vorstellen. Seien Sie kreativ und suchen Sie nach neuen Wegen, um an Ihr Ziel zu kommen. Warum z.B. nicht mal den Schreibort oder das Schreibmedium wechseln? Es sind manchmal schon Kleinigkeiten, die viel verändern können. Vernetzen Sie sich in Ihrer Fachcommunity und tauschen Sie sich mit anderen Promovierenden aus. Sie werden sehen, Sie sind mit Ihren Problemen nicht alleine. Holen Sie sich Unterstützung bei Ihrer Betreuung, wenn Sie Hilfe benötigen und schieben Sie es nicht zu lange vor sich her. Krisen in der Promotion und während des Schreibprozesses gehören dazu. Auch wenn es nicht immer leicht ist: Nehmen Sie sie an und versuchen Sie, sich diese zu Nutze zu machen. Vielleicht hilft es Ihnen ja in solchen Momenten, an Krisen oder Ziele zu denken, die Sie schon gemeistert haben und die Sie langfristig vorangetrieben haben?

Und last but not least und frei nach Mark Twain: „Gib jedem Tag die Chance, der schönste Deiner Diss zu werden".

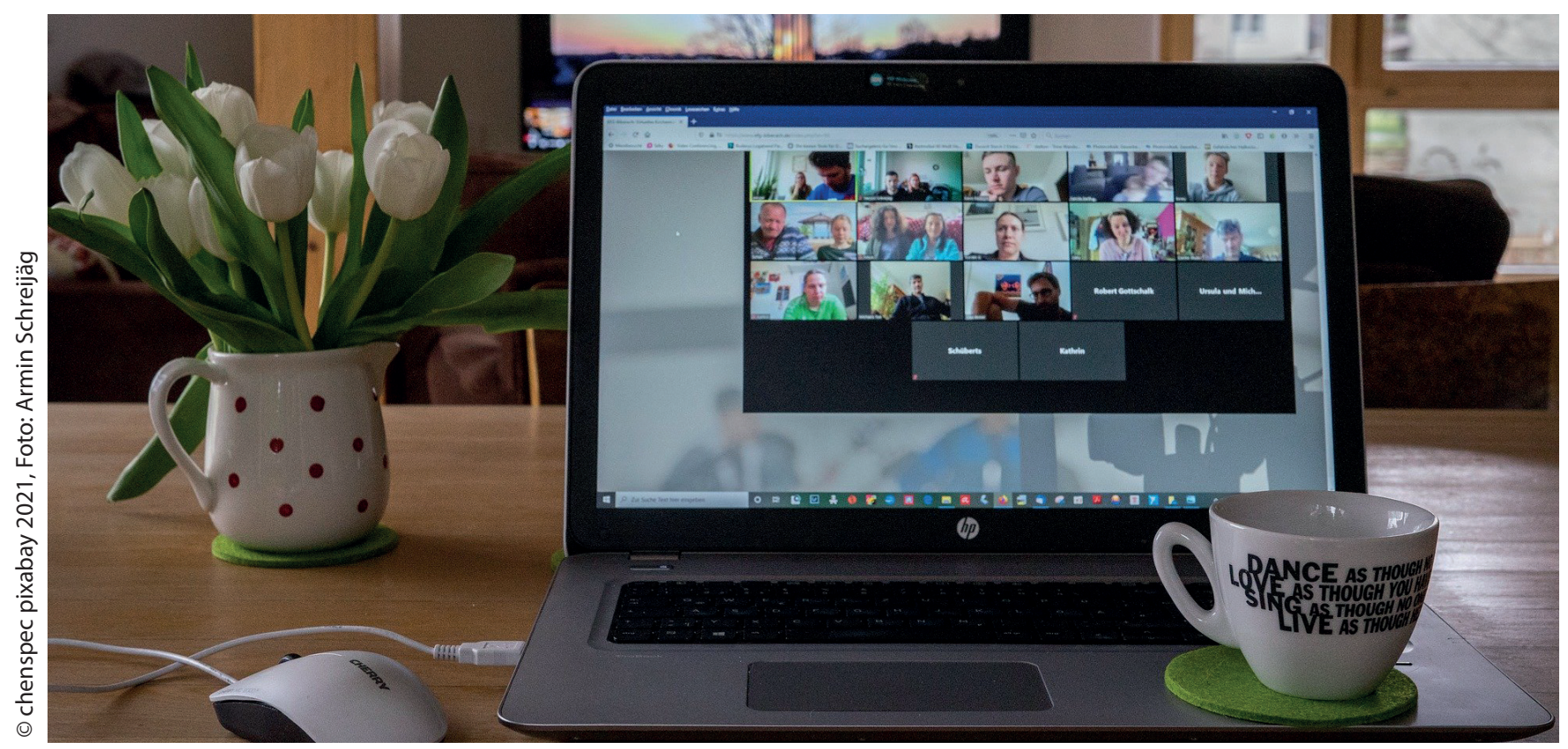




\section{Zum Weiterlesen:}

Günauer, Franziska et al. (2017): GEW-Handbuch Promovieren mit Perspektive: Ein Ratgeber von und für Doktorandlnnen. Bielefeld: wbv Media.

Wergen, Jutta: Promotionsplanung und Exposee (2019): Die ersten Schritte auf dem Weg zum Weg zum Doktortitel. Opladen, Toronto: utb (Verlag Barbara Budrich).

\section{Anm. Prof. Dr. Tobias Schmohl:}

Die Autorin dieses Beitrags ist kurz vor Fertigstellung des Manuskriptes nach kurzer, schwerer Krankheit unerwartet verstorben. In Rücksprache mit den Herausgeberinnen dieser Zeitschrift habe ich den Beitrag redaktionell überarbeitet, sodass er hier posthum erscheinen kann. Dafür möchte ich mich nochmals ausdrücklich bedanken, da ich weiß, dass Louise Hoffmann sich über die Manuskriptannahme sehr gefreut hatte. Das Dissertationsprojekt von Louise Hoffmann habe ich seit Anfang 2018 als kooperative Promotion gemeinsam mit Prof. Dr. Julia Schütz (FernUniversität in Hagen) betreut. Die nachfolgende Kurzvita entstammt meiner Feder.

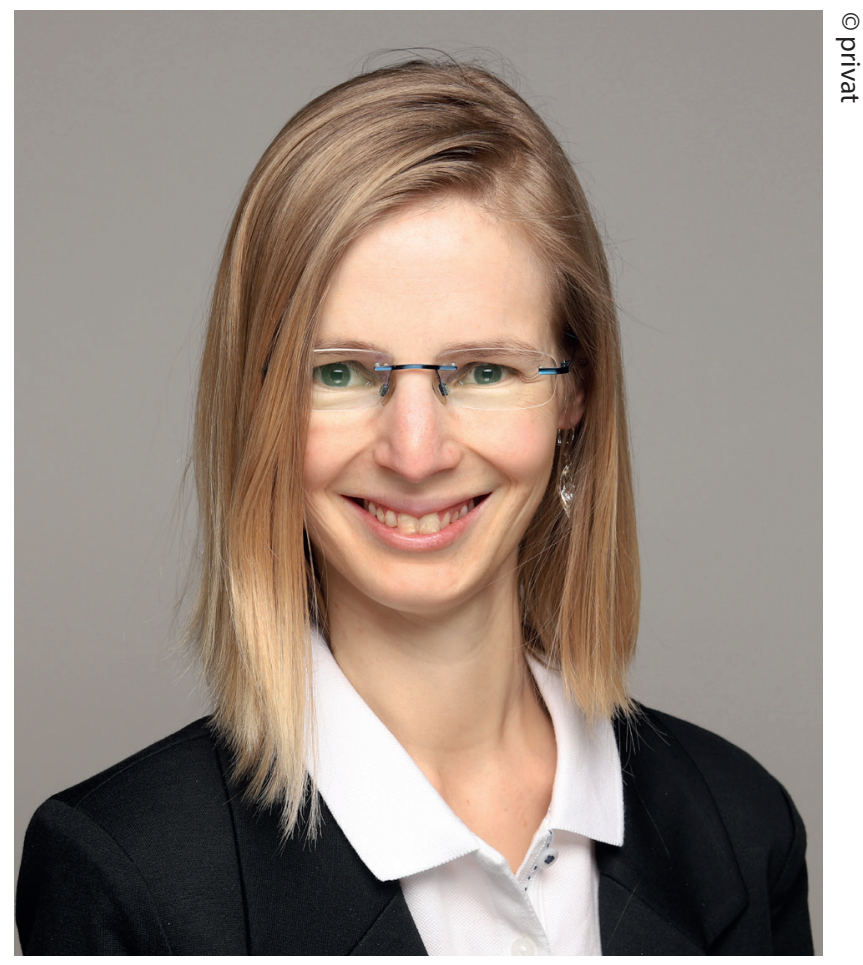

Louise Hoffmann, M.A. (geb. Lenz) war fachlich im Bereich der wissenschaftlichen Schreibdidaktik angesiedelt. Sie war Mitglied der Gesellschaft für Schreibdidaktik und Schreibforschung e. V. Ihr Promotionsthema befasste sich mit der schreibdidaktischen, diversitätssensiblen Unterstützung von Studierenden in berufsbegleitenden Masterprogrammen an deutschen Hochschulen. Ziel ihrer Forschung war es, die Schreibsozialisation bei Masterstudierenden im Fernstudium zu untersuchen, um ihre Bedürfnisse herauszufinden und langfristig entsprechende Fördermaßnahmen zum selbstregulierenden Schreiben entwickeln zu können. Ein besonderer Fokus lag auf der heterogenen Zusammensetzung dieser LernendenGruppe im Hinblick auf unterschiedliche Bildungsverläufe, Schreiberfahrungen aus formellen und informellen Lernkontexten sowie fachliche Enkulturationen. Mehr über sie und ihr vielseitiges Engagement finden Sie auf ihrer Webseite: https://www.louise-hoffmann.de/. 


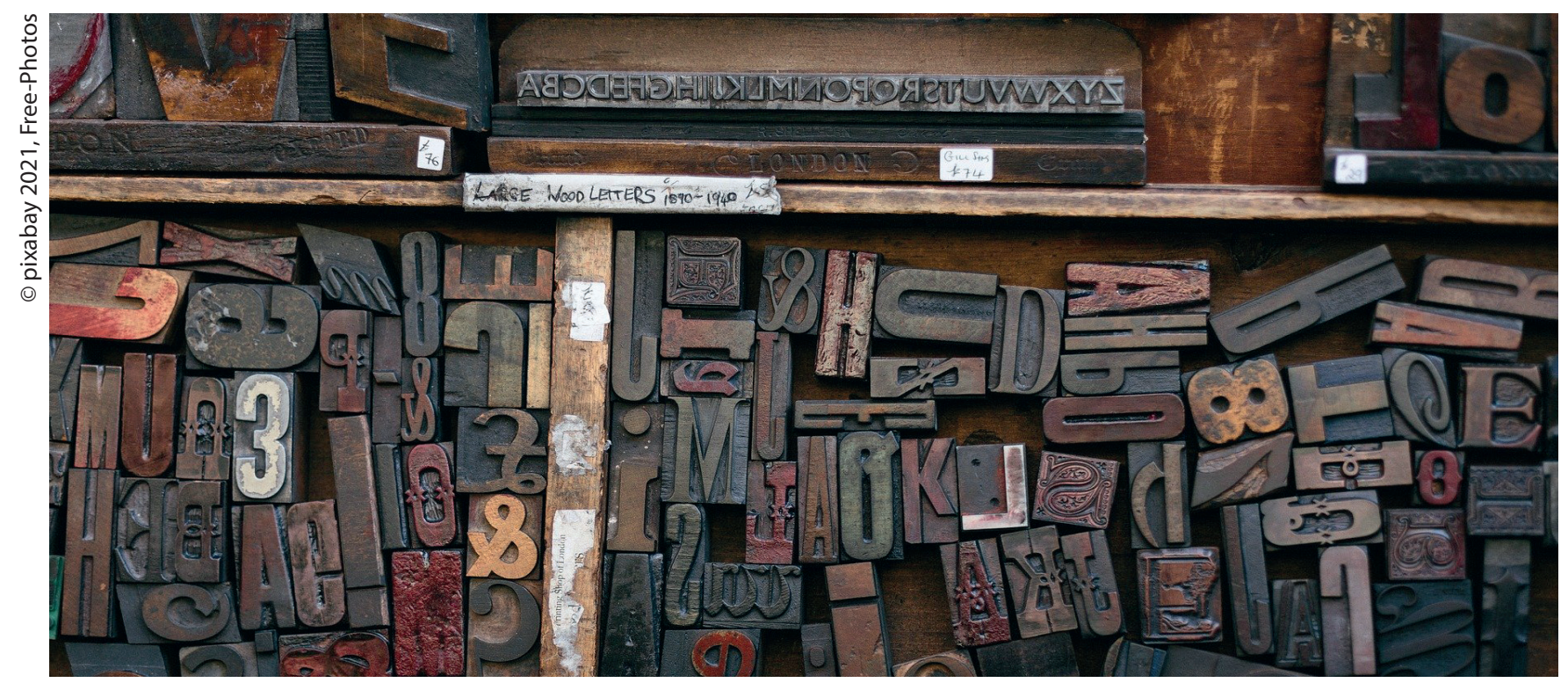

\section{Die Promotion veröffentlichen}

\section{von Barbara Budrich}

Im deutschsprachigen Raum gilt für Doktorarbeiten vielfach eine Publikationspflicht. Häufig haben Promovierende die Wahl, ob sie kumulativ oder monografisch vorgehen. In beiden Fällen ist das zeitnahe, angemessene Publizieren nicht trivial. Lassen Sie uns beide Varianten mit ihren Vor- und Nachteilen kurz beleuchten.

\section{Kumulativ Publizieren}

Die Vorgaben zum kumulativen Publizieren sind unterschiedlich - von Hochschule zu Hochschule und von Fachbereich zu Fachbereich. Was bedeutet, dass Sie im Falle einer kumulativen Promotion zunächst die Spielregeln herauszufinden haben. Und zwar am besten, bevor Sie sich fest- und loslegen.

Mir ist es in meiner Beratungspraxis schon begegnet, dass eine Promovierende vor der Aufgabe stand, in einem gerankten Journal zu veröffentlichen - in einem Fachbereich, in dem es zu diesem Zeitpunkt keine gerankten deutschsprachigen Journals gab. Ihre Fragestellung allerdings bezog sich explizit auf Deutschland, und es war für sie nicht leicht, überhaupt einen englischsprachigen Text zu verfassen. Bei anderer Gelegenheit war das Thema einer Doktorarbeit derart interdisziplinär ausgerichtet, dass es schwierig war, eine passende Zeitschrift zu finden - oder gar drei bis vier verschiedene, um dort zu veröffentlichen. Der Doktorvater kannte sich in diesem Bereich mit den Publikationsmöglichkeiten selbst nicht aus und konnte nicht unterstützen. Zwei Beispiele, die andeuten, wo Probleme liegen können.

Wenn Sie also Ihre Dissertation kumulativ Publizieren möchten, stellen Sie sicher, dass Sie eine Vorstellung davon haben, in welchen Zeitschriften dies für Sie angemessen möglich ist.

Hinzu kommt die Zeitschiene: Es mag einfach klingen, innerhalb der vorgegebenen Zeit drei oder vier Aufsätze zu publizieren. Je nachdem, in welcher Disziplin Sie mit welchem Schwerpunkt unterwegs sind und innerhalb welches Zeitrahmens die von Ihnen in die engere Wahl genommenen Zeitschriften operieren, kann dies zu einer Herausforderung werden.

Ich kenne nicht wenige Zeitschriften, bei denen vom Call for Papers bis zur Publikation 12 bis 18 Monate vergehen. Bei manch einer Zeitschrift dauert es von der Einreichung bis zur Rückmeldung bereits drei bis sechs Monate. Solange Ihr Vorschlag oder Manuskript akzeptiert wird, mag daraus ein für Ihre Belange passender Zeitrah- 
men werden. Kassieren Sie hingegen eine oder gar mehrere Absagen und es kommen Überarbeitungsschleifen hinzu, kann das Ganze rasch zu einer sehr langwierigen Operation ausarten.

Schließlich bleibt noch die Rechtefrage, wenn Ihre Arbeit nach den Veröffentlichungen der einzelnen Aufsätze als Ganzes publiziert werden soll. Diese Frage ist weder kompliziert noch besonders anspruchsvoll - es empfiehlt sich lediglich, bereits vor der Veröffentlichung der Aufsätze mit der jeweiligen Redaktion über Ihre Verpflichtung zu sprechen, diesen Aufsatz erneut in einem anderen Kontext zu publizieren.

\section{Die Doktorarbeit als Monografie}

Um Ihre Doktorarbeit als Monografie zu veröffentlichen, haben Sie zahlreiche Möglichkeiten. Welchen Weg Sie beschreiten können und wollen, liegt vor allem an Ihren eigenen Kriterien.

Während die Veröffentlichung in einem renommierten Wissenschaftsverlag für gewöhnlich die größte Reputation bietet, ist dies im Vergleich mit den übrigen Publikationswegen tendenziell die langwierigste, aufwendigste und teuerste Variante.

In der Abbildung finden Sie eine Matrix, die potenzielle Publikationspartner und einige Autor*innen-Kriterien verknüpft. Bitte verstehen Sie die Kriterien nur als Beispiele: Es gibt weitere und andere Dinge, die Ihnen wich- tig sind - die vorgestellten Anforderungen sind weder vollständig, noch muss jede einzelne für Sie relevant sein.

Übrigens ist die Veröffentlichung als eBook zumeist selbstverständlich, und Open Access zu publizieren ist häufig eine Option. Bevor Sie sich auf einen Publikationspartner festlegen, stellen Sie sicher, dass Ihre Monografie in der von Ihnen präferierten Variante bzw. im von Ihnen gewünschten Format veröffentlicht wird und dass Sie im Besitz aller notwendigen Rechte sind, die zur Veröffentlichung notwendig sind.

\section{Ihr Ziel - Ihr Weg}

Welcher Weg der "richtige" ist, vermag ich nicht zu sagen: Das hängt von Ihnen, Ihren Zielen und Ihren Möglichkeiten ab. Mir sind beinahe schon so viele unterschiedliche Kriterien, Wünsche und Vorstellungen untergekommen wie Promovierende. Die eigenen Ideen mit der Realität abzugleichen, ist unabdingbar (entschuldigen Sie die Trivialität!) - und häufig gibt es im je eigenen Umfeld nur Wenige, die sich mit den unterschiedlichen Optionen des Publizierens umfassend auskennen. Wie in vielen Bereichen des Lebens ist durch die Vervielfältigung der Wahlmöglichkeiten die Unsicherheit nicht kleiner geworden. Wenn Sie aber Ihre eigenen Ziele, Ihre Motivation und Ihre Möglichkeiten klar vor Augen haben, fällt die Wahl leichter.

\begin{tabular}{|c|c|c|c|c|c|}
\hline $\begin{array}{l}\text { Anforderung } \\
\text { Publikations- } \\
\text { partner }\end{array}$ & $\begin{array}{l}\text { „Ich möchte } \\
\text { möglichst schnell } \\
\text { veröffentlichen!" }\end{array}$ & $\begin{array}{l}\text { „Ich möchte, dass } \\
\text { meine Publikation } \\
\text { im Buchhandel zu } \\
\text { beziehen ist!" }\end{array}$ & $\begin{array}{l}\text { „Mir soll niemand } \\
\text { in meinen Text } \\
\text { „reinquatschen“!" }\end{array}$ & $\begin{array}{l}\text { „Ich möchte die } \\
\text { größtmögliche } \\
\text { Reputation } \\
\text { erreichen!" }\end{array}$ & $\begin{array}{l}\text { „Die Publikation } \\
\text { soll mich möglichst } \\
\text { wenig kosten.” }\end{array}$ \\
\hline $\begin{array}{l}\text { Renommierter } \\
\text { Wissenschafts- } \\
\text { verlag }\end{array}$ & & + & & + & \\
\hline $\begin{array}{l}\text { Bibliotheks- } \\
\text { server }\end{array}$ & + & & + & & + \\
\hline $\begin{array}{l}\text { Dissertations- } \\
\text { verlag }\end{array}$ & + & $(+)$ & + & & \\
\hline
\end{tabular}

Abb. 1: Publikationspartner-Kriterien-Matrix für die Dissertation (eigene Darstellung) 


\section{Die Autorin}

Barbara Budrich arbeitete über 10 Jahre im Verlag Leske + Budrich ihres Vaters, bevor sie 2004 den Verlag Barbara Budrich gründete. Sie hat zahlreiche Bücher und Aufsätze publiziert, übersetzt und geschrieben. Seit 2012 geben sie und ihr Team im von ihr etablierten Unternehmen budrich training (www.budrich-training.de) ihr Know-how zum wissenschaftlichen Publizieren und Schreiben systematisch in Vorträgen, Workshops und Coachings weiter. Neuestes Projekt für den wissenschaftlichen Nachwuchs ist die Zeitschrift Exposé, deren Herausgeberin sie ist.
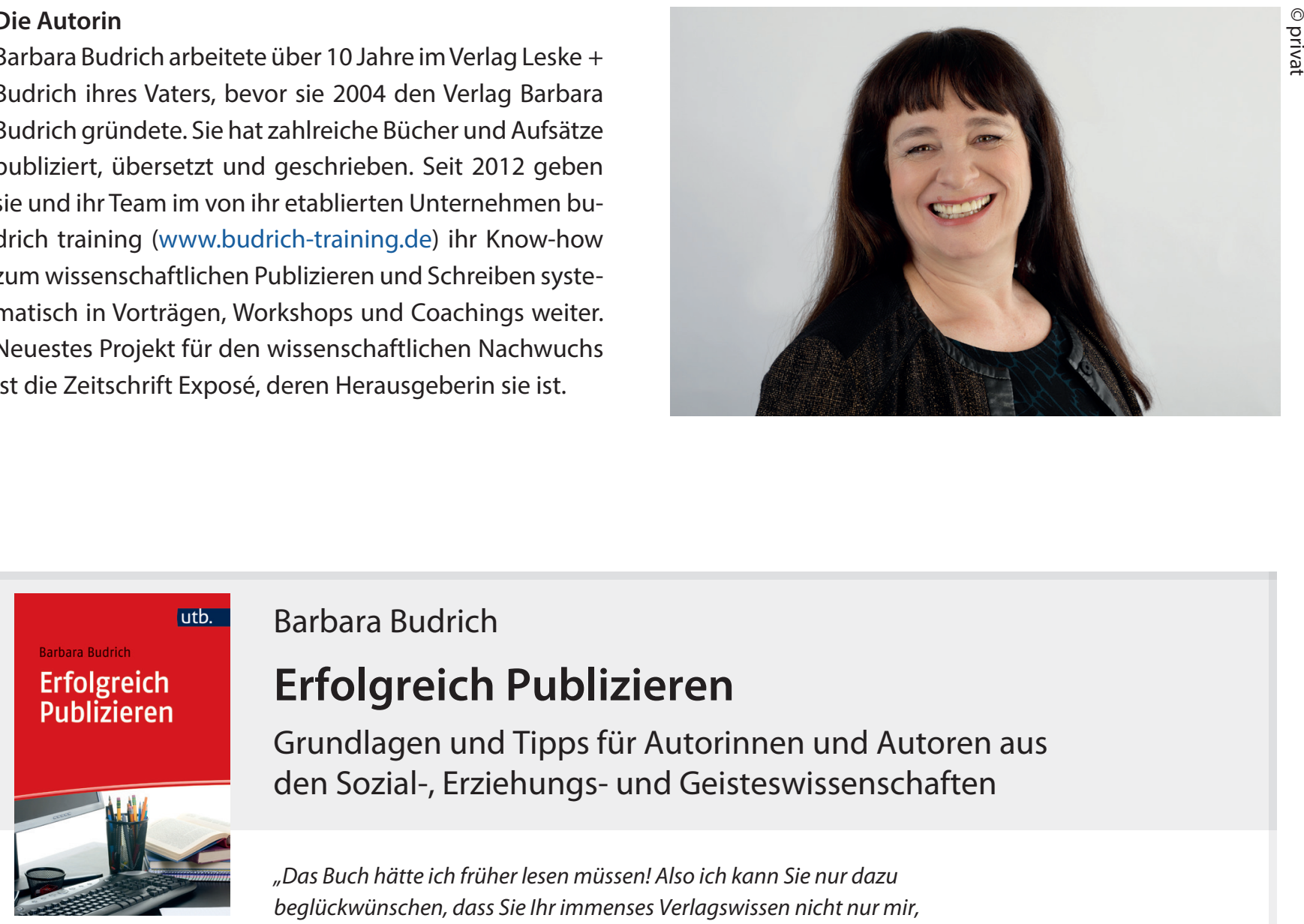

Barbara Budrich

\section{Erfolgreich Publizieren}

\section{Grundlagen und Tipps für Autorinnen und Autoren aus den Sozial-, Erziehungs- und Geisteswissenschaften}

"Das Buch hätte ich früher lesen müssen! Also ich kann Sie nur dazu beglückwünschen, dass Sie Ihr immenses Verlagswissen nicht nur mir, sondern auch anderen so gut geschrieben zugänglich gemacht haben." Prof. Dr. Jochen Kade (zur 2. Auflage)

\section{Kostenfreie E-Mail-Serie von Barbara Budrich}

\section{„Veröffentlichen: den richtigen Publikationspartner finden und ansprechen"}

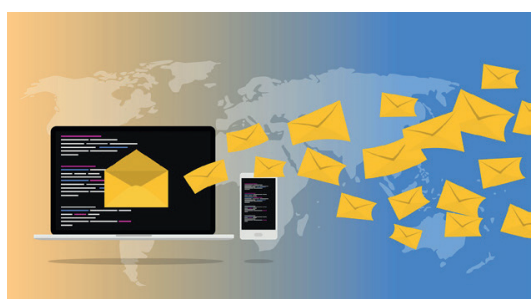

In der kostenfreien E-Mail-Serie erhalten Sie in sieben E-Mails an sechs aufeinanderfolgenden Tagen wertvolle Tipps und Handreichungen, wie Sie Ihr ganz persönliches „Projekt Buchveröffentlichung“ richtig angehen. Und das dazugehörige 12-seitige Arbeitsbuch (zum Download als Word-/PDF-Datei) enthält Fragen und Aufgaben, die Sie auf dem Weg zu mehr Klarheit begleiten - ebenfalls komplett kostenfrei.

Weitere Informationen und Anmeldung unter: https://budrich.de/veroeffentlichen-e-mail-serie 


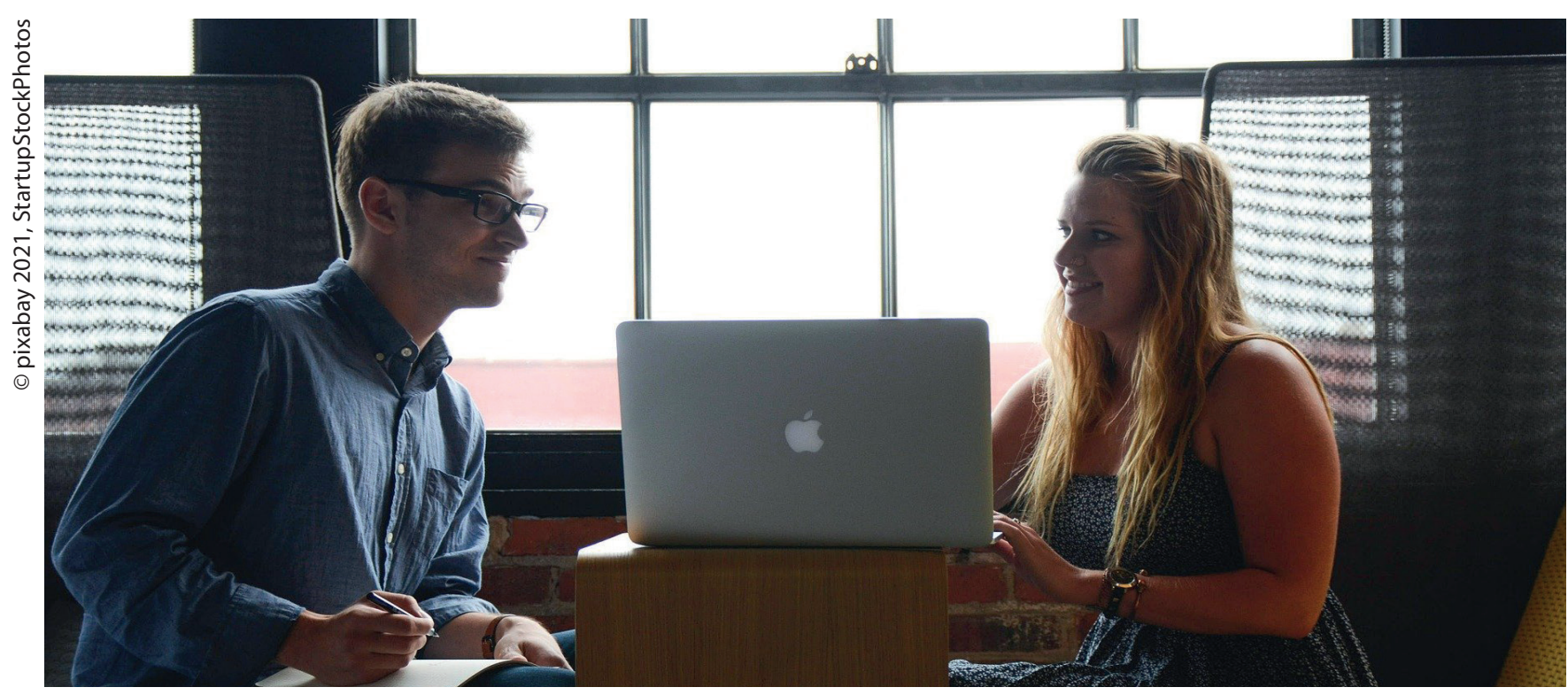

\section{Das Lektorat als wichtiger} Bestandteil Ihres

\section{Promotionsprojektes}

\section{Wie Sie Ihrer Doktorarbeit den professionellen Feinschliff geben und warum Sie darauf nicht verzichten sollten}

\section{von Isabelle Romann}

Sie stehen als Promovierende* ${ }^{*}$ kurz vor der Fertigstellung Ihrer Dissertation und wissen: Um die sprachliche Qualität Ihres jahrelangen Projektes sicherzustellen, brauchen Sie nun mehrere Korrekturdurchgänge durch Ihren Text. Inhaltlich sind Sie bereits auf der sicheren Seite, doch auch ein wenig erschöpft angesichts der nun anstehenden Aufgaben, und Frust macht sich breit. Gleichzeitig haben Sie einen hohen Qualitätsanspruch an sich selbst, und Ihnen ist wichtig, dass Ihr gesamtes Werk bei Gutachter*innen und Leser*innen einen professionellen Eindruck hinterlässt. Tippfehler, Redundanzen, uneinheitliche Schreibweisen, fehlerhafte Textformatierungen und Literaturangaben haben da keinen Platz. Allerdings stecken Sie als Autor*in sehr tief drin in der Materie und kennen Ihren Text schon fast auswendig. Da überliest das Auge schon einmal beispielsweise Buchstabendreher.

Die Lösung: Sie holen sich Unterstützung in Form eines Lektorats.

Was kann ein Lektorat beinhalten - und was nicht? Das Lektorat für eine Doktorarbeit legt seinen Schwerpunkt einerseits auf eine sprachliche Optimierung. Betrachten Sie also Lektor*innen am besten als Testleser*innen, die Ihnen wichtige Hinweise in puncto Sprache und Form geben. Sie selbst entscheiden, welche Hinweise Sie beherzigen wollen und welche nicht. 
Zur Orientierung seien ein paar Aufgabenschwerpunkte von Lektor*innen in puncto Sprache genannt: Optimierung von Orthografie, Grammatik, Interpunktion und Typografie (z. B. Binde- vs. Gedankenstriche), Prüfung auf Verständlichkeit, Füllwörter sowie Häufung von vermeidbaren Wortwiederholungen und Redundanzen, Augenmerk auf die einheitliche Schreibweise von Begrifflichkeiten, Fremdwörtern und zusammengesetzten Wortgruppen, Überprüfung der vollständigen Bezugnahme auf enthaltene Abbildungen, der grafischen Darstellungen und Tabellen sowie Kontrolle der vollständigen Nummerierung und aussagekräftigen Beschriftung dieser Elemente.

Darüber hinaus kann andererseits stilistisch auf Wunsch darauf geachtet werden, inwiefern die Leser*innen der Argumentation Ihrer Arbeit durch den sog. roten Faden gut folgen können. Es gilt, Logikfehler aufzudecken und auf schwer Verständliches hinzuweisen.

Wenn Sie es wünschen, wird im Rahmen des Lektorats auch geprüft, ob die formalen Anforderungen erfüllt werden. Das betrifft beispielsweise die Vollständigkeit der Quellenverzeichnisse und die einheitliche, fehlerfreie Darstellung von Quellenangaben - sowohl im Text als auch in den Verzeichnissen im Anhang. Die frischen Augen des Lektors oder der Lektorin können dabei Gold wert sein, denn er oder sie sieht diesen Text ja zum ersten Mal, während Sie bereits betriebsblind sein könnten.

Wichtig zu wissen: Ein Lektorat grenzt sich allein aus rechtlichen Gründen deutlich vom Ghostwriting ab. Auch sehen seriöse Lektor*innen davon ab, ganze Textpassagen neu zu formulieren. Das liegt daran, dass die wissenschaftliche Leistung bei Qualifikationsarbeiten ausschließlich von Ihnen selbst erbracht werden muss. Andernfalls werden Ihnen Leistung, Arbeit und gegebenenfalls Titel aberkannt.

\section{Warum sollten Sie ein Lektorat in Ihr Promotionsprojekt als festen Bestandteil einplanen? \\ Der Nutzen, den ein Lektorat für die Bewertung Ihrer Dissertation und damit für Ihre Reputation hat, kann gar nicht hoch genug eingeschätzt werden. Behalten Sie die wichtigsten Gründe immer im Hinterkopf:}

\section{Hinterlassen Sie einen professionellen Eindruck!}

Leser*innen (und Gutachter*innen) mögen es nicht, wenn ihr Lesefluss durch eine hohe Fehlerquote gestört wird. Sobald hier zu viel Irritation hervorgerufen wird, stellen sie sich ganz automatisch die Frage, ob in dieser Arbeit nicht auch mit fachlichen Ungenauigkeiten zu rechnen ist. Fazit: Die sprachliche Nachlässigkeit wird ungewollt zum Indikator für fachlich minderwertige Qualität. In der Folge leiden Ihre Reputation, die Bewertung der Dissertation, und dieser Gesamteindruck verhindert sogar im schlimmsten Fall einen erfolgreichen Berufseinstieg. Deshalb: Sorgen Sie dafür, dass Ihre Arbeit in jeder Hinsicht einen professionellen Eindruck hinterlässt!

\section{Verschaffen Sie sich Sicherheit in sprachlichen Fragen!} Auch wenn Sie Meister*in Ihres Faches sind, so kann es sein, dass Sie sich bei der ein oder anderen Schreibweise eines Begriffes oder der Kommasetzung unsicher sind. Damit Sie zur Klärung dieser Fragen nicht selbst Zeit für die Recherche investieren müssen, legen Sie Ihre Dissertation vertrauensvoll in die Hände von Lektor*innen, den Expert*innen für sprachliche Themen. Somit können Sie am Ende der Zusammenarbeit sicher sein, dass Ihre Doktorarbeit sowohl inhaltlich als auch sprachlich der Qualität entspricht, die Sie sich wünschen.

\section{Jede*r profitiert von einem Lektorat - auch versierte} Texter*innen und Autor*innen!

Es ist ein natürlicher Vorgang, dass man während der eigenen Korrekturdurchgänge Fehler nicht mehr findet. Als Autor*in kennen Sie Ihren Text so gut, dass Gehirn und Auge das sehen, was sie kennen und sehen wollen, nicht aber immer das, was tatsächlich auf dem Papier oder dem Bildschirm steht. Das hat absolut nichts damit zu tun, ob man sprachlich fit ist oder nicht. Selbst die professionellsten Schreiber*innen brauchen zwei zusätzliche frische Augen, um ihre Texte in bestmöglicher Qualität veröffentlichen zu können. Nutzen also auch Sie diese Möglichkeit!

Wenn Sie sich dazu entschlossen haben, diese Dienstleistung in Anspruch zu nehmen, ist es ratsam, sich möglichst früh auf die Suche nach dem/der richtigen Lektor*in zu machen. Zum einen sollte es sich um eine Person Ihres Vertrauens handeln, der Sie Ihr wertvolles Werk bedenkenlos überlassen wollen. Zum anderen ist 
sicherzustellen, dass der gewählte Kooperationspartner auch zum von Ihnen gewünschten Zeitpunkt freie Kapazitäten hat. Für eine Dissertation mit einem Umfang von ca. 300 Seiten sollten Sie mit einer Bearbeitungszeit von zwei bis vier Wochen rechnen - je nach aktueller Auslastung und nach Umfang der Aufgaben.

Planen Sie also von Beginn an das Lektorat als eigene Phase in Ihr Promotionsprojekt ein. Sie haben dann genügend Zeit, um die richtige Person zu finden, alle Rahmenbedingungen abzuklären und eventuellen Termindruck gegen Projektende zu vermeiden. Denn sowohl Universitäten als auch Verlage legen großen Wert auf die Einhaltung der gesetzten Abgabetermine.

\section{Für die Buchveröffentlichung: Lektorat in zwei Stufen}

Die bisherigen Empfehlungen beziehen sich sowohl auf die Dissertation, bevor sie zur Bewertung bei den universitären Gutachtern abgegeben wird, als auch auf die Phase vor der Veröffentlichung in einem Verlag. Für mein Empfinden ist jedoch die Relevanz eines Lektorats vor der Abgabe im Verlag noch höher, denn Ihr Publikum wächst mit der Herausgabe einer Monografie. Für diesen letztgenannten Fall ist sogar über zwei Stufen eines Lektorats nachzudenken: über das Erstlektorat, das so abläuft wie oben beschrieben. Nachdem Sie als Autor*in das lektorierte Dokument dann selbst überarbeitet haben und der Text in ein Buchlayout übertragen wurde (durch Sie selbst oder den veröffentlichenden Verlag), ist ein Schlusslektorat unverzichtbar. Dieses beinhaltet neben allem, was noch auffällt beim abschließenden Lesedurchgang, eine sogenannte Satzkontrolle. Sie stellt sicher, dass Silbentrennungen und Seitenumbrüche richtig umgesetzt wurden. Das Schlusslektorat ist damit eine weitere unverzichtbare Stufe der Qualitätssicherung, bevor Ihre Dissertation als Buch das Licht der Welt erblickt.

Es wird einmal mehr deutlich: Je präziser Sie Ihren ausgewählten lektorierenden Kooperationspartner über Ihre aktuelle Situation informieren und Ihren Bedarf transparent kommunizieren, desto erfolgreicher gestaltet sich die Zusammenarbeit und desto zufriedener werden Sie sein. Ihre Dissertation wird dann den von Ihnen gewünschten professionellen Eindruck bei Ihrer Zielgruppe hinterlassen und Ihre Position als Expert*in für Ihr Thema nachhaltig untermauern.

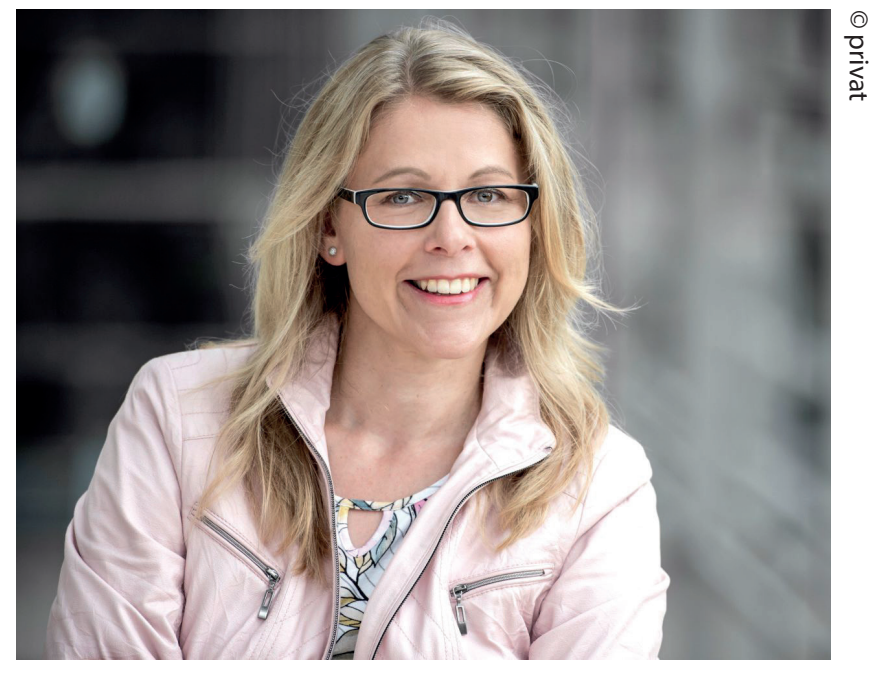

\section{Die Autorin}

Isabelle Romann studierte Betriebswirtschaftslehre an der Berufsakademie Heidenheim (heute DHBW) sowie Romanistik und Orientalistik/Islamwissenschaft an der Ruhr-Universität Bochum. Nachdem sie in der freien Wirtschaft jahrelang als Personalentwicklungsreferentin tätig war, machte sie sich 2012 als freie Lektorin für deutschsprachige Fach- und Sachtexte hauptberuflich selbstständig. Seitdem begleitet sie zahlreiche wissenschaftliche Arbeiten aus unterschiedlichen Fachrichtungen bis zur Abgabe und/oder Veröffentlichung. Des Weiteren lektoriert sie regelmäßig Publikationen von bereits etablierten Wissenschaftler*innen, Lehrmaterial mehrerer großer deutscher Fernhochschulen sowie Fach- und Sachbücher von Unternehmer*innen, die sich mit ihren Werken als Expert*innen in ihrem Fachgebiet positionieren wollen. 


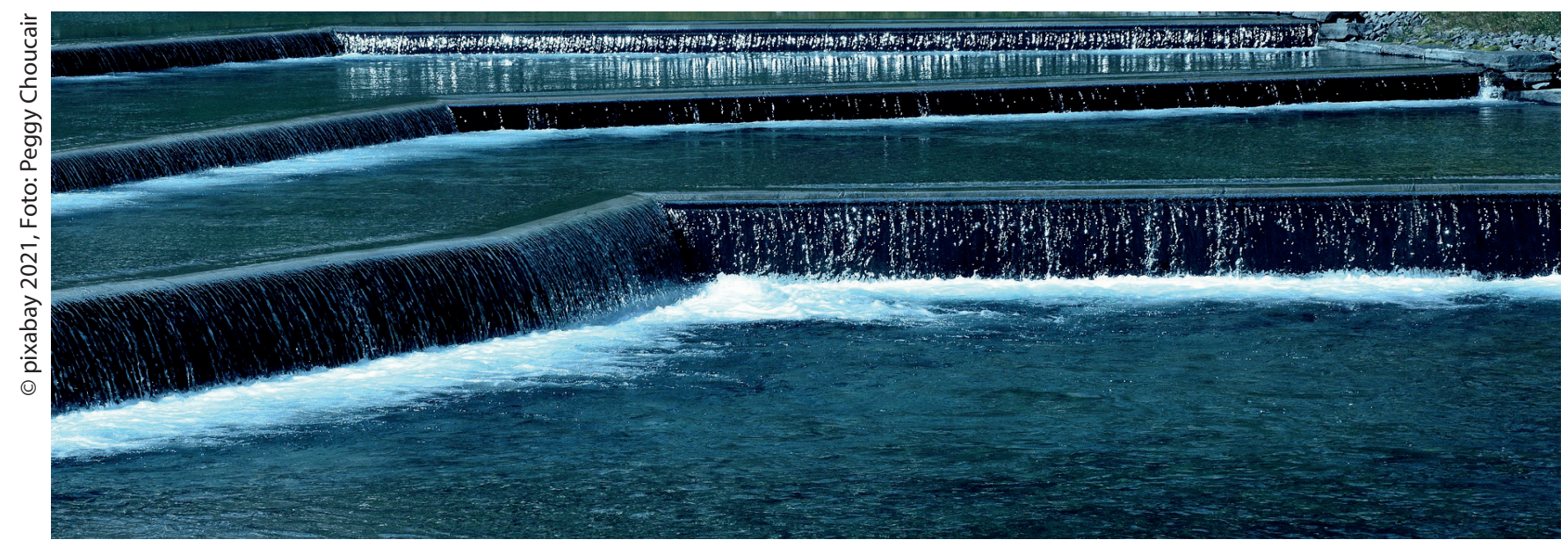

\section{Promovieren als}

\section{handlungsorientiertes Projekt}

\section{Das Kaskadenmodell wissenschaftlicher Textproduktion}

von Dagmar Knorr

"Lohnt es sich denn schon, mit dem Schreiben zu beginnen? Ich kenne ja noch nicht die gesamte Literatur!" Kommt Ihnen diese Aussage bekannt vor?

Hinter dieser Aussage steht die Auffassung eines geordneten Schreibprozesses: Erst wird sich ein Überblick verschafft und geplant, dann geschrieben, zum Schluss überarbeitet. Allerdings läuft ein Schreibprozess selten in dieser Form ab. Vielmehr überlappen sich die verschiedenen Phasen und es wird zwischen ihnen hin und her gesprungen. Das Textproduzieren wird deshalb häufig als chaotisch und als äußerst individueller Prozess wahrgenommen. Das Kaskadenmodell wissenschaftlicher Textproduktion ${ }^{1}$ bietet einen Einstieg, die verschiedenen Phasen und Handlungen des Schreibens so zu strukturieren, dass es eine Reflektion des eigenen Schreibprozesses ermöglicht. Dahinter steht die Annahme, dass die Selbstreflektion hilfreich ist, um das eigene Schreibhandeln zu regulieren. Schreibhandeln umfasst die Tätigkeiten des Lesens, Redens und des Schreibens. Wer gezielt Techni-

1 Das Kaskadenmodell wissenschaftlicher Textproduktion ist eine Weiterentwicklung des Modells „Phasen und Handlungen akademischer Textproduktion“ (Knorr 2016). ken und Strategien einsetzen kann, um eine Aufgabe zu bewältigen, kann als kompetente*r Schreibende* ${ }^{*}$ angesehen werden.

Der Textproduktionsprozess wird in Phasen und Handlungen unterschieden, die durch die fortlaufende Zeit strukturiert werden. Am Beispiel des Verfassens einer Dissertation werden zunächst die Phasen, dann die Handlungen näher erläutert. Das Kaskadenmodell bildet den Prozess eines komplexen Schreibprozesses ab, wie das beim Verfassen einer Monografie der Fall ist. Beim kumulativen Promovieren wird der Prozess mehrfach durchlaufen und ist anders gerahmt (vgl. Abbildung 2).

Jede Phase im Schreibprozess weist spezifische Charakteristika auf:

Der Entschluss, promovieren zu wollen, markiert den Eintritt in das Schreibprojekt. In diesem Moment beginnt die Findungsphase. Auch wenn diese sich in der Regel noch nicht nach "Schreiben" anfühlt. Prozesse des Lesens, des Redens über das mögliche Projekt, des Ideengenerierens, des Sich-Annäherns an ein Thema sind aber Bestandteile des Textproduktionsprozesses, da die Aus- 


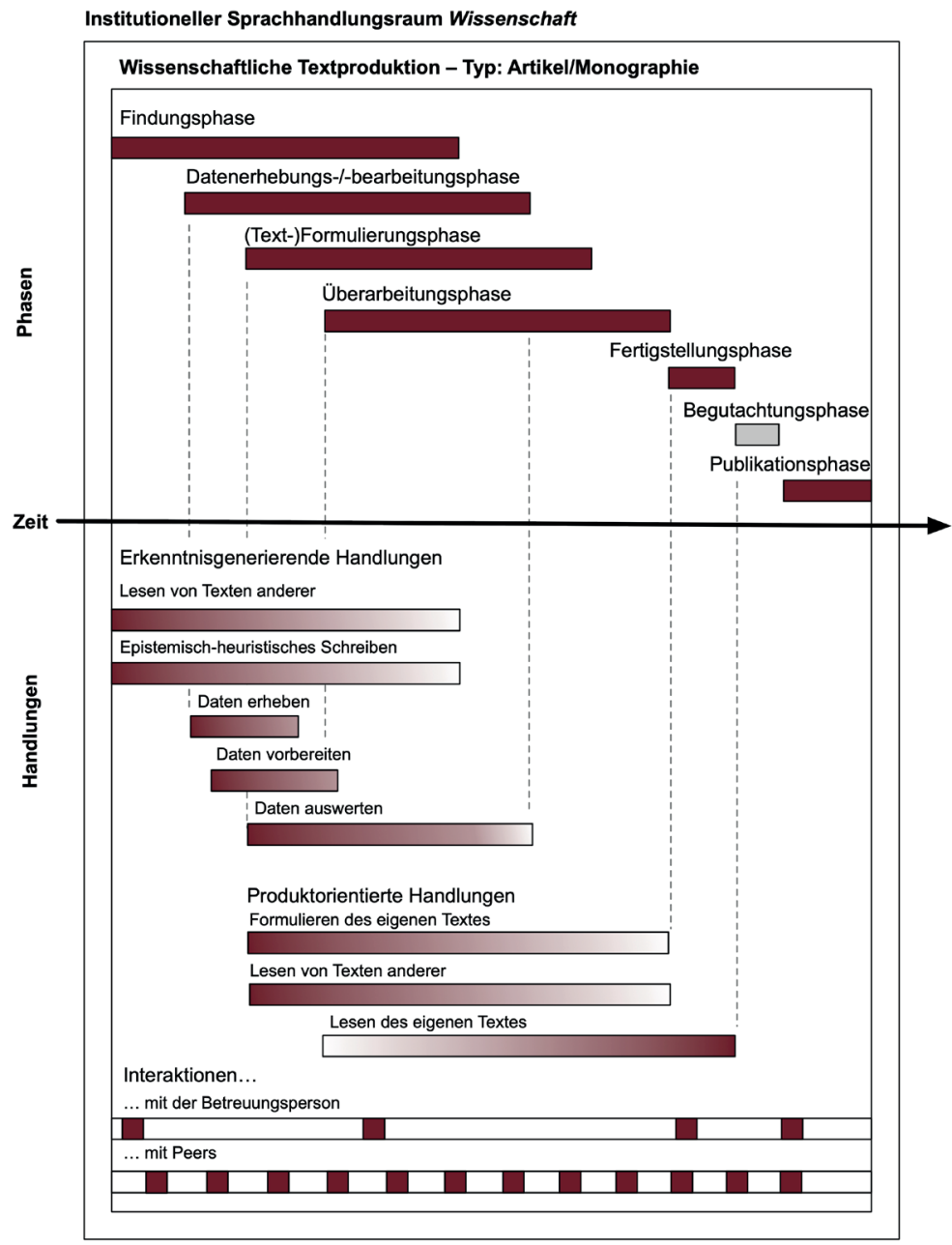

Abb. 1: Kaskadenmodell wissenschaftlicher Textproduktion. Typ: Monografie (eigene Darstellung)

einandersetzung mit dem wissenschaftlichen Diskurs und die eigene Verortung in ihm ein wesentlicher Bestandteil der zu erbringenden wissenschaftlichen Leistung ist. In der Findungsphase besteht einerseits die Notwendigkeit in die Breite denken zu müssen, um das Thema greifen und im Diskurs verorten zu können. Andererseits bedarf es einer Fokussierung, um eine bearbeitbare Fragestellung entwickeln zu können. Ist das Schreibprojekt mit eigener Datenerhebung verbunden, müssen methodische Entscheidungen hinsichtlich des Designs getroffen werden. Aufgrund der zeitlichen Restriktionen im hochschulischen Kontext wird von den Schreibenden in der Regel eine frühzeitige Festlegung gefordert - selbst wenn die Fragestellung noch nicht endgültig ist. Je nach Schreibtyp ist die Textformulierungsphase durch die Notwendigkeit zur Festlegung und dem Wunsch geprägt, sich möglichst lange vielfältige Optionen offen zu halten. Die Überarbeitungsphase stellt für Promovierende häufig eine Herausforderung dar: Einige überarbeiten gar nicht, andere können vor lauter Überarbeiten ihren Text nicht abgeben. In jedem Fall ist die Auseinandersetzung mit dem eigenen Text wesentlicher Bestandteil der Textproduktion und der Umgang mit ihm gilt der Schreibforschung als Maßstab für die wissenschaftliche Schreibkompetenz.

Eine Fertigstellungsphase wird in Modellierungen des Schreibprozesses, wie sie in der Schreibforschung und Schreibdidaktik zu finden sind, meist nicht explizit erwähnt, sondern als Teil des Überarbeitungsprozesses verstanden. Im Gegensatz dazu wird in professionellen Zusammenhängen, wie beispielsweise der technischen Dokumentation und dem Verlagswesen, dem Prozess der Dokumentaufbereitung für den Druck besondere Aufmerksamkeit - und damit auch Zeit - zuerkannt. Während die vorherigen Phasen sich alle überlappen, beginnt die Fertigstellungsphase erst nach Abschluss der Überarbeitung. Ihr Endpunkt ist in der Regel durch ein extern definiertes Abgabedatum fixiert. Dadurch, dass diese Fertigstellungsphase im Modell Raum einnimmt, kann sie Eingang in die individuelle Zeitplanung finden.

In der Prüfungsphase werden die Gutachten für den Text erstellt. Den Abschluss bildet die Disputation. Doch dann ist das Schreibprojekt immer noch nicht abgeschlossen. Denn die Arbeit muss noch publiziert werden. Hierfür gibt es verschiedene Möglichkeiten, wie das Hochladen auf Dissertationsservern und Buchveröffentlichungen.

Wird kumulativ promoviert, sind Überlegungen über Publikationsorte bereits in der Findungsphase angesiedelt (vgl. Abbildung 2). Innerhalb des Gesamtprozesses bilden die verschiedenen zu produzierenden Texte eigenständige Textproduktionsprojekte, die jedoch in ein Gesamtprojekt eingebettet sind.

Das Rahmenpapier ist ein eigenständiges Textprojekt innerhalb des Gesamtprojekts. Seine Konzeption beginnt häufig schon mit der Erstellung eines Exposés, weil dieses einen ersten Entwurf für die Gliederung des Rahmen- 
papiers enthält. Die Erfahrungen von kumulativ Promovierenden zeigen dann jedoch, dass die Hauptarbeit am Rahmenpapier erst beginnt, wenn die notwendigen Einzelartikel eingereicht sind. Den Abschluss des Gesamtprozesses bildet hier die Prüfungsphase, da in der Regel die kumulative Arbeit als solche nicht publiziert wird. Die Handlungen sind in dieser Abbildung nicht noch einmal aufgeführt, da sie sich an den einzelnen Phasen orientieren.

Die Handlungen wissenschaftlichen Arbeitens werden hinsichtlich ihrer Funktion im Gesamtprozess betrachtet. Es werden erkenntnisgenerierende Handlungen, produktorientierte Handlungen und Interaktionen mit Personen unterschieden und mit den Basishandlungen Lesen, Schreiben und Reden verbunden.

Leseprozesse in der Findungsphase dienen in der Regel dazu, sich in ein Thema einzuarbeiten und Wissen zu generieren. Demgegenüber wird während der Formulierungsphase gelesen, um vorhandenes Wissen zu reaktualisieren. Mit fortschreitender Zeit nimmt das Lesen des eigenen Textes zu. Während der Fertigstellungsphase sollte - im Idealfall - kein Rückgriff auf Fachtexte anderer mehr notwendig sein. Alle notwendigen Prüfprozesse sind als Bestandteile der Überarbeitungsphase konzeptualisiert. Allerdings wird an dieser Stelle die Idealisierung des Modells deutlich. In der Praxis kommt es immer wieder vor, dass bei der Überprüfung formaler Aspekte der eine oder andere Fachtext noch einmal angefasst werden muss.

Geschrieben wird in allen Phasen, jedoch unterscheiden sich die Zwecke erheblich: Denn epistemisch-heuristische Schreibprozesse sind erkenntnisgenerierend und müssen sich daher nicht an textuellen Anforderungen orientieren. Und: Sie sollten es auch nicht. Denn in der Vorstellung, dass alles, was geschrieben wird, Teil des einzureichenden Textes ist und dementsprechend sprachlich und formal diesen Ansprüchen genügen muss, liegt das größte Missverständnis über das Schreiben - und Ursache für so manche Schreibblockade. Wer sich darüber bewusst ist, warum und mit welchem Ziel sie oder er gerade schreibt, gewinnt viel: In Situationen, in denen man sich über seine eigenen Gedanken klar werden will oder

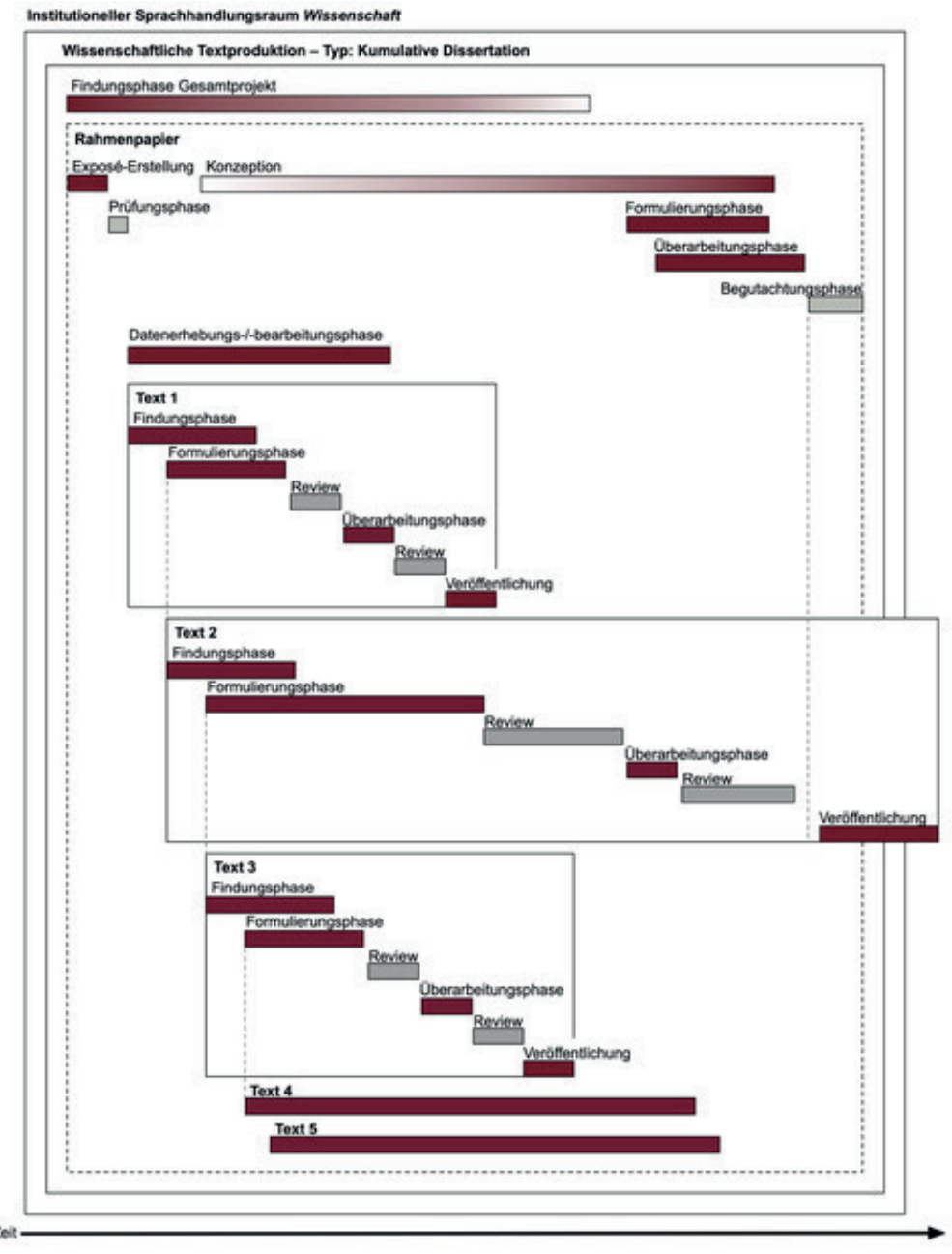

Abb. 2: Kaskadenmodell wissenschaftlicher Textproduktion. Typ: Kumulative Dissertation (eigene Darstellung)

etwas notiert, um dem Vergessen entgegen zu wirken, kann und darf man anders schreiben, als wenn es darum geht, Text zu produzieren, der Teil der Dissertation sein soll. Die Zeit, die es kostet, auf diese Art zu schreiben, ist in der Regel sehr gut investierte Zeit. Denn man kann nur das verständlich und klar aufschreiben, was einem selbst klar ist. Denkschlaufen gehören zum Promovieren und zum argumentativen Schreiben dazu. Gedankliche Arbeit ist Schwerstarbeit. Sie sollte nicht zusätzlich dadurch belastet werden, dass jede Formulierung perfekt oder eventuell - beim Schreiben in einer Fremdsprache - auch noch sprachliche Hindernisse überwunden werden müssen. Hier zwei Arbeitsgänge einzulegen und das erkenntnisgenerierende vom produktorientierten Schreiben zu trennen, kann sehr entlasten. 
Das Reden über das Schreiben ist ein wesentlicher Bestandteil kompetenten Schreibhandelns (vgl. Girgensohn/Sennewald 2012: 102). Die Einbindung interaktiver Handlungen als Bestandteil von Textproduktion trägt dem Umstand Rechnung, dass professionelles Schreiben nicht einsam ist bzw. sein muss. Im hochschulischen Kontext kann zwischen zwei Personengruppen unterschieden werden, mit denen geredet werden kann: So reden Schreibende mit Betreuenden und Gutachtenden. Mit diesen werden mindestens Rahmenbedingungen und inhaltliche Ausrichtungen besprochen. Im Modell sind deshalb nur wenige Interaktionen visualisiert. Minimal gibt es zwei Interaktionen zwischen Schreibenden und Betreuenden: Zu Beginn des Schreibprojekts sollte eine Verständigung über die Rahmenbedingungen des Schreibprojekts erfolgen, am Ende die Mitteilung über die Bewertung des Textes. Ob und wenn ja, welche weitere Interaktionen stattfinden, ist von den interagierenden Personen abhängig. Zusätzlich können (und sollten!) Schreibende mit Peers interagieren. Peers können andere Promovierende, Mitarbeitende von schreibdidaktischen Einrichtungen sein, aber auch Freund*innen, Verwandte etc. Die möglichen Interaktionen sind daher sehr vielfältig und reichen von emotionaler Unterstützung, über das „allmähliche Verfertigen der Gedanken beim Reden" (Kleist 1805) bis hin zu formativem Feedback auf Textteile bzw. dem Text und Reflexion des Arbeits- und Schreibprozesses.

Zusammenfassend hat das Kaskadenmodell einen Zweck: die Reflexion und das Sprechen über das Schreiben anzuregen - wenn dies gelingt, ist ein wichtiger Schritt hin zu einer erfolgreichen Promotion getan.

Weitere Informationen und Ressourcen zum wissenschaftlichen Schreiben, u. a. auch einen Schreibtypentest, finden Sie unter http://leuphana.de/SWC-Ressource.

\section{Literatur}

Girgensohn, Katrin/Sennewald, Nadja (2012): Schreiben lehren, Schreiben lernen. Eine Einführung. Darmstadt: WBG [Einführung Germanistik].
Kleist, Heinrich von (1805): Über die allmähliche Verfertigung der Gedanken beim Reden. Internetausgabe. Version 11.02 von 2002. Heilbronn: Kleist-Archiv Sembdner.

Knorr, Dagmar (2016): Modell „Phasen und Handlungen akademischer Textproduktion“. Eine Visualisierung zur Beschreibung von Textproduktionsprojekten. In: Ballweg, Sandra (Hrsg.): Schreibzentrumsarbeit: Theorie, Empirie, Praxis. Frankfurt/Main u. a.: Lang [Wissen - Kompetenz - Text; 11], 251-273.

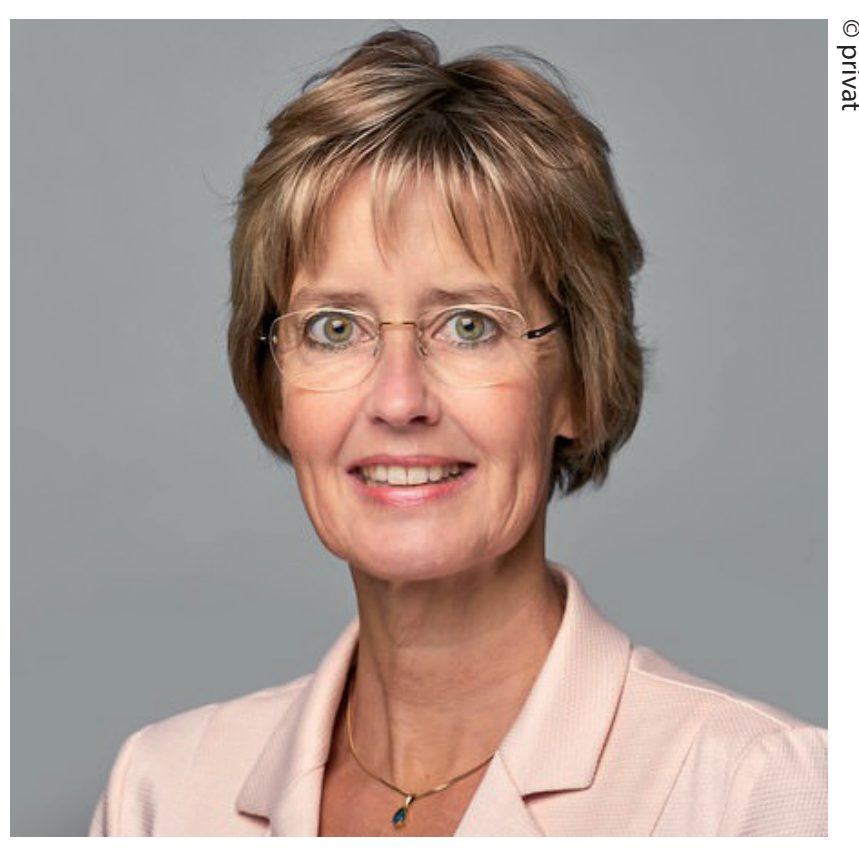

\section{Die Autorin}

Dr. Dagmar Knorr ist Schreibwissenschaftlerin und Linguistin. Sie forscht, lehrt und publiziert zum wissenschaftlichen Schreiben unter Bedingungen von Mehrsprachigkeit. Seit 2017 leitet sie das Schreibzentrum/Writing Center der Leuphana Universität Lüneburg. Zuvor war sie in Hamburg und Modena tätig. Sie setzt sich dafür ein, dass das Schreiben als Thema von den Hochschulen stärker in den Blick genommen wird. So hat sie als Vorstandsmitglied der Gesellschaft für Schreibdidaktik und Schreibforschung federführend am „Positionspapier Schreibkompetenz im Studium" mitgearbeitet. Und in der Gesellschaft für Angewandte Linguistik gründete sie und leitet seitdem die Sektion Schreibwissenschaft. 


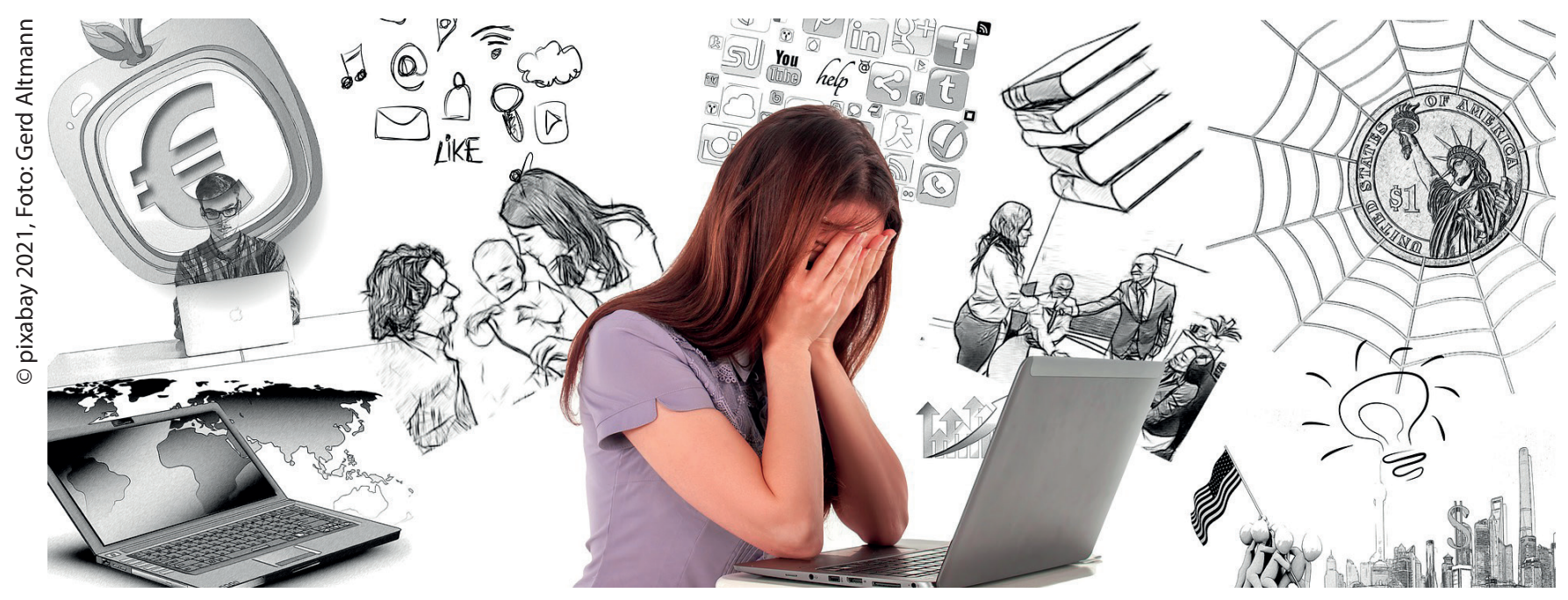

\section{Promovieren mit Kind: Wie lassen sich Dissertation und Familie} unter einen Hut bringen?

von Majana Beckmann

\section{Die Herausforderung Vereinbarkeit}

Als promovierende Eltern stehen Sie vor der besonderen Herausforderung, mit der Dissertation und der eigenen Familie zwei bedeutsame Lebensbereiche zu vereinbaren. Immer wieder gilt es abzuwägen, welcher von beiden gerade Vorrang hat. Und immer wieder kann sich das ungute Gefühl einstellen, dem jeweils anderen nicht gerecht zu werden. „Ich habe schon viel zu lange nichts für die Dissertation gemacht." "Soll ich mich noch zum Arbeiten aufraffen, wenn die Kinder schlafen?" "Reserviere ich das Wochenende für die Familie oder schreibe ich an der Dissertation?" Wenn ein Kind krank wird oder eine Deadline im Projekt abläuft, erhöht sich der Druck noch. Diese inneren Konflikte sind belastend. Oft resultiert daraus eine Unzufriedenheit, die sich in Schreibblockaden, Prokrastination oder Zweifeln niederschlägt. Das Promotionsprojekt rückt in den Hintergrund und die Hürden, es fortzusetzen, wachsen. Wie kann es gelingen, die Doktorarbeit in den Familienalltag zu integrieren? Dieser Beitrag lädt Sie zu einem neuen Blick auf Ihre Situation ein.

\section{Vorteile der Promotion mit Kind}

Eine Doktorarbeit zu schreiben und Kinder zu haben, ist (noch) nicht Normalität. Zwischen ca. 13 und 30 Prozent der Nachwuchswissenschaftler*innen ${ }^{1}$ sind Eltern. Interessant ist, dass diese tendenziell zufriedener und weniger gestresst sind als ihre Kolleg*innen ohne Kinder, wenngleich sie sich durch die Gleichzeitigkeit von Familie und Beruf stärker belastet fühlen (Bundesbericht Wissenschaftlicher Nachwuchs 2017: 236; 244).

Was sind Gründe für diese Zufriedenheit? Erstens ergänzen sich hier zwei intensive, fordernde und auch erfüllende Lebensbereiche: Sie haben sowohl die Möglichkeit, ein interessantes Thema in aller Tiefe zu bearbeiten als auch die eigenen Kinder beim Aufwachsen zu begleiten. Promovierende Eltern beschreiben häufig, dass die Zeit mit dem Kind der perfekte Ausgleich zur Forschungsarbeit ist. Zweitens sehen sich Eltern als sehr pragmatisch

1 Hierunter sind Promovierende und Promovierte zusammengefasst. 
und flexibel. Sie reagieren gelassener auf unerwartete Änderungen und entwickeln zügig einen Plan B. Drittens sorgt der Tagesablauf oft für klar definierte Schreibzeiten. Diese werden als wertvoll erachtet, was wiederum die Produktivität steigert. Die Zeitfenster zum Promovieren sind meistens kleiner, jedoch ganz klar in eine Struktur integriert.

Sollte Ihre vorgesehene Schreibzeit häufig ungenutzt bleiben, ist es ratsam, die Promotion im Hinblick auf Motivation, Rahmenbedingungen und Aufgabenmanagement zu prüfen.

\section{Die Motivation: Was ist Ihr großes Ziel?}

Zuerst lohnt sich eine innere Bestandsaufnahme: Wie wichtig ist es Ihnen gerade, Ihre Dissertation voranzubringen? Welches persönliche Ziel verfolgen Sie damit? Zu wie viel Prozent ist Ihre Motivation momentan spürbar? Mit der Geburt eines Kindes kann sich die Einstellung zur Promotion verändern. Mütter und Väter übernehmen plötzlich eine neue Rolle, die mit einem großen Verantwortungsgefühl einhergeht. Das Leben steht Kopf und hat einen neuen bzw. weiteren Mittelpunkt.

Für die einen ist es eine willkommene Abwechslung, sich in der Elternzeit mit der eigenen Forschungsarbeit geistig herauszufordern. Für die anderen ist es genau richtig, die Aufmerksamkeit allein dem Kind zu schenken. Werden die Fäden wieder aufgenommen, ist das eine gute Gelegenheit, die Bedeutung der Doktorarbeit für sich selbst zu überprüfen. Wenn sich an dieser Stelle Zweifel einstellen, können Sie überlegen: Was wäre nötig, damit ich die Promotion weiterhin verfolgen kann und will? Haben Sie die Promotion bereits mit Kind(ern) begonnen, dann sind diese Gedanken vermutlich vorausgegangen. In jedem Fall ist es gut zu klären, welche Relevanz die Promotion jetzt in Ihrem Leben hat. Mithilfe dieser Erkenntnis können Sie das Maß an Zeit und Energie bestimmen, das Sie Ihrer Dissertation derzeit widmen wollen.

\section{Der Realitätscheck: Was sind Ihre Rahmenbedingungen?}

Angenommen, Sie wären zu 100 Prozent motiviert und wollten Ihre Promotion mit voller Energie verfolgen. Wie realistisch ist das unter den gegebenen Lebens- und Ar- beitsbedingungen? Wenn diese Bedingungen im Widerspruch stehen zu Ihren Erwartungen, dann ist Unzufriedenheit vorprogrammiert. Es lohnt sich also, erst einmal die familiären und beruflichen Tatsachen zu prüfen. Dafür sind bspw. die Anzahl und das Alter der Kinder wichtig, sowie Ihre Vorstellungen vom Betreuungsumfang. Wer ist wann für die Kinder da? Wer übernimmt im Notfall die Betreuung des kranken Kindes? Welche Aufgaben erledigen Sie im Alltag? Wer trägt wofür die Verantwortung? Auf der beruflichen Seite gilt es etwa zu beachten, ob und in welchem Umfang Sie angestellt sind, ob die Promotion Bestandteil Ihrer Arbeitszeit ist und welche Erwartungen Ihre Betreuungsperson hat. Erfordert Ihr Forschungsprojekt Laborarbeiten oder Auslandsaufenthalte? Wie flexibel sind Arbeitsort und -zeiten?

Alle diese Dinge in den Blick genommen, lässt sich abschätzen, wie viele Stunden pro Woche Sie für Ihre Dissertation Zeit haben. Sind dies mehrere Stunden am Stück oder viele kleine Zeitfenster? Wie viel Zeit bräuchten Sie mehr, damit Ihre Planung aufgeht? Oder fehlt es nicht an Zeit, sondern an etwas Anderem?

Sollte Zeit der entscheidende Faktor für Sie sein, geht es darum, Ihren Spielraum zu erkennen. Wen können Sie für die Kinderbetreuung mit ins Boot holen? Welche Aufgaben können Sie aus der Schreibzeit auslagern? Haben Sie sich ganz bewusst für mehr Zeit mit den Kindern und weniger Zeit mit der Dissertation entschieden, dann wären die langfristige Zeitplanung oder die Terminabsprachen mit Doktormutter oder -vater mögliche Stellschrauben für Sie. Sie sehen: So individuell wie die Antwort auf die Frage nach dem Stellenwert der Dissertation fällt auch die Anpassung der Rahmenbedingungen aus.

\section{Die Promotion in den Alltag holen: Wie gelingt $\mathrm{lhr}$ Aufgabenmanagement?}

Als Eltern kennen Sie das nur zu gut: Der Alltag mit Kindern ist von ständigen Unwägbarkeiten geprägt. Auch der Weg zum Doktortitel verläuft so gut wie nie geradlinig. Im Gegenteil, einige Promotionsphasen bergen ein ziemlich hohes Krisenpotential (vgl. Beckmann 2020). In beiden Lebensbereichen sind Sie also gefordert, mit großen Unsicherheiten umzugehen. Häufig ist es die Dissertation, die zurückstecken muss, wenn etwas im Familien- 
alltag oder im Job nicht nach Plan verläuft. Je häufiger das vorkommt, desto mehr stellt sich eine Distanz ein, die weiteres Aufschiebeverhalten nach sich zieht.

An dieser Stelle geht es darum, die Dissertation wieder in den Alltag zu holen, und zwar so wie sie ist und so wie Ihr Alltag ist. Das können kleine Schritte sein, z.B. eine Liste mit aktuellen Fragen, eine MindMap zur Gliederung, die Lektüre eines geschriebenen Abschnitts. Alles, was sich machbar anfühlt, ist richtig. Zusätzlich helfen verlässliche Strukturen wie

- Vereinbarungen zur Kinderbetreuung: Schaffen Sie feste Zeiten, die für Ihre Dissertation reserviert sind und stehen Sie dafür ein, diese zu nutzen.

- Klare Prioritäten: Planen Sie am Abend vorher Ihre Aufgaben für die Schreibzeit, damit Sie direkt loslegen können.

- Rituale: Tun Sie etwas, mit dem Sie sich auf den Arbeitsprozess einlassen und inn zufrieden beenden können.

Schließlich können Sie sich auf Ihre Stärken als Eltern verlassen: Nutzen Sie Ihre Flexibilität und Ihren Pragmatismus auch für die Promotion. Seien Sie großzügig mit sich, wenn ein Plan nicht aufgeht. Und machen Sie es Ihrer Dissertation so einfach wie möglich, in Ihrem Leben stattzufinden.

\section{Nützliche Gedanken: Was hilft Ihnen, wenn nichts mehr geht?}

Es gibt Tage, da läuft es einfach nicht wie gewünscht. Die Motivation bleibt aus, das Anfangen erscheint unmöglich und die bisherigen Ergebnisse erscheinen unzureichend. In solchen Momenten hilft es, einige „Notfallgedanken" parat zu haben.

- „Eins nach dem Anderen.“”

Gehen Sie Ihre Aufgaben nacheinander statt nebeneinander an. Wenn die Kinder in der Betreuung sind, dürfen Sie den Fokus auf die Promotion legen. Alles, was Ihnen an sonstigen Dingen in dieser Zeit einfällt, findet Platz auf einem Notizzettel.

- "Gut ist gut genug."

Das gilt sowohl für das Familienleben als auch für die Promotion. Sie müssen weder Wunder vollbringen noch das Rad neu erfinden. Klopfen Sie sich zwischendurch auf die Schulter: Was Sie gerade leisten, ist nicht selbstverständlich.

- "Zusammen ist man weniger allein."

Gegenseitige Unterstützung, z.B. in Mastermindgruppen oder Schreibtandems, gibt Kraft. Hören Sie in krisenhaften Zeiten den Menschen zu, die an Sie und Ihr Ziel glauben.

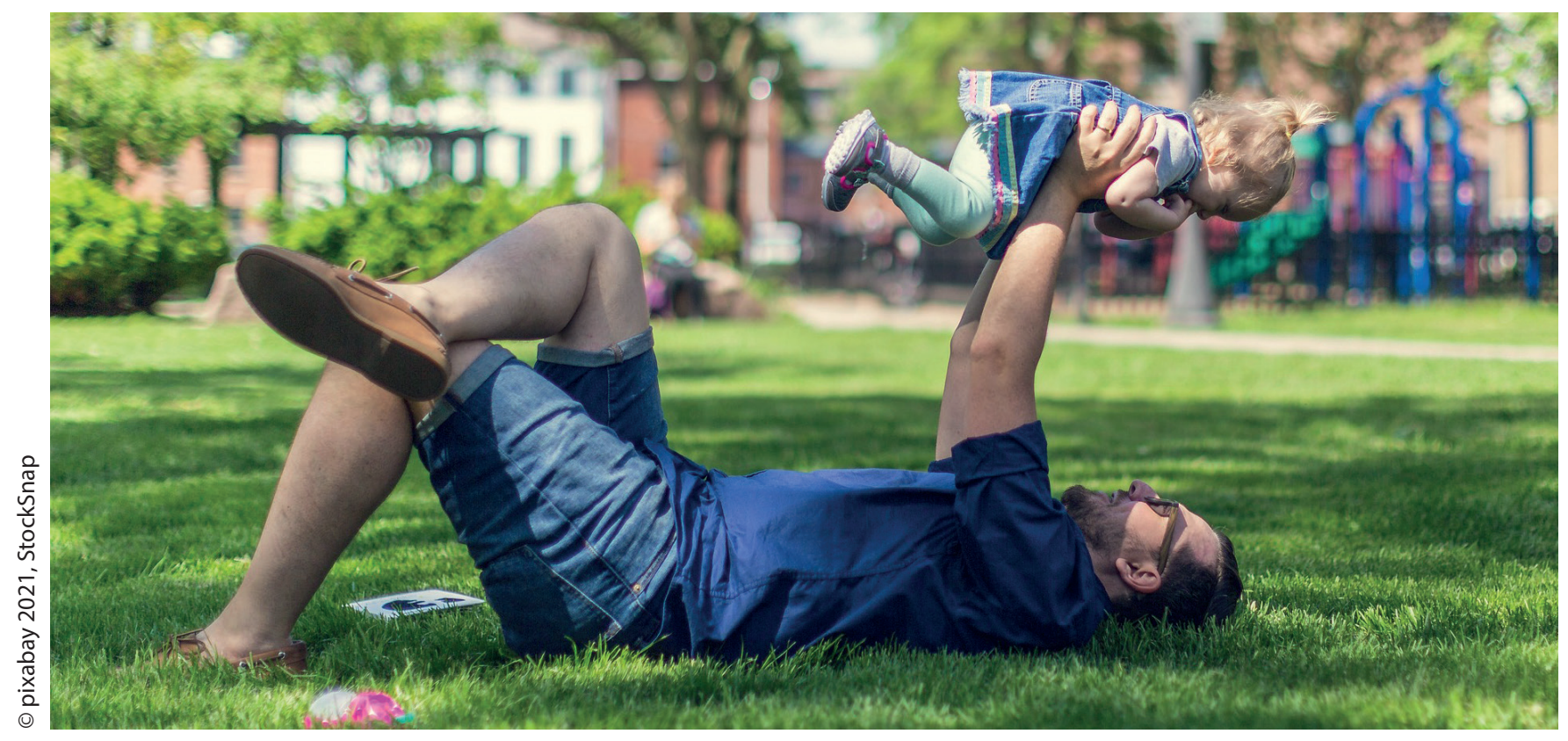




\section{Promovieren mit Kind: Ist das möglich?}

Ganz eindeutig: Ja. Promovieren und Familie(ngründung) können Hand in Hand gehen. Wichtiger als die Frage nach dem $\mathrm{Ob}$ ist Ihre persönliche Antwort auf das Wie. Vereinbarkeit ist ein Rädchen, das ständig in Bewegung ist und immer wieder nachjustiert werden will. Prüfen Sie regelmäßig, wie gut Ihr Promotionsprojekt und Ihre Rahmenbedingungen zusammenpassen. Hilfreiche Voraussetzungen sind eine klare Motivation, feste Prioritäten und verlässliche Absprachen, sowie Menschen, die Sie mental unterstützen. Mit einer guten Mischung aus Tatkraft und Flexibilität bringen Sie Ihre Dissertation Schritt für Schritt voran.

\section{Literatur}

Beckmann, Majana (2020): Welche Phasen hat eine Promotion? 11 Tipps für Höhen und Tiefen. [Blogartikel]. URL: https://klarwaerts-coaching.de/welche-phasenhat-eine-promotion-11-tipps-fuer-hoehen-und-tiefen/ (letzter Zugriff: 27.11.2020).

Konsortium Bundesbericht Wissenschaftlicher Nachwuchs (2017): Bundesbericht Wissenschaftlicher Nachwuchs 2017. Statistische Daten und Forschungsbefunde zu Promovierenden und Promovierten in Deutschland. Bielefeld: wbv.

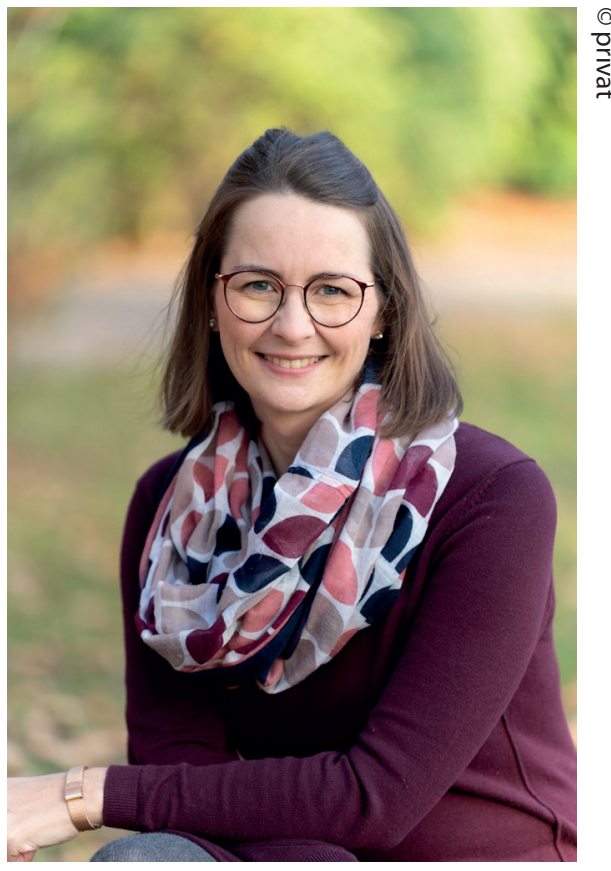

\begin{abstract}
Die Autorin
Majana Beckmann ist promovierte Linguistin, systemische Beraterin (SG), Mutter von zwei Kindern und Inhaberin von KLARwärts - Coaching für Promovierende (https://www.klarwaerts-coaching.de). Über zehn Jahre lang hat sie Berufserfahrung in der akademischen Leh$r$, in der Erwachsenenbildung und in der medien- und hochschuldidaktischen Beratung gesammelt. Sie ist als Promotionscoach mit dem zusätzlichen Schwerpunkt „Promovieren mit Kind*ern" selbstständig. Auf ihrem Blog (https://www.klarwaerts-coaching.de/blog/) finden promovierende Eltern Unterstützung für ihren Alltag mit Doktorarbeit und Familie.
\end{abstract}




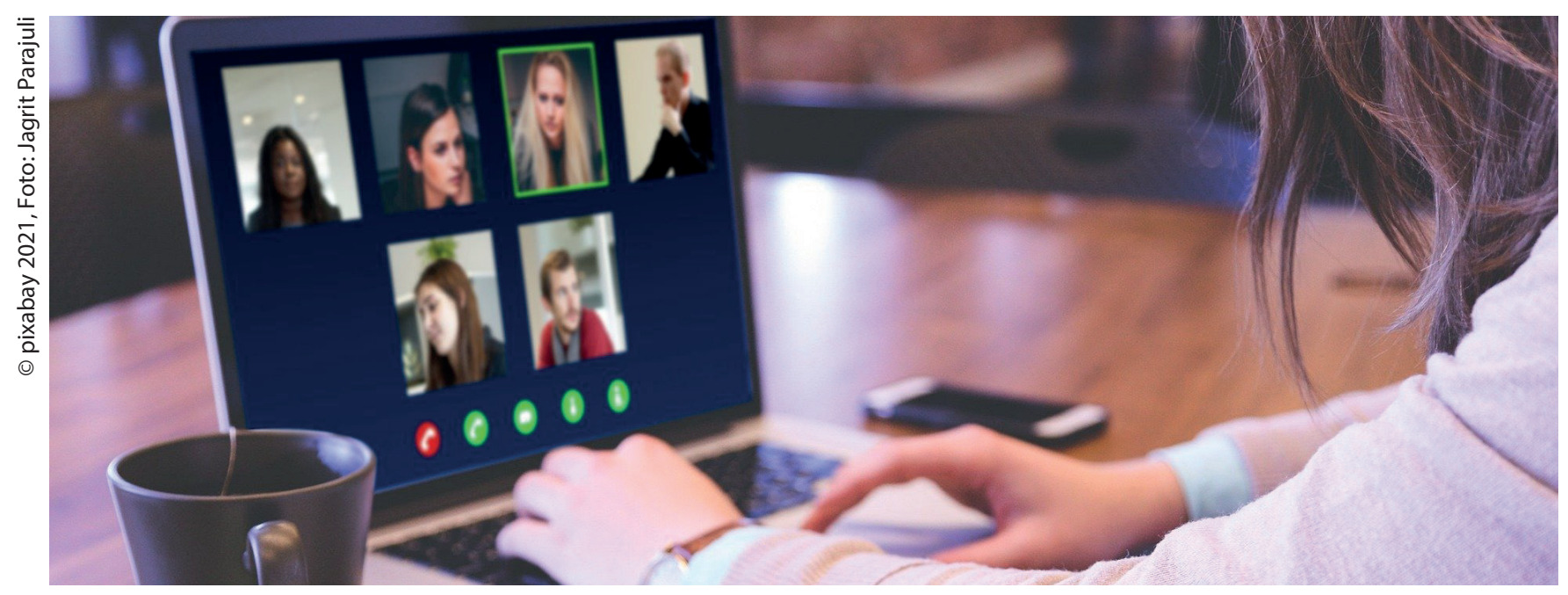

\title{
Der Nutzen von selbst-
}

\section{organisierten Arbeitsgruppen während der Promotion}

\author{
von Alexander Parchow
}

Die Zeit während einer Promotion wird von aktuell und ehemalig Promovierenden häufig als intensive persönliche Entwicklung beschrieben. Im Promotionsprozess wird man einerseits bei der Anfertigung der Dissertation fachlich und methodisch herausgefordert und andererseits durch das z.T. hohe Maß an Selbständigkeit, das Agieren in Unsicherheit, das Aushalten von Zweifeln an der eigenen Arbeit sowie die stetige Präsenz der eigenen Dissertation im Alltag emotional stark gefordert. Nicht selten fühlen Promovierende sich überfordert, obwohl es verschiedene Möglichkeiten der Unterstützung gibt: an Universitäten angeschlossene Kolloquien, spezielle Schreibcoachings und Workshops, Forschungswerkstätten oder auch das direkte Beratungsgespräch mit dem/ der Betreuenden.

Ich möchte in diesem Beitrag auf eine andere Form der niedrigschwelligen „inoffiziellen" Arbeitsunterstützung eingehen und deren Vorteile aufzeigen: von Promovierenden selbstorganisierte Arbeitsgruppen.
Diese Arbeitskontexte sind vor allem in sozialwissenschaftlichen Projekten von qualitativ Forschenden wie Franz Breuer als Vertreter der Grounded Theory, Ulrich Oevermann als Begründer der objektiven Hermeneutik oder Ralf Bohnsack, dem Urheber der dokumentarischen Methode empfohlen und dort unter der Bezeichnung "Interpretationsgruppen" etabliert (vgl. Reichertz 2013: 13). Gemeinsam mit einer kleinen Zahl von Forschenden gleicher Thematik oder Methodik wird in solchen Gruppen das Ziel verfolgt, abwechselnd das vorliegende Datenmaterial zu interpretieren. Dadurch werden die Perspektive auf die Daten erweitert, Unsicherheiten kompensiert und die Interpretationen hinsichtlich ihrer Konsistenz kontrolliert (vgl. Breuer u.a. 2019: 321).

Jedoch reicht die Funktion solcher selbstorganisierten Arbeitsgemeinschaften weit über die Interpretation hinaus. Somit kann es auch für Promovierende, die ihre Dissertation nicht im Kontext qualitativer Sozialforschung anfertigen, gewinnbringend sein, sich einer selbstorganisierten Arbeitsgruppe anzuschließen oder diese zu 
gründen. Im Folgenden möchte ich ausgehend von der Leitfrage, warum diese Arbeitssettings besonders günstig sind, die Vorteile und Chancen für den Promotionsprozess aufzeigen.

\section{Selbstorganisierte Arbeitsgruppen Promovierender}

Das Setting selbstorganisierter Arbeitsgruppen hat viele unterschiedliche Formen. Manchmal kommen Forscher*innen in solchen Gruppen nur für kurz Zeit zusammen, sodass sich die Gruppen nach einigen Sitzungen wieder auflösen. Häufiger sind aber auf Dauer etablierte Gruppen anzutreffen, die an einer Universität angeschlossen sind. Den Zugang erhält man dort durch eine/n Unterstützenden (z.B. Promotionsbetreuer*in, Spezialist*in einer bestimmten Fachrichtung). Einige verstetigte Gruppen haben jedoch keinen institutionellen Anschluss, weswegen der Zugang etwas schwieriger ist. Häufig erfährt man durch Zufall von diesen eher „inoffiziellen" Gruppen.

In den Arbeitsgruppen - zumindest innerhalb der qualitativen Sozialforschung - finden sich meist vier bis zehn Wissenschaftler*innen zusammen. Ich halte aus eigener Erfahrung eine Gruppengröße von mindestens vier und maximal sechs Personen für ideal. Sofern regelmäßige Treffen in einem beispielsweise zweiwöchigen Turnus stattfinden, hat bei dieser Gruppenstärke jedes Mitglied wiederkehrend alle zwei bis drei Monate die Möglichkeit, eigenes Material, Themen und Fragen einzubringen, um die Diskussion zu bestimmen. Als sinnvoll und praktikabel hat sich eine Sitzungsdauer von zwei bis drei Stunden gezeigt. Diese Dauer ist zum einen lang genug, um sich in Daten, ins Thema oder die Fragen einzufinden und zum anderen kurz genug, um konzentriert arbeiten zu können. Besonders gut lässt sich arbeiten, wenn jeder Person das zu besprechende Material in Kopie oder digital vorliegt. Dadurch können individuelle Markierungen sowie Notizen vorgenommen und als Ausgangspunkt für weiterführende Diskussionen genutzt werden.

In der Regel wechseln bei kontinuierlich bestehenden Arbeitsgruppen von Promovierenden die Mitglieder im Laufe der Zeit. Wenn Projekte und Dissertation zum Ende kommen, verlassen Mitglieder die Gruppe und neue werden aufgenommen. Die Promovierenden befinden sich deshalb an unterschiedlichen Stellen im Promotionsprozess. Für Personen, die gerade mit der Promotion beginnen und beispielsweise ein Exposé verfassen, können bereits erfahrenere Promovierende wertvolle Tipps geben und eine Mentor*innenfunktion übernehmen. Promovierende, die sich auf die Datenerhebung vorbereiten, profitieren vom Wissen und den Erfahrungen derer, die diese Phase bereits durchlaufen haben. Und letztlich erhalten die Forscher*innen, die mit ihrer Arbeit schon weit vorangekommen sind, neue Impulse.

Arbeitsgruppen mit institutionellem Anschluss unterscheiden sich von selbstorganisierten Gruppen Promovierender dadurch, dass die unterstützende Person oft an den Sitzungen teilnimmt, diese meist moderiert und die Struktur bestimmt. Institutionelle Rollenzuschreibungen und Hierarchien können so nie ganz aufgelöst werden und wirken sich auf die Offenheit der Mitglieder, die Atmosphäre und das Arbeitsverhalten aus. Während in den "offiziellen" Arbeitsgruppen daher die interne Arbeitsstruktur meist vorgegeben ist, entwickelt sich diese bei selbstorganisierte Gruppen Promovierender im Laufe der Zeit eher von selbst. Es erscheint dennoch sinnvoll, sowohl für selbstorganisierte als auch Gruppen mit institutionellem Anschluss, jede Sitzung in eine Einstiegsrunde, eine Arbeitsphase und eine Abschlussrunde zu unterteilen. In der Einstiegsrunde können kurz aktuelle Befindlichkeiten und Themen angesprochen werden. In der Arbeitsphase konkretisiert die einbringende Person ihr zu bearbeitendes Anliegen und stellt ihre Fragen an die Gruppe. In der Abschlussrunde wird die Sitzung reflektiert, das nächste Treffen terminiert sowie festgelegt, wer als nächstes seine Themen bearbeiten möchte.

\section{Möglichkeiten und Chancen}

Auch wenn es in den selbstorganisierten wie auch in institutionell angeschlossenen Arbeitsgruppen vorrangig um die Bearbeitung von Daten durch mehrere Personen geht, befindet man sich während der Forschungsarbeit nicht kontinuierlich in der Auswertungsphase. Insofern ist die gemeinsame Interpretation von Daten nicht immer erforderlich und das vorrangige Ziel solcher Gruppen nicht immer einlösbar. Lohnenswert ist es dann, die Arbeitsgruppe dazu zu nutzen, relevanteThemen der Dissertation und aktuelle Anliegen zu erörtern oder zu bera- 
ten. Dies können Diskussionen über Theorien, Methoden oder den Forschungsstand sein. Gewinnbringend ist zudem die gemeinsame Auseinandersetzung beispielsweise mit eigens verfassten Dissertationskapiteln oder Fachartikeln. Kommentare und Feedback helfen bei der Steigerung der Qualität der eigenen Textarbeit.

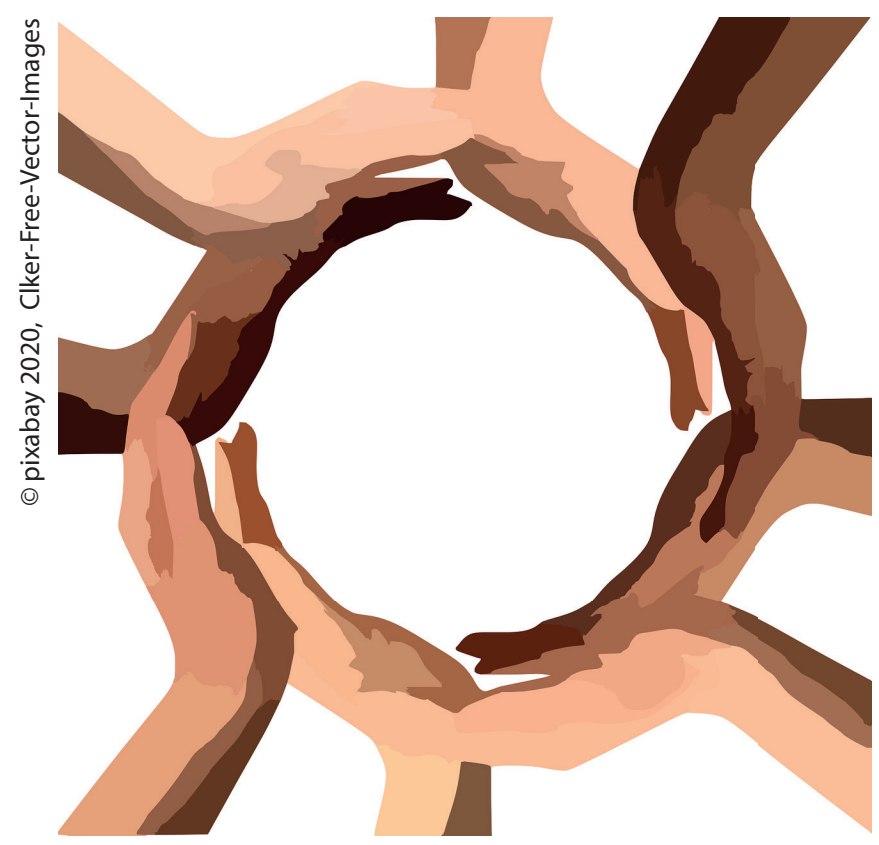

Der „inoffizielle" Kontext von selbstorganisierten Arbeitsgruppen erfüllt aber vor allem im Promotionsprozess noch weitaus mehr Funktionen. Denn man befindet sich unter Gleichgesinnten, mit den gleichen Problemen, Ängsten, Befürchtungen und Unsicherheiten. Daraus entsteht rasch eine Vertrauensbasis. Im Lauf der Zeit kann vor allem in selbstorganisierten Gruppen ein geschützter Raum mit individuell ausgehandelten Arbeitsweisen und einer Arbeitsatmosphäre entstehen, in der auch sensible Themen bearbeitet werden können. Es ist nicht notwendig Erfolge, das Vorankommen und den Stand der Arbeit zu präsentieren. Vielmehr besteht die Möglichkeit, sich ohne Gefahr von Repressionen emotional zu öffnen, die eigenen Ängste und seine Sorgen zu thematisieren und damit Stress zu reduzieren. Insofern kann die selbstorganisierte Arbeitsgemeinschaft Promovierender die Chance einer emotionalen Stütze bieten und entlastende Effekte haben.
Ein weiterer positiver Aspekt selbstorganisierter Arbeitsgruppen ist, dass man gemeinsam mit anderen an der eigenen Dissertation arbeitet und umgekehrt. Hin und wieder kommt es vor, dass man im langwierigen Promotionsprozess Widerstände gegen die Schreib- und Forschungsarbeit aufbaut. Man beginnt, bewusst oder unbewusst, seine Arbeit aufzuschieben. Erschwerend kommt hinzu, dass die Arbeiten an der Dissertation eigenverantwortlich, häufig ohne „Deadlines" und mit eigens aufgestellter Zeit- und Arbeitsstruktur stattfinden.

Die wiederkehrenden Treffen in der Arbeitsgruppe ermutigen dazu, sich seinen Texten und Daten wieder zu nähern sowie sich gedanklich positiv damit auseinanderzusetzen. Vor allem, wenn es darum geht, Texte für die Dissertationsschrift zu verfassen, kann die selbstorganisierte Arbeitsgruppe dabei helfen, indem gemeinsame Schreibtreffen stattfinden oder zum Beispiel in den außergewöhnlichen Zeiten der Corona-Pandemie digital verabredet werden. Folglich kann eine selbstorganisierte Arbeitsgruppe im Promotionsprozess dabei helfen, Antriebsschwierigkeiten zu überwinden und die Motivation zu steigern.

Im Laufe des Bachelor- und Masterstudiums, der Arbeitskarriere und letztlich auch während der Promotion hat sich jede ${ }^{*} r$ spezifische Arbeitsweisen und -strategien angeeignet. In einer selbstorganisierten Arbeitsgruppe können diese Strategien offener als in einer Gruppe mit institutionellem Anschluss reflektiert und hinsichtlich ihrer Effektivität und Effizienz überprüft werden. Es werden die blinden Flecken des eigenen Handelns aufgedeckt und ausgeleuchtet. Zudem wird durch den Austausch die Perspektive erweitert, sodass neue Methoden der Arbeitsorganisation erlernt werden können. Dadurch kann die selbstorganisierte Arbeitsgruppe den Effekt haben, die eigenen Strukturen, Strategien, den Workflow sowie den Output zu optimieren.

\section{Abschließende Gedanken}

Sich einer selbstorganisierten Arbeitsgruppe Promovierender anzuschließen oder gemeinsam mit anderen eine solche zu gründen, kann alle Beteiligten bei ihrer Promotion unterstützen und viele positive Effekte haben. Ob man als vorrangiges Ziel gemeinsam Daten interpretiert, 
sich gegenseitig motiviert, gemeinsam schreibt, neue Arbeitsstrategien erörtert oder relevante wissenschaftliche Themen diskutiert, obliegt jeder Arbeitsgruppe selbst.

In der Gruppe sollte jede*r abwechselnd die Möglichkeit haben seine Themen, Daten und Anliegen vorzustellen und mit den Mitgliedern zu bearbeiten. Mit einer grundsätzlichen Offenheit für Gruppenprozesse kann dieses Arbeitssetting zu einem unabhängigen, sicheren und geschützten Ort werden.

\section{Literatur}

Breuer, Franz/Muckel, Petra/Dieris, Barbara (2019): Reflexive Grounded Theory. Eine Einführung für die Forschungspraxis. 4., durchgesehene und aktualisierte Auflage. Wiesbaden: Springer VS.

Reichertz, Jo (2013): Gemeinsam Interpretieren. Die Gruppeninterpretation als kommunikativer Prozess. Wiesbaden: Springer VS.

Reichertz, Jo (2016): Qualitative und interpretative Sozialforschung. Eine Einladung. Wiesbaden: Springer VS.

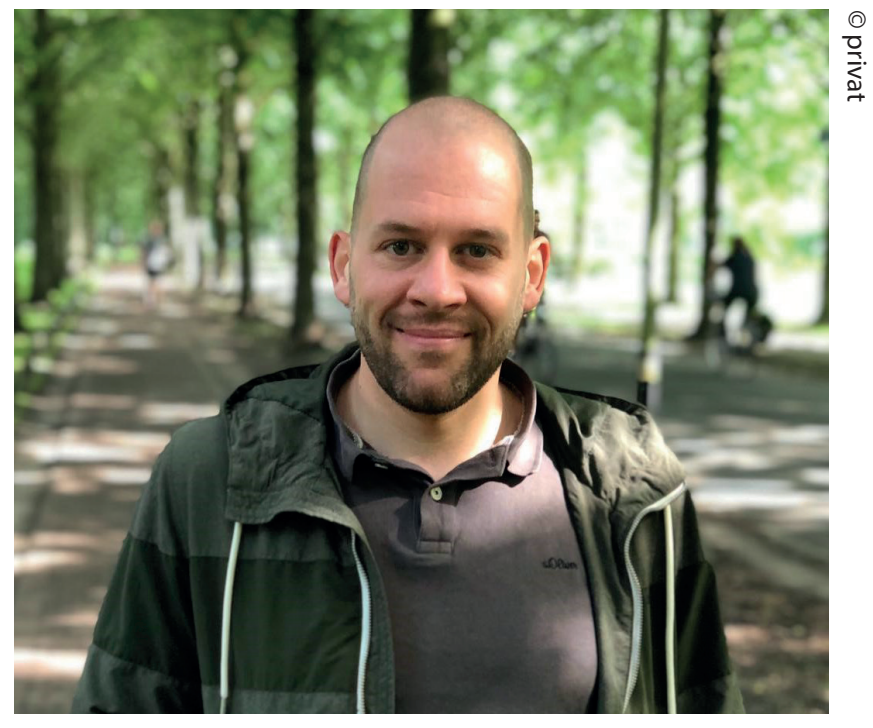

\section{Der Autor}

Alexander Parchow hat mehr als zehn Jahre Praxiserfahrung in verschiedenen Handlungsfeldern der Sozialen Arbeit. Seit 2019 ist er wissenschaftlicher Mitarbeiter an der Fachhochschule Münster im Fachbereich Sozialwesen mit dem Arbeits- und Forschungsschwerpunkt erzieherische Hilfen. Er promoviert am Institut für Erziehungswissenschaften der Westfälischen Wilhelms-Universität Münster zu dem Thema der Wirkungen, Folgen und Bedeutung stationärer Heimunterbringung im Leben junger Menschen. 


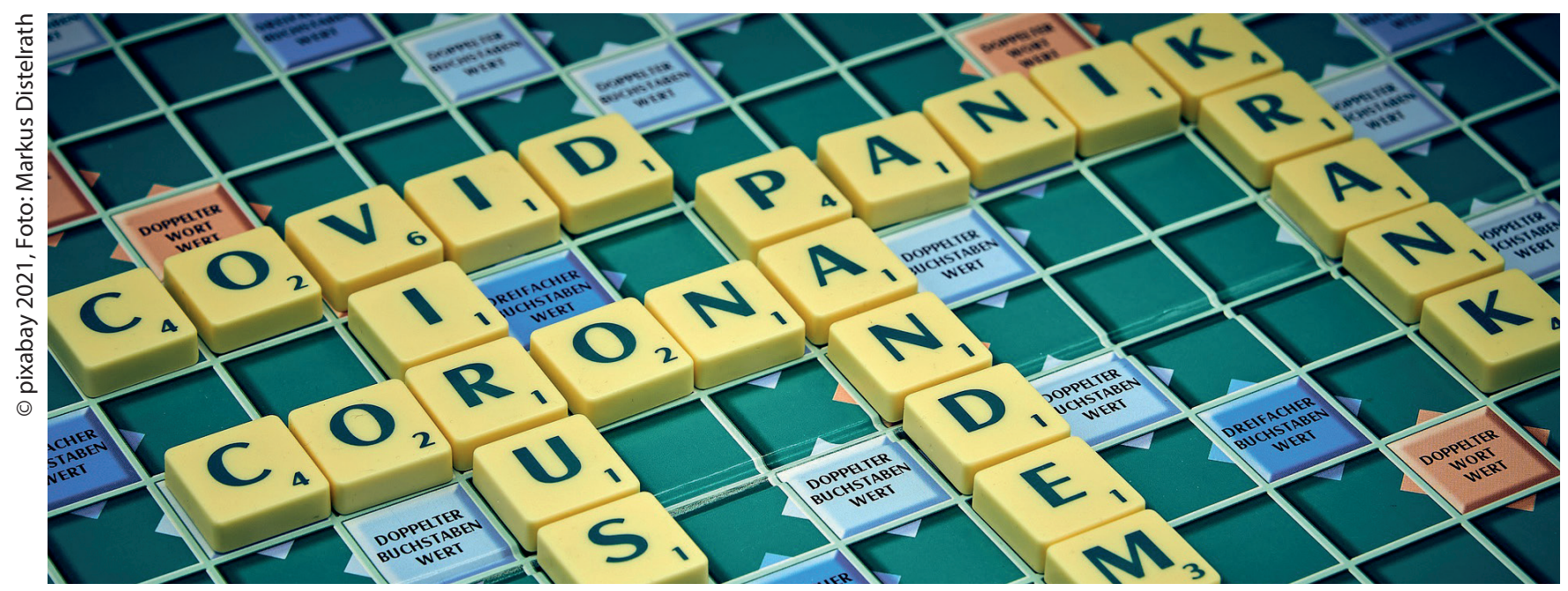

\section{Die Disputation in Zeiten der Covid-19-Pandemie}

von Lena Greinke

\section{Die Verteidigung}

Der vorläufige Abschluss bzw. die Begutachtung der Dissertation endet zumeist mit einer mündlichen Prüfung in Form eines Rigorosums, eines Kolloquiums oder einer Disputation (vgl. Becker 2020; HRK 2020; Uni Tübingen 2020). Welche Prüfungsform und -dauer möglich ist, entscheidet die Promotionsordnung (vgl. Feidel 2020; HRK 2020; Uni Tübingen 2020). Zumeist folgt einer wissenschaftlichen Präsentation der Inhalte der Dissertation die Verteidigung und Diskussion dieser, in der auf die Kritik der Gutachter*innen sowie der Prüfungskommission eingegangen wird (vgl. Flandorfer 2019; HRK 2020). Dabei findet die mündliche, zumeist hochschulöffentliche Prüfung in der Regel vor der Prüfungskommission, Kolleg*innen, Freund*innen, der Familie sowie weiteren Zuhörer*innen statt (vgl. HRK 2020; Wergen 2020). Im Anschluss an die Prüfung erfolgen häufig die Bekanntgabe der Bewertung sowie eine Feier mit den Beteiligten und Gästen. Doch die Covid-19-Pandemie hat vieles verändert. Persönliche Treffen in Räumlichkeiten der Universität waren zum Zeitpunkt meiner Disputation untersagt. Dementsprechend hieß es: flexibel sein, Chancen erkennen und Lösungen finden.

\section{Mein Vorgehen}

Für mich war schnell klar, dass ich den Termin der Disputation nicht verschieben wollte. Es war ohnehin schwierig gewesen, einen passenden Termin zu finden, an dem die gesamte Prüfungskommission mit externen Prüfern verfügbar war. Also habe ich ein Aufschieben als Option verworfen: Ich wollte fertig werden und da ließ ich mich von einem Virus nicht aufhalten.

Inhaltlich hatte ich den Vortrag bereits vor der Pandemie ausgearbeitet. Aus der Prüfungsordnung hatte ich entnommen, auf welche Rahmenbedingungen ich mich einstellen konnte. Zudem hatte ich meine Gutachter kontaktiert und den Fokus der Präsentation abgestimmt. Neben der inhaltlichen Vorbereitung hatte ich auch ein paar strategische Punkte beachtet. Dabei hatte ich zum Beispiel die (Forschungs-)Schwerpunkte meiner Prüfungskommission analysiert und für die Diskussion im Anschluss meines Vortrags auf mein Thema übertragen. Ich hatte eruiert, welche Fragen mir gestellt werden könnten. Den Vortrag hatte ich immer wieder geprobt: Die Animationen auf den Folien und auch der Text waren zeitlich abgestimmt. Allerdings wurde mir bewusst, dass 
meine Disputation in Zeiten der Pandemie völlig anders ablaufen würde als sonst.

\section{Erste Herausforderungen meistern}

Physische Treffen mit mehreren Personen waren aufgrund des Kontaktverbots in Deutschland nicht erlaubt. Es wären zu viele Personen in einem Raum gewesen, sodass die damaligen Hygiene- und Abstandsregelungen nicht hätten eingehalten werden können. Deshalb war auch die Nutzung der Räumlichkeiten in der Universität für die Disputation untersagt. Das bedeutete für mich, dass ich die bisherige Organisation mit Raum- und Technikreservierung, Einladung der Gäste, Präsentation etc. noch einmal überarbeiten musste. Da meine Disputation kurz nach Ausbruch der Covid-19-Pandemie in Deutschland stattfand, hatte ich mich zunächst auf eine reine Online-Disputation eingestellt. Dafür musste ich einiges beachten. Meine Präsentation war für ein Online-Format viel zu überladen. Schriftgröße und Abbildungen waren zu klein. Denn nicht jede ${ }^{*} r$ hatte im Homeoffice einen großen Bildschirm und musste die Prüfung auch auf einem kleinen Laptop verfolgen können. Dementsprechend hieß es: vereinfachen und neu planen. Animationen und Texteinschübe wurden entfernt. Ich stellte also meinen Vortrag um, kürzte, löschte usw. Ich übte mit verschiedenen Videokonferenztools, filterte Optionen der Programme und versuchte passende technische Lösungen zu finden. Gleichzeitig prüfte ich immer wieder, welche Programme ich seitens der Universität und auch aus Gründen des Datenschutzes verwenden durfte. Familie und Freunde mussten in frühmorgendlichen und nächtlichen Probekonferenzen meinen Vortrag anhören. Nach einiger Zeit fühlte ich mich mit der neuen Präsentation und der Technik einigermaßen sicher. Ich konnte meinen Bildschirm teilen sowie anderen Nutzer*innen erklären, wie Kamera und Ton zu bedienen sind. Es ging vorwärts und das war ein gutes Gefüh!!

\section{Rückschläge hinnehmen und Chancen erkennen}

Danach folgte jedoch die Lockerung der Maßnahmen zur Eindämmung der Pandemie. Physische Treffen waren nun unter Einhaltung der Hygiene- und Abstandsregelungen wieder möglich. Für mich bedeutete das eine erneute Um- bzw. Neuplanung, denn es war nicht klar, ob die Prüfung nun doch in den Räumlichkeiten der Univer- sität als Live-Vortrag oder weiterhin nur online möglich war. Ich telefonierte also mit zahlreichen Zuständigen der Universität, um zu erfahren, wie ich damit umgehen konnte. Für mich wurde klar: Eine Disputation mit allen Mitgliedern der Prüfungskommission war aufgrund der Pandemie-Regelungen an der Universität nicht möglich. Also behielt ich die Inhalte meines Vortrags bei, da mindestens ein paar Mitglieder meiner Prüfungskommission online teilnehmen würden.

Die Entscheidung fiel letztendlich für eine hybride Lösung. Ich machte mich auf die Suche nach Räumlichkeiten, die mit einer entsprechenden Videokonferenztechnik ausgestattet waren und mir somit die Möglichkeit boten, zumindest technisch professionell präsentieren zu können. Dank meines Betreuers konnte ich schnell einen Raum finden und erhielt durch seine Unterstützung die Zustimmung der Universität, meine Prüfung in hybrider Form durchzuführen. Wieder begann ich mit Familie, Freund*innen sowie Kolleg*innen zu proben und die Technik zu testen. Das Üben nahm mir meine Ängste.

Inzwischen war ich recht sicher im Umgang mit der Konferenztechnik - musste ich auch, denn die Prüfung rückte immer näher. Zum Schluss organisierte ich noch einige Aspekte, die ohne die Pandemie auch anders gewesen wären. Gäste waren nicht erlaubt, sodass eine Feier ausblieb. Offen war noch die Frage der Kleidung. Feststand, dass sie der Prüfung angemessen sein sollte und ich mich dennoch wohlfühlte. Bei meinem Outfit beachtete ich, dass ich nicht zu dunkel und nicht zu farbenfroh gekleidet war. Aufwendige Muster vermied ich, damit die Kamera alles in angemessener Qualität übertrug.

\section{Mein Fazit}

Letztlich bin ich froh, dass alles so passiert ist. Meine Prüfung lief hervorragend. Ich nutze während des Vortrags ein Headset und in der Diskussion den Lautsprecher mit Mikrofon aus der Konferenztechnik. Um Sprache, Gestik und Mimik gut darzustellen, musste ich jedoch deutlicher sein als sonst. Meine Präsentation wurde recht flüssig übertragen und alle konnten sich in der Diskussion gut verstehen. Neben mir waren nur zwei Prüfer im Raum, damit der Abstand eingehalten werden konnte. Durch die hybride Prüfung konnte ich zudem Zeit und 
damit Sicherheit gewinnen. Ich kannte mich mit dem Thema und der Technik aus. Alle Beteiligten waren sehr wohlwollend, denn für die meisten war es auch die erste hybride Prüfung.

Ich möchte alle Promovierenden ermuntern, die Chancen solcher Situationen zu nutzen. Sicherlich hätte einiges besser und reibungsloser laufen können, aber ich habe viel gelernt - nicht nur technisch. Eine strukturierte Vorbereitung und gute Unterstützung durch Familie und Freund*innen geben Halt. Für mich gilt: Üben macht den/die Meister*in. Schwierige Situationen können helfen, mit den Herausforderungen zu wachsen. Ich gehe davon aus, dass zukünftig immer mehr hybride Formate in unseren Alltag integriert werden (müssen), was für uns alle auch ein Stück Freiheit bedeuten kann.

\section{Literatur}

Becker, Julia (2020): Disputation und Rigorosum. Muss ich nach der Promotion weitere Abschlussprüfungen absolvieren? https://www.academics.de/ratgeber/dissertationskolloquium-rigorosum-disputation (letzter Zugriff am 17.7.2020).

Feidel, Marina (2020): Die Disputation nach der Dissertation vorbereiten. https://www.lektorat-dissertation.de/ disputation/ (letzter Zugriff am 20.7.2020).

Flandorfer, Priska (2019): Was dich bei der Disputation erwartet. https://www.scribbr.de/dissertation-doktorarbeit/disputation/ (letzter Zugriff am 17.7.2020).

Hartung, Manuel J./Kerstan, Thomas (Hrsg.) (2019): ZEIT CAMPUS Ratgeber Promotion. Entscheiden, planen, durchhalten: Die wichtigsten Tipps für die Dissertation in allen großen Fachgebieten. ZEIT CAMPUS in Kooperation mit der Klaus Tschira Stiftung.

HRK - Stiftung zur Förderung der Hochschulrektorenkonferenz (2020): Promotion - Mündliche Prüfung. https://www.hochschulkompass.de/promotion/promotionsphase/muendliche-pruefung.html (letzter Zugriff am 17.7.2020).
Petri, Stefan/Klauth, Carlo (2012): Abschluss der Promotion: Disputation oder Rigorosum? in: Günauer, Franziska/Krüger, Anne K./Moes, Johannes/Steidten, Torsten/ Koepernik, Claudia (Hrsg.): GEW-Handbuch Promovieren mit Perspektive. Ein Ratgeber von und für Doktorandlnnen, S. 307-313.

Uni Tübingen - Eberhard Karls Universität Tübingen (2020): Mündliche Prüfung: Disputation/Promotionskolloquium/Rigorosum. https://vitruv.uni-tuebingen.de/ ilias3/goto.php?target=wiki_wpage_516_610\&client_ $\mathrm{id}=$ graduiert\&lang=da. (letzter Zugriff am 20.7.2020).

Wergen, Jutta (2020): Disputation vorbereiten: Wie Du Deine Disputation gut vorbereitest. https://coachingzonen-wissenschaft.de/disputation-vorbereiten/ (letzter Zugriff am 20.7.2020).

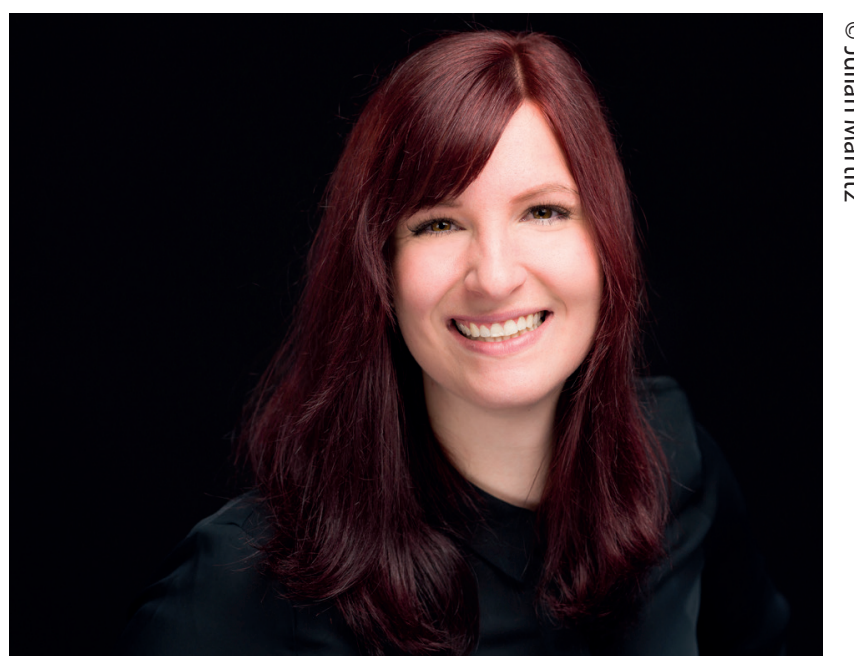

\section{Die Autorin}

Lena Greinke ist Umweltplanerin und wissenschaftliche Mitarbeiterin am Institut für Umweltplanung in der Abteilung Raumordnung und Regionalentwicklung an der Gottfried Wilhelm Leibniz Universität Hannover. Zu ihren Schwerpunkten in Forschung und Lehre zählen Untersuchungen zu Fragen der Regionalentwicklung, insbesondere der Partizipation sowie der Entwicklung urbaner und ländlicher Räume. Sie hat zu berufsbedingten multilokalen Lebensweisen in ländlichen Räumen und deren gesellschaftliche und räumliche Auswirkungen als planerische Herausforderung promoviert. 


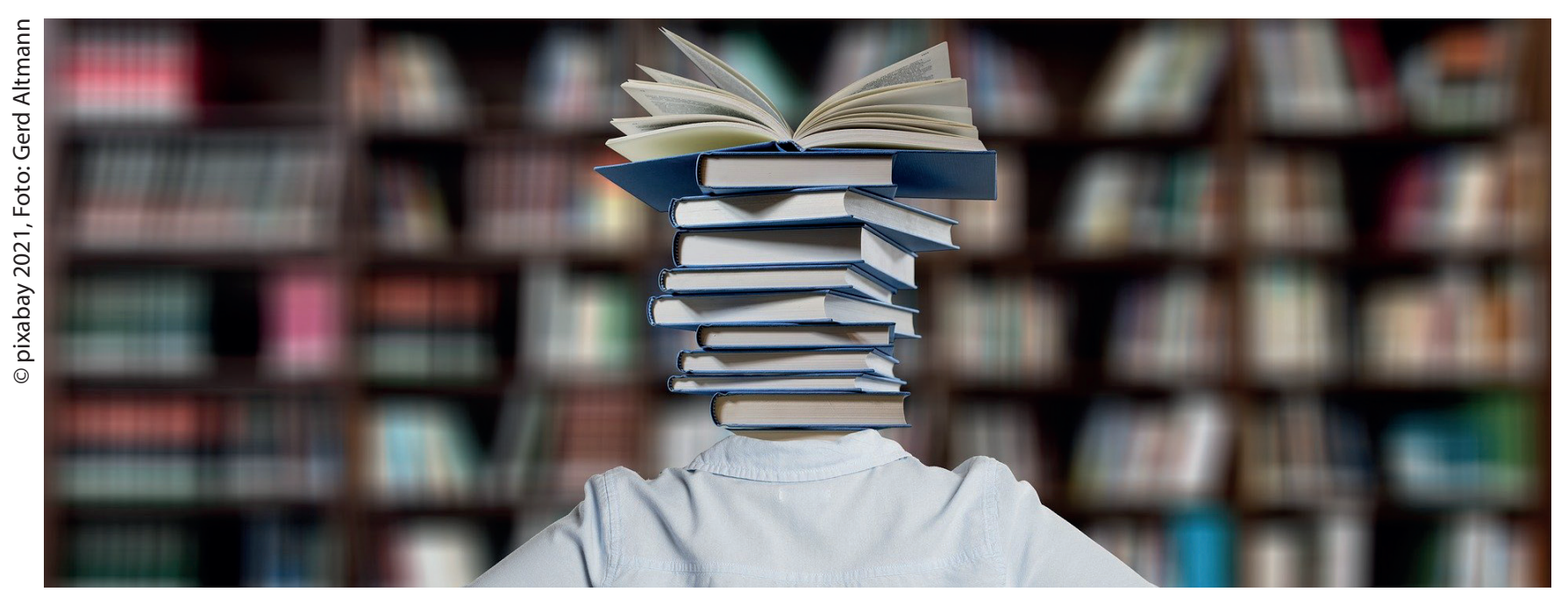

\section{Erste leisten Pionierarbeit}

\section{Wie man als Bildungsaufsteiger*in Netzwerke erobert und Wege findet}

\section{von Jasmin Döhling-Wölm}

Aus meiner Beratungspraxis weiß ich, dass drei Fragen Bildungsaufsteigende besonders beschäftigen. Erstens: Wie finanziere ich das kommende Semester? Zweitens: Woher weiß ich, dass ich hier richtig bin? Drittens: Wie halte ich durch?

Forschung erfordert ein gesichertes Umfeld. Insbesondere mit der COVID19-Krise hat es all jene Studierende, Promovierende und Forschende hart getroffen, die neben dem Verlust des Austausches mit Peers auch noch Erwerbseinkommensquellen und Jobs verloren haben. Forschung lebt vom diskursiven Miteinander. Und das benötigt Zeit und einen gewissermaßen sorgenfreien Raum.

Diskussionen benötigen also Zeit und Sorgenfreiheit in Bezug auf die existenzielle Basis. Die Suche nach Lösungen und kreativen Konzepten gelingt in der Regel dann, wenn ein Mensch diese Sorgenfreiheit besitzt und die eigene Zeit einsetzen kann; wenn jemand weiß, dass das Geld für die Existenz reicht. Zeit ohne ausreichend Geld, wie es für viele Menschen in der aktuellen strukturellen Krise gerade die Realität ist, ist aber keine unbeschwerte, frei verfügbare Zeit.
Ein Wissenschaftssystem, das zudem auf einer Teilzeitjobber-Struktur aufbaut, um Bildungsaufstieg zu ermöglichen, nimmt in Kauf, dass die ideenerforschenden, diskursiven, zeitintensiven Gesprächsrunden von finanziell abgesicherten Zielgruppen wahrgenommen werden, während die anderen ihren Lebensunterhalt erwirtschaften müssen bzw. sich davon erholen oder darauf vorbereiten müssen und maximal die Pflichtveranstaltungen besuchen können.

Intellektuelle Diskussionsrunden in Mensen, Cafeterias, Studierendenbuden und an digitalen Stammtischen sind daher nicht selten eher die Kür. Dabei werden in genau diesen Diskussionsnetzwerken die intellektuellen Kaderschmieden gebildet. Die Peers sollten nicht nur Zeitgenoss*innen sein, sondern auch zukünftige Gefährt*innen in den Karrierefeldern.

Das ist also ein strukturelles Dilemma: prozessorientiert diskutieren oder ergebnisorientiert und ganz existenziell Geld verdienen? Es ist ein Vereinbarkeitsproblem.

Wer forschen und studieren will, benötigt finanzierte Zeit. Es gab tatsächlich nicht wenige Stimmen in meinem aka- 
demischen Umfeld, die meinten, dass die COVID19- „Pause" im Lockdown im Frühjahr 2020 doch genutzt werden könnte, um zu studieren und zu promovieren. Zeit wäre ja nun reichlich vorhanden. Es war und ist aber für viele Menschen keine finanzierte Zeit. Gerade die Servicejobs sind es, die betroffen waren und sind, und die vielen Studierenden und Promovierenden einen Bildungsaufstieg ermöglichen.

Besonders zentral im Netzwerkcoaching wurden während der Pandemie die individuellen Strategien, Finanzierungen zu entwickeln. Dabei ging es ebenso um kurzfristige Finanzierungshilfen wie auch um mittel- und langfristige Forschungsförderstrategien.

\section{Woher weiß ich, dass ich hier richtig bin?}

Eine zweite Frage, die sich viele Bildungsaufsteigende stellen, ist: Bin ich hier wirklich richtig?

Als einstige Studienberaterin und als internationale Wissenschaftscoach erlebe ich oft, dass äußerlich sehr erfolgreiche Menschen ein Unwohlsein bis hin zu einer panischen Angst in sich tragen, als totale Versager*innen und Schaumschläger*innen entlarvt zu werden.

Überwiegend trifft das in meinem Tätigkeitsfeld auf Frauen zu. Jedoch sind auch Männer davon betroffen. Vor allem aber trifft das Phänomen auf Bildungsaufsteigende und Menschen mit Migrationserfahrung zu. All das weist einerseits auf immer noch bestehende, teils unsichtbare Netzwerkgrenzen hin und andererseits auf die Fähigkeit, ebendiese Grenzen überschreiten zu können, aber dann mit emotionalen und mentalen Irritationen umgehen können zu müssen.

Hinter diesen ersten Indikatoren kann sich ein Impostor-Syndrom, das sogenannte Hochstapler*innen-Phänomen verbergen. Das heißt, die unbegründete Angst, ein*e Hochstapler*in zu sein und andere zu betrügen.

Einige Anzeichen für dieses weitreichende Syndrom sind zum Beispiel:

- Prüfungsangst und Vermeiden von Tests;

- Unwohlsein bei Lob und Anerkennung für Leistungen;
- Angst, Erwartungen nicht erfüllen zu können;

- Fokussieren auf schlechte Ergebnisse und Abwerten von guten Benotungen;

- das ständige Gefühl, man hätte noch mehr machen können;

- das Gefühl, Erfolge nicht reproduzieren zu können.

Im Rahmen einer Coachingveranstaltung mit dem Ziel der Professur richtete mal eine Teilnehmerin folgenden Satz an ihre Übungspartnerin im Rahmen der StärkenSchwächen-Analyse: „Naja, wenn du schon nicht an dich glaubst, wer soll es denn dann tun?"

Die Angesprochene verfiel daraufhin in eine Art Lethargie über die restliche Zeit bis zum Ende des ersten Tages und wollte sich dann abends bei mir für den zweiten Tag abmelden und in den kommenden Tagen auch vom gesamten Programm, da sie "spürte", dass sie nicht nach Akademia gehöre. Sie würde ihren Weg schon gehen, sagte sie. Bevor sie ging, gab ich ihr eine Hausaufgabe. Ich bat sie, den Impostor-Phänomen-Test noch am selben Abend zu machen und mir umgehend die Ergebnisse aufs Handy zu senden. Wenn sie am nächsten Tag immer noch der Meinung sei, sie wolle nicht kommen, wäre es wenigstens eine selbstbestimmte Entscheidung, sagte ich ihr. Sie war sehr niedergeschlagen, versprach aber, den Test zu machen und mir die Ergebnisse mitzuteilen. Ich war noch auf dem Weg zum Hotel, da klingelte mein Handy. Es war die Teilnehmerin, die mir unter Tränen mitteilte, dass sie am nächsten Tag auf jeden Fall käme und wenn die Hölle zufrieren würde. Und sie würde mit den anderen Teilnehmerinnen diesen Test diskutieren wollen.

Sie war also weiterhin dabei und wirkte wie ausgetauscht. Sie wusste zwar noch nicht, an welche persönlichen Stärken und Leistungen sie wirklich glauben konnte, aber sie wusste nun, wie sie es anpacken konnte, sich selber in Leistungsfragen mehr zu vertrauen. Sie hatte erkannt, dass sie die richtigen Menschen um sich herum brauchte und diese bislang nicht hatte. Sie wollte netzwerken und vernetzte sich direkt nach der Veranstaltung mit mir und anderen Coaches über Social Media, wie ich freudig registrierte. 
Der Satz "Naja, wenn du schon nicht an dich glaubst, wer soll es denn dann tun?" mag inhaltlich viel Wahres ausdrücken, er ignoriert jedoch einen wichtigen Sachverhalt: Die Unfähigkeit, an die eigenen Kompetenzen zu glauben und ihnen zu vertrauen, ist ebenso erlernbar wie die Fähigkeit, sich richtig einzuschätzen. Und beides hängt zum großen Teil von einem förderlichen Netzwerk $a b$, das angemessen ermutigt und bestärkt.

Die Psychologinnen Pauline Clance und Suzanne Imes haben den Begriff Impostor-Syndrom geprägt und dazu einen Test zur Selbstanalyse entwickelt. Wenn Sie herausfinden möchten, ob und mit welcher Stärke Sie an dem Impostor-Phänomen leiden, dann machen Sie doch kurz den IP-Test der Psychologin Pauline Clance: https://paulineroseclance.com/pdf/IPTestandscoring.pdf.

Gleichgültig wie stark das Syndrom ausgeprägt ist: Die Macht dieses Netzwerkphänomens auf Ihren Karriereverlauf - bedingt durch prägende biographische Erlebnisse - verringert sich, sobald Sie sich des Phänomens bewusst werden. Je häufiger Sie sich mit anderen darüber austauschen, desto schwächer wird die Wirkung im Alltag. Auch wenn ich beobachte, dass die Wirkung bei den Coachingfällen, die ich begleite, nie ganz zu verschwinden scheint. Doch es kann auch nicht schaden, ein wenig Selbstkritik zu behalten, wenn es um neue Herausforderungen geht. Das macht uns Menschen umsichtig, lässt uns bescheiden bleiben und schützt vor allzu großen Risiken.

Was das mit den eigenen Netzwerkaktivitäten zu tun hat? Bauen Sie sich gezielt Netzwerke mit Menschen auf, die Sie unterstützen und bestärken. Wer sich als großzügiger Mensch mit Großzügigen umgibt, bleibt in einer positiven Bilanz, kann auf andere zählen und schafft die belastbaren Beziehungen.

\section{Wie halte ich durch?}

Wenn man als Erste oder Erster in der Familie einen anderen Weg geht, ist es oft nicht leicht. Auch wenn die bisherigen sozialen Beziehungen wie Familie und Freundschaften es meist gut meinen, so kann es ermüdend oder gar frustrierend sein, sich für den eingeschlagenen Weg immer wieder erklären zu müssen. In vielen Coachingfällen mit Bildungsaufsteigenden wird erzählt, dass häufig

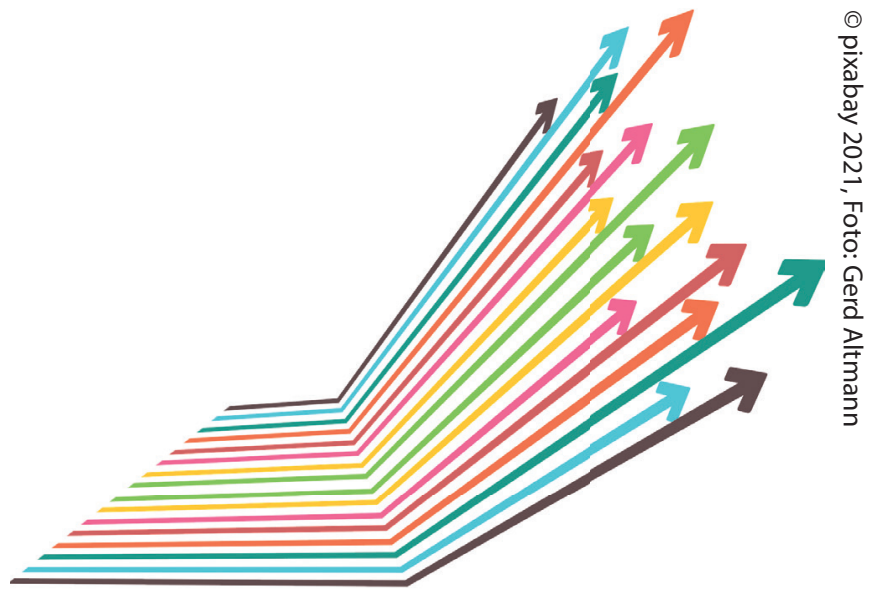

danach gefragt wird, wann denn endlich „richtiges Geld“ verdient wird oder auch, wann die „Familie" gegründet wird und wovon diese dann ernährt werden soll. Unser Umfeld, die herrschenden Denkmodelle und Meinungen beeinflussen uns mehr als wir es gern wahrhaben wollen.

Wer einen anderen Weg gehen will als die bisherige Bezugsgruppe in Familie und Freundeskreis, muss zu den Leistungsherausforderungen, die für alle gleich scheinen, zusätzlich viel emotionale Ablösungsarbeit leisten. Willenskraft und Zielbewusstsein reichen da nicht immer.

Der US-amerikanische Psychologe Benjamin Hardy hat in seinem Buch "Willpower doesn't work" sehr treffend beschrieben, dass jede Heldin und jeder Held ein Produkt der Situation ist und anstelle von selbstdisziplinierender, harter Willenskraft vor allem kleinere, routinierte Erfolgsmechanismen im alltäglichen Handeln zum Erfolg führen. Und dieses kleinteilige Erfolgshandeln kann auch mentale Barrieren im Herkunftsfeld überwinden.

Nachhaltiger Erfolg gelingt nur in der Kombination folgender Faktoren:

- Entwicklungswille,

- Erfolgsroutinen,

- fördernde Netzwerkpartner*innen.

Das Kernstück seiner Empfehlung ist: Entwickle Trigger, um Selbstsabotage vorzubeugen. 
„Rather than relying on willpower, you'll need to create an automated response for how to deal with challenges. In other words, you'll need to create a trigger for the trigger" (Hardy 2018:110).

Was Hardy damit beschreibt, nennt die Psychologie implementation intentions. Klingt kompliziert, ist aber sehr einfach. Das Konzept der implementation intention nutzt eine Wenn-dann-Beziehung:

- Wenn ich in Versuchung gerate meine E-Mails zu checken, während ich an meiner Publikation schreibe, dann mache ich mir einen Tee.

- Wenn ich ein Kapitel meines Lernstoffs auslassen will, weil ich inn für zu schwierig halte, dann frage ich in meinem Netzwerk, wer es verstanden hat und sich mit mir darüber austauscht.

- Wenn ich das Gefühl habe, den akademischen Weg aufgeben zu wollen, weil die Finanzierung nicht reicht, dann recherchiere ich Kontakte an meiner Uni, die mir Informationen zu Forschungsfinanzierung geben können.

Auch die WOOP-Technik der deutschen Psychologieprofessorin Gabriele Oettingen nutzt das Konzept der implementation intention.

WOOP steht für:

$\mathrm{W}=$ (wish) Formulieren Sie Ihr Ziel!

$\mathrm{O}=$ (outcome) Beschreiben Sie, wie das Ergebnis aussehen soll!

$\mathrm{O}=$ (obstacle) Benennen Sie Ihre möglichen Hürden für das Durchhalten!

$\mathrm{P}=$ (plan) Machen Sie sich einen Plan, was Sie anstelle des Aufgebens tun, wenn die Hürden auftauchen!

Warum Sie diese Techniken nutzen sollten? Weil der beste Plan nichts bringt, wenn Sie den Selbstsabotagen nichts entgegensetzen. Da hilft dann auch das beste Netzwerk nicht. Zum Erfolg getragen werden aus meiner Erfahrung nur die wenigsten.

\section{Literatur}

Clance, Pauline R. (1985): The Imposter Phenomenon: Overcoming the Fear That Haunts Your Success. Atlanta: Peachtree Publishers.

Hardy, Benjamin (2018): Willpower doesn't work. Discover the hidden keys to success. New York: Hachette Books.

Oettingen, Gabriele (2017): Die Psychologie des Gelingens. München: Droemer Taschenbuch.

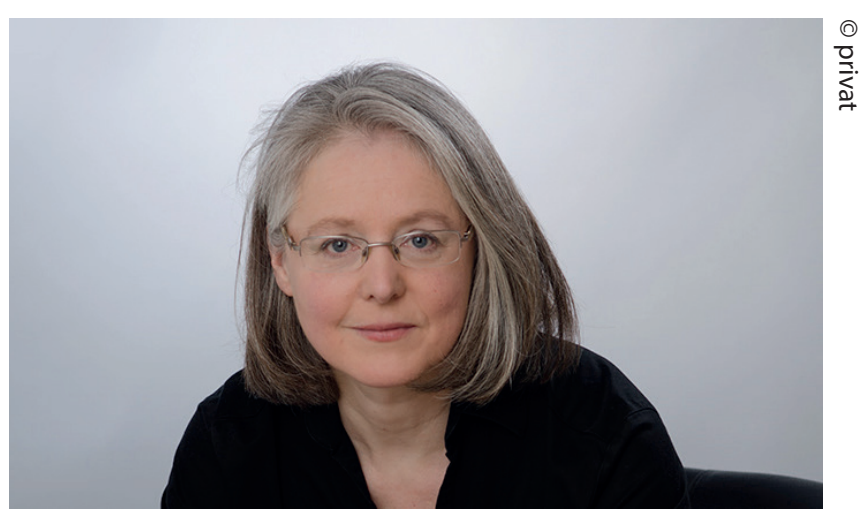

\section{Die Autorin}

Jasmin Döhling-Wölm baute als Pädagogin und Wissenschaftsmanagerin an den Universitäten Hannover, Bremen und Oldenburg wissenschaftlich konzipierte Lehrund Personalentwicklungsprogramme für Studierende, Forschende und Lehrende auf. 2001 gründete sie das Consulting-Institut für akademische Karriereentwicklung karrierekunst (www.karrierekunst.de) mit dem heutigen Sitz in Bremen. Mit ihrem Team ist sie in Deutschland, Österreich und der Schweiz tätig als Consultant und Coach für Fach- und Führungskräfte in inner- und außeruniversitären Karrieresystemen. 


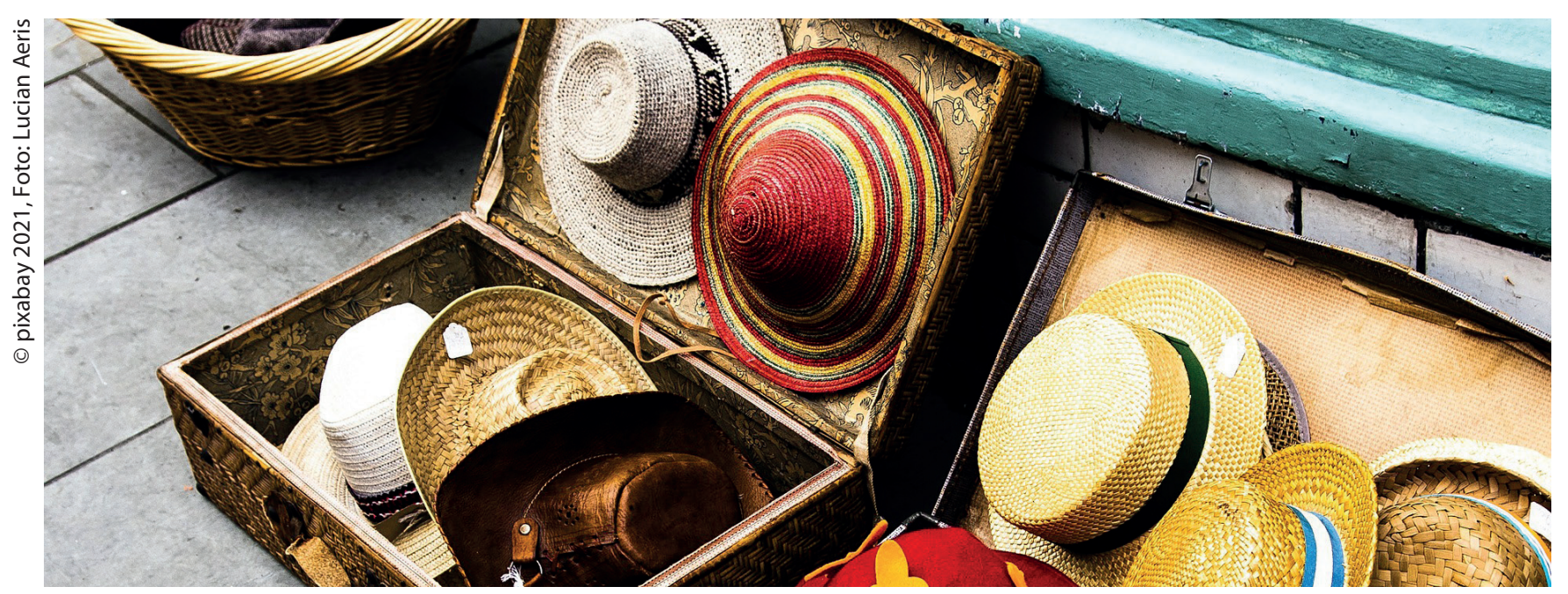

\title{
Die Auswahl der passenden statistischen Methode
}

\author{
von Daniela Keller
}

Das häufigste und wichtigste Thema in meinen Beratungen und meinen Kursen ist die Frage: Was ist die passende statistische Analysemethode für mein Projekt? Und dies ist zu Recht eine häufig gestellte Frage, denn sie ist nicht pauschal und meist auch nicht kurz und einfach zu beantworten. Die Antwort hängt vom Studiendesign, den Variablentypen, der Stichprobengröße und den Fragestellungen ab und klärt sich häufig erst im Verlauf der Datenanalyse, weil z.B. durch Voranalysen neue Erkenntnisse zu den Forschungsfragen oder auch einfach nur zu den untersuchten Daten gewonnen werden.

Leider kann ich Ihnen diese individuelle Frage also nicht in diesem Artikel beantworten. Ich will Ihnen aber eine Vorgehensweise an die Hand geben, mit der Sie selbst für Ihr Projekt - bzw. für jede Hypothese Ihres Projekts die passende Methode herausfinden können. Gehen Sie dazu einfach die folgenden Punkte durch:

\section{Von der Forschungsfrage zu den statistischen Hypothesen}

Starten Sie für die Auswahl der passenden statistischen Methode noch einmal bei der Formulierung Ihrer For- schungsfrage. Das klingt wie ein Schritt in die falsche Richtung, ist aber wichtig. Denn Sie brauchen richtig formulierte Hypothesen und dazu ist es notwendig, nochmal genau zu überlegen, was in der Forschungsfrage untersucht werden soll.

Aus der Forschungsfrage heraus formulieren Sie sich die Hypothesen. Hier sollten Sie darauf achten, dass Sie die Hypothesen präzise und genau formulieren, dass sie nur eine Idee pro Hypothesenpaar verarbeiten und dass die Hypothesen auch messbar sind. Dass Sie also alle in den Hypothesen verwendeten Parameter auch erhoben haben.

Das statistische Hypothesenpaar besteht aus Null- und Alternativhypothese. Die Alternativhypothese beschreibt das, was Sie nachweisen wollen, z.B. „Es gibt einen Zusammenhang". Die Nullhypothese ist das Gegenteil der Alternativhypothese, z.B. formuliert „Es gibt keinen Zusammenhang.. Der Signifikanztest später versucht die Nullhypothese abzulehnen und damit die Alternativhypothese zu bestätigen. 


\section{Das Studiendesign ergibt die Variablen und Variablentypen}

Wenn Sie Ihre Hypothesen fix haben, werden Sie sich klar über Ihr verwendetes Studiendesign: Haben Sie mehrere Messzeitpunkte? Wenn ja, welche und wie viele? Werden verschiedene Gruppen verwendet? Wie viele und welche? Welche Parameter werden erhoben?

Sollten Sie Ihre Daten schon vorliegen haben, ist das längst alles schon fix. Trotzdem ist es sinnvoll, noch einmal darüber nachzudenken. Dadurch haben Sie Ihr Studiendesign dann glasklar vor sich liegen, wenn Sie im nächsten Schritt über die passende statistische Methode entscheiden.

Die Beantwortung der oben genannten Fragen führt dazu, dass Sie wissen, welche Variablen Sie mit welchem Messniveau erhoben haben. Außerdem wird klar, ob es bei den vorher formulierten Hypothesen um Gruppenvergleiche oder um Analysen von Messwiederholungen geht. Beides ist entscheidend für die Auswahl der passenden statistischen Methode.

\section{Voraussetzungen prüfen}

Wenn Sie nun sowohl Ihre Hypothese als auch die dazugehörigen Variablen und das Studiendesign klar vor Augen haben, ergibt sich damit eine Auswahl an möglichen statistischen Methoden. Das sind einerseits deskriptive Methoden, die Sie zum Beschreiben der Daten, der Unterschiede oder Zusammenhänge verwenden. Außerdem Grafiken, mit denen Sie diese Unterschiede oder Zusammenhänge veranschaulichen können.

Auch haben Sie jetzt eine Idee, welche Signifikanztests oder auch welche komplexeren Modelle für Ihre Auswertung in Frage kommen. Beides sind Methoden der schließenden Statistik, mit denen Sie die von Ihnen formulierten Hypothesen auf Signifikanz prüfen. Sie haben nach den oben durchgeführten Schritten nun bereits eine oder mehrere mögliche Methoden ausgewählt. Zusätzlich ist aber wichtig, dass viele dieser Tests und Modelle Voraussetzungen an z.B. die Verteilung der Daten stellen.

Diese Voraussetzungen müssen nun geprüft werden, damit Sie entscheiden können, ob sie die angedachte
Methode einsetzen dürfen. Sie können z.B. die Normalverteilung der Variablen oder auch der Residuen betreffen, eine bestimmte Form des Zusammenhangs (Linearität) zwischen den Parametern oder auch eine genügend große Zellbesetzung bei der Analyse von Kreuztabellen beinhalten. Abhängig vom Ergebnis dieser Prüfung entscheiden Sie dann, ob die bisher ausgewählte Methode möglich ist. Wenn ja, wenden Sie sie an. Wenn nein, brauchen Sie ein alternatives Vorgehen.

\section{Alternativen finden}

Alternativen können darin bestehen, Datentransformationen durchzuführen, z.B. um eine Normalverteilung in der metrischen Variablen zu erzeugen oder indem Sie Kategorien sinnvoll zusammenfassen, um eine genügend große Zellbesetzung zu erreichen. Für einige Methoden stehen als Alternative auch nichtparametrische Verfahren zur Verfügung, die keine oder weniger Anforderungen an die Verteilung der Daten stellen. Oder Sie argumentieren über die Robustheit der ausgewählten Methoden oder setzen Bootstrapping zur Absicherung Ihrer Ergebnisse ein.

Welcher Weg der Beste ist, hängt von der individuellen Situation ab, von der Stichprobengröße, der Art der Hypothese, den zur Verfügung stehenden Methoden (auch softwareabhängig) und dem Ziel Ihrer Arbeit.

Mit dieser Schritt-für-Schritt-Vorgehensweise schaffen Sie es, die passende Analysemethode für jede Ihrer Hypothesen herauszufinden, ohne sich dabei zu verlaufen und ohne dabei etwas Wichtiges zu vergessen. Je nach Datensituation und Komplexität der Hypothese kommen Sie durch diesen Prozess sehr schnell und einfach hindurch oder müssen auch mal ein paar Schleifen drehen und - wie im letzten Abschnitt beschrieben - nach alternativen Methoden suchen.

Was Sie in jedem Fall brauchen ist ein Grundverständnis der statistischen Konzepte und das Wissen um die Eigenschaften und Voraussetzungen der einzelnen statistischen Methoden. Beides möchte ich Ihnen in dieser Artikelserie vermitteln. 


\section{Die Autorin}

Daniela Keller ist leidenschaftliche Statistik-Expertin und berät Studierende und Wissenschaftler*innen zu allen Themen der statistischen Datenanalyse. Während ihres Studiums der Diplom-Mathematik gründete sie mit Kommilitonen eine studentische statistische Beratung und arbeitete anschließend selbständig in diesem Feld. Neben Einzelberatungen und Workshops unterstützt sie Ihre Kund*innen seit 2019 mit der Statistik-Akademie, ihrem Online-Mitgliederbereich für alle, die Statistik verstehen und selbständig anwenden wollen. Ihr Blog (www.statistik-und-beratung.de/blog) und ihr YouTubeKanal sind Fundgruben für leicht verständlich aufbereitetes Statistikwissen für die Praxis.

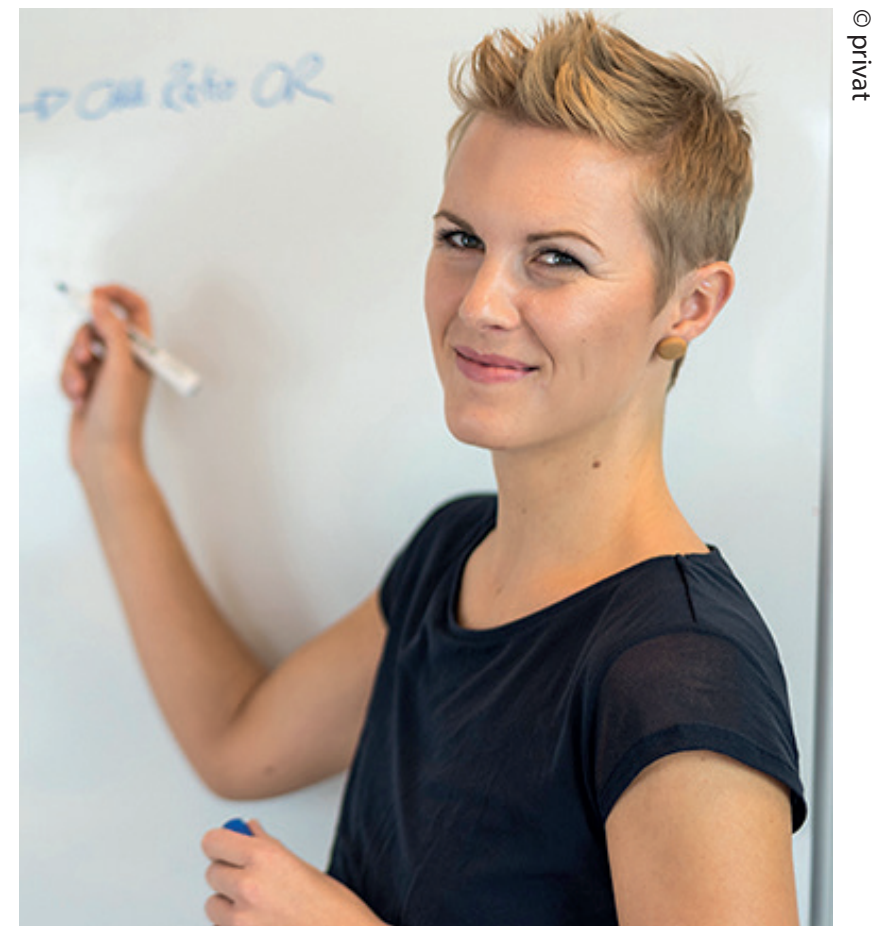




\section{Nachwuchstipps}

\section{Rezensionen}

\section{Taking Control of Writing Your Thesis}

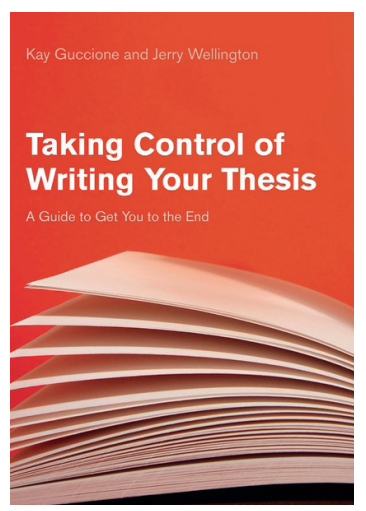

Promovierende sind bis zur Fertigstellung ihrer Dissertation mit einigen Herausforderungen konfrontiert. Diese thematisieren Kay Guccione und Jerry Wellington in ihrem Buch, einem an Promovierende gerichteten "guide to get you to the end", in dem sie ihre Erfahrungen aus der Beratung von Promovierenden zugänglich machen.

Zentrales Thema im Buch ist der Schreibprozess und dessen Organisation vom Exposé bis zur Abgabe der Arbeit. Promovierenden wird nachvollziehbar nahegelegt, weshalb es sinnvoll ist, so früh wie möglich mit dem Schreiben zu beginnen, was die Autor*innen als „our repeated mantra“ (s. S. 21) bezeichnen. Anhand von konkreten und inspirierenden Hinweisen erläutern sie, wie die vielfältigen Herausforderungen beim Schreiben gelingen können. Die Themenpalette reicht von Feedback-einholen, über Vernetzung mit anderen Promovierenden, Schreibmotivation, emotionale Aspekte, Zeitmanagement bis hin zur Verknüpfung der Lektüre von Fachpublikationen mit dem eigenen Text.

Mögliche Hürden in der Promotionsphase werden ebenfalls besprochen, beispielsweise die eigene Einstellung und Motivation oder das Verhältnis zu Betreuer*innen. Hierzu geben die Autor*innen eine ganze Bandbreite nachvollziehbarer Beispiele und Hinweise, von denen Promovierende im Umgang mit den jeweiligen Herausforderungen, die sich ihnen stellen, profitieren können. Auch für die Verteidigung der Dissertation erhalten Leser*innen Tipps zur gezielten inhaltlichen und mentalen Vorbereitung.

Das Buch ist somit ein anregender Begleiter während des gesamten Promotionsprozesses mit seinen Höhen und Tiefen. Gerade weil immer wieder betont wird: „do what works for you“, vermittelt es zwar viele Hinweise, jedoch keine Rezepte und ermuntert die Leser*innen, ihren eigenen Weg zu finden. Magdalene Schmid

Kay Guccione/Jerry Wellington (2017): Taking Control of Writing Your Thesis. A Guide to Get You to the End. Bloomsbury.

\section{Wissenschaftlich schreiben leicht gemacht}

Kornmeier steigt in seinen Ratgeber sympathisch ein mit der Analogie zwischen dem Backen eines Gugelhupfs und dem Verfassen einer Hochschulschrift und zeigt, was bei der Produktion so alles schiefgehen kann: So wie man bspw. keine Eier mit abgelaufenem Haltbarkeitsdatum verwenden sollte,

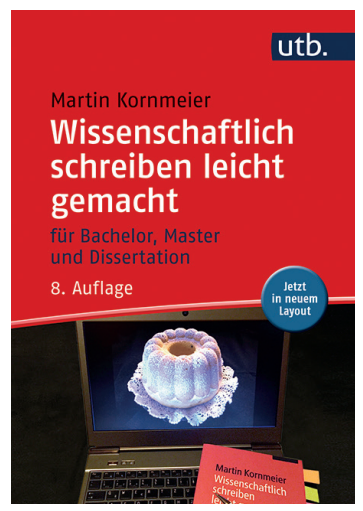
sollte man auch beim wissenschaftlichen Schreiben aktuelles Wissen verarbeiten und nicht auf veraltete empirische Befunde setzen. So wie man die Zutaten für den Teig ausreichend verrühren sollte, verlangt auch wissenschaftliches Arbeiten eine intensive Auseinandersetzung mit dem eigenen Text und dem eigentlichen Thema. Die Back-Analogie zieht sich als roter Faden durch das Buch: von der Themensuche und dem Festlegen einer geeigneten Fragestellung (Kap. 3), dem Umgang mit der Literatur (Kap. 4; Recherche, Lesen und Exzerpieren, Literaturauswahl) über das Gliedern der Arbeit und den argumentativen Aufbau der einzelnen Teile (Kap. 5) bis hin zum Formulieren und der sprachlichen Arbeit am Text (Kap. 6) sowie Hinweisen zu Formalia (Kap. 7) und zum Zeitmanagement (Kap. 8).

Ein kleineres Manko dieses Buches: Angesichts der 8. Auflage hätten einige inhaltliche Aktualisierungen dem Buch gutgetan: So empfinde ich die Ausführungen zur Frage „männliche und/oder weibliche Ausdrucks- 
form" als nicht (mehr) zeitgemäß. Auch finden sich keine Hinweise zur Verwendung hilfreicher Software, bspw. zu Literaturverwaltungsprogrammen.

Ein größeres Manko: Wirklich didaktisch aufbereitet sind die Inhalte nur bedingt. So erfährt man und bekommt exemplarisch vorgeführt, warum bspw. präzise Adjektive, konkrete Substantive und aktive Formulierungen zu bevorzugen, hingegen Verben mit unnötigen Vorsilben, Infinitivkonstruktionen, Funktionsverbgefüge, Floskeln, Füllwörter und einiges mehr zu vermeiden sind. $\mathrm{Ob}$ man nach der Lektüre des Buches in der Lage ist, was man erfahren hat, beim Schreiben anzuwenden und auf den eigenen Text zu übertragen, ist fraglich. Konkrete Übungen finden sich (fast) keine. Als Lesebuch (nicht Übungsbuch) und als Anregung, über das eigene Schreiben zu reflektieren, ist Kornmeiers Ratgeber aber uneingeschränkt empfehlenswert und für alle Qualifikationsstufen und über alle Fächer hinweg mit Gewinn zu lesen. Sarah Brommer

Martin Kornmeier (2018): Wissenschaftlich schreiben leicht gemacht. Für Bachelor, Master und Dissertation. utb (Haupt Verlag).

\section{Die Arbeit ist fertig - was nun?}

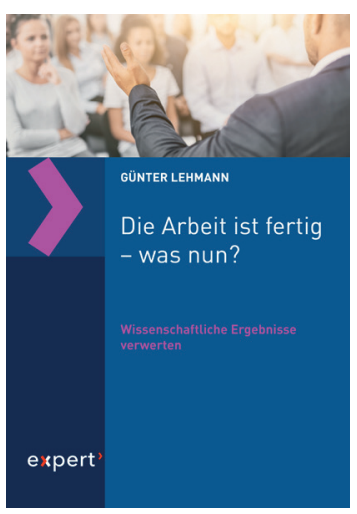

Eine Fülle an Ratgebern begleitet angehende Wissenschaftler*innen bis zur Abschlussarbeit - selten wird in der Studienliteratur der Blick darüber hinaus gerichtet, wie anschließend die eigenen Forschungsergebnisse für die Positionierung und Karriere eingesetzt werden können. „Die Idee, die Kreation allein, entfaltet noch keine Wirkung. Auf ihre Umsetzung, die Innovation kommt es an!" Und so stellt der Autor Günter Lehmann fünf „Verwertungskanäle" vor: Publizieren (in unterschiedlichen Medien), Vortragen (auf Tagungen und Meetings), Vermitteln (in Unterweisungen und Seminaren), Umsetzen (in Organisationen) und Selbstverwerten (in Existenzgründungen).

Das Buch enthält erstaunlich konkrete und stringente Handlungsempfehlungen, anschaulich verdichtet in über 100 Abbildungen. Die zahlreichen Checklisten (z.B.
"Vorbereitung Rede" oder "Vorbereitung Fachartikel") und Fragestellungen, deren Klärung Handlungen evoziert, erweitern den Ratgeber zum Praxishandbuch. Eine wahre Fundgrube, in der für alle Absolvent*innen etwas dabei ist: vom Überblick verfügbarer Publikationsformen, -medien und ihrer Spezifika, die Vorstellung möglicher Argumentationsketten, angeleitete Beispiele didaktischer Vereinfachungen für populärwissenschaftliche Zwecke, knappe Übersichten zu conference abstracts, extended abstracts, ihren Unterschieden, Vorbereitungen für Interviews uvm. Es verwundert nicht, dass die Vielfalt an Themen in der vorliegenden Form nicht vertieft werden kann, dafür wird an jedem Kapitelende umfangreich weiterführende Literatur empfohlen.

Die Zielgruppe ist nicht auf Promovierende an Universitäten beschränkt, Diplom-, Master- und Bachelorstudiengänge an Hochschulen, Berufsakademien sowie Weiterbildungseinrichtungen mit Graduiertenstudiengängen aller Fachrichtungen sind eingeschlossen. Allen Absolvent*innen bietet dieses Buch eine bereichernde Perspektive: Die Ergebnisse ihrer Qualifikationsschrift als "Schatz" (s. S. 7) zu betrachten, der über die Fachöffentlichkeit hinaus wissenschaftliche Innovation für die Bewältigung gesellschaftlicher Herausforderungen beiträgt. Lehmann selbst schreibt über seine Verwertungsvorschläge: „Sie dienen allerdings bestenfalls als Treppengeländer, nicht als Haustürschlüssel. Den muss der Verfasser selbst finden“ (s. S. 20). Das Buch gibt genügend inspirierende Anregungen, um herauszufinden, wo sich der Schlüssel im selbst produzierten Stoff befindet, der die nächste Karrieretür öffnet.

Günter Lehmann (2019): Die Arbeit ist fertig - was nun? Wissenschaftliche Ergebnisse verwerten. expert. 


\section{Auszeichnungen}

\section{Promotionsförderung der Studienstiftung}

Die Studienstiftung fördert Promovierende unterschiedlicher fachlicher und persönlicher Hintergründe. Laut ihrer Satzung wird „die Hochschulbildung junger Menschen, deren hohe wissenschaftliche oder künstlerische Begabung und deren Persönlichkeit besondere Leistungen im Dienst der Allgemeinheit erwarten lassen" unterstützt. Ziel der Förderung ist es, die Promotionsstipendiat*innen bestmöglich darin zu befähigen, diese Talente weiter zu entfalten und für die Gesellschaft einzusetzen - sei es im Rahmen einer weiteren akademischen Laufbahn oder in vielfältigen anderen beruflichen wie persönlichen Kontexten.

Die Promotionsförderung bietet ein hohes Maß an Flexibilität bei der Ausgestaltung individueller Wege hin zur Promotion. Das Stipendium ermöglicht wertvolle Freiräume bei der Wahl von Thema und Betreuung sowie ein hohes Zeitbudget für die wissenschaftliche Arbeit am Dissertationsprojekt. Die Doktorand*innen erhalten ein monatliches Stipendium und können Zuschüsse für Auslandsvorhaben beantragen. Die Studienstiftung fördert den wissenschaftlichen Austausch der Promovierenden untereinander sowie mit Wissenschaftler*innen, bietet Beratung und ein breites Bildungsprogramm. Auch haben Geförderte die Chance, den jährlich zweifach verliehenen, renommierten Promotionspreis der Studienstiftung zu gewinnen.

Hochqualifizierte und gesellschaftlich engagierte Promovierende können gemeinsam mit der/dem Betreuenden den Antrag auf ein Promotionsstipendium stellen. Ein Antrag ist jederzeit möglich, es gibt keine Fristen. Informationen und Formulare finden Sie unter https:// www.studienstiftung.de/infos-fuer-promovierende/promotionsfoerderung-der-studienstiftung/promotionsvorschlag/.

\section{Förderprogramm der Hans Sauer Stiftung}

Das jährlich ausgeschriebene Förderprogramm unterstützt gesellschaftlich relevante und innovative Vorhaben mit Bezug zu Wissenschaft und Forschung in einem bestimmten Themenschwerpunkt. Seit Frühjahr 2018 verfolgt die Hans Sauer Stiftung im Rahmen des Arbeitsschwerpunkts "Circular Society" auf mehreren Wegen das Ziel, das Thema Zirkularität - im Sinne eines Denkens und Handelns in Kreisläufen - in verschiedenen gesellschaftlichen Bereichen zu stärken. Als Ziel sieht die Stiftung die Etablierung kreislauforientierter und -fähiger gesellschaftlicher Praktiken und neue Formen gesellschaftlichen Wissens, Denkens und Handelns. Das Förderprogramm 2021 setzt den Schwerpunkt fort und erneut beim Thema Wissensgenerierung und -vermittlung an: Für den Übergang zu einer Kreislaufgesellschaft bedarf es verschiedener Wissensformen im Sinne einer "Circular Literacy", welche die Fähigkeit umschreibt, natürliche, technische und stoffliche Kreisläufe zu verstehen und entsprechend handeln zu können. Charakteristisch dafür sind systemisches und reflexives Denken sowie die Fähigkeit, komplexe Zusammenhänge zu durchdringen. Die Bereitschaft, über verschiedene Disziplinen und soziale Unterschiede hinweg zu kooperieren und zu gestalten, ist ein weiterer Bestandteil dieser komplexen Kompetenz.

Konkret möchte das Programm Vorhaben unterstützen und vorantreiben, die in verschiedenen, nicht nur schulischen Bildungskontexten, die beschriebenen Wissensformen und Kompetenzen vermitteln. Mit 20.000 Euro gefördert werden Lehr- und Lernformate, Kooperationen und Dialogveranstaltungen an Schnittstellen von Wissenschaft und Praxis, die im oben genannten Sinn Ziel-, System- oder Transformationswissen zum Thema Zirkularität vermitteln; Praxisvorhaben und Bildungsangebote zur Wissensvermittlung in diesem Themenbereich, solange sie wissenschaftlich begleitet sind oder Bezug auf aktuelle Forschungsfragen nehmen; Vermittlungsmaterialien und Publikationen zum Thema; Vorhandene wissenschaftsbasierte Bildungsangebote, die um das Thema Zirkularität erweitert werden. Bewerben können sich Körperschaften öffentlichen Rechts wie Hochschulen und Universitäten mit Sitz in Deutschland, auch als gemeinnützig anerkannte Organisationen mit Sitz in Deutschland wie Vereine, Stiftungen, gGmbHs, gUGs, u. Ä.

Fristende für die Antragstellung: 15.6.2021

Informationen zur Ausschreibung, Förderrichtlinien und Antrag finden Sie unter https://www.hanssauerstiftung. de/foerderprogramm/. 


\section{Veranstaltungen}

\section{Online-Tagung: Lesen und Schreiben}

Schreiben ist ohne Lesen nicht denkbar. Gerade das wissenschaftliche Schreiben kann ohne entsprechende Lesekompetenzen nicht erfolgreich sein. Wissenschaftliches Arbeiten und Schreiben setzt oft das Verarbeiten mehrerer Quellen, mehrerer Texte voraus. Das erfordert andere Lesestrategien, als wenn ein einzelner Text verarbeitet werden soll. Um mehrere Quellen verarbeiten zu können, müssen diese nicht nur verstanden, sondern sie müssen auch kritisch eingeschätzt und zueinander in Beziehung gesetzt werden. Gleichzeitig stellt dies auch andere Anforderungen an das schreibende Verarbeiten. Beides ist in den letzten Jahren verstärkt in den Fokus der Lese- und Schreibforschung gerückt.

Die Tagung widmet sich der Verbindung von wissenschaftlichem Lesen und Schreiben - sowohl an der Hochschule als auch im Beruf. Sie will aus wissenschaftlicher und didaktischer Perspektive auf entsprechende Kompetenzen blicken und diese diskutieren.

Die Online-Tagung am 11./12.6.2021 wird von www. forumschreiben.ch ausgerichtet, in enger Zusammenarbeit mit der www.gefsus.de und der www.gewisss.at. Es ist die zweite trinationale Tagung der Gesellschaften für wissenschaftliches Schreiben in Deutschland, Österreich und der Schweiz. Anmeldung sowie fortlaufend aktualisierte Informationen zur Tagung auf der Tagungswebsite www.fhnw.ch/fws-tagung. Fristende für die Bewerbung ist der 29. Mai 2021.

\section{Online-Angebot: Schreib-Freitag für Promovierende}

Sie schreiben an Ihrer Dissertation und wollen raus aus Ihrem Schreiballtag? Sie wollen vorankommen beim Schreiben? Der "Schreib-Freitag" ist ein kostenfreies Online-Angebot des schreibzentrum.berlin für Promovierende: An jedem ersten Freitag im Monat, von 09:30 bis 12:00 Uhr, trifft sich die Schreib-Community online, um gemeinsam am Schreibprojekt zu arbeiten.
Sie setzen sich zum Einstieg ein Schreibziel und teilen es der Schreibgruppe mit. Anschließend bekommen Sie einen Impuls zum "Warmschreiben“, die weitere Schreibzeit mit Hilfe der Pomodoro-Technik anmoderiert. Das Schreibtreffen schließt mit einem gemeinsamen kurzen Check-Out.

Unter https://www.schreibzentrum.berlin/veranstaltungen/schreib-freitag-fuer-promovierende-2021-08-06/ können Sie sich für die einzelnen Termine anmelden.

\section{Online-Angebot: Publishing Insights}

Die Publishing Insights sind eine Fortsetzung der Webinar-Reihe "Verlagssprechstunde" vom Verlag Barbara Budrich und budrich training, mit brandneuen Themen und zusätzlich ergänzt um sechs englischsprachige Sessions. Die Webinare finden einmal im Monat mittwochs von 15:30 Uhr bis 17:00 Uhr statt, jedes unter einem eigenen Oberthema aus wechselnden Verlagsbereichen: von Stilfragen für das akademische Schreiben bis zur Veröffentlichungsförderung, vom Publishing Agreement bis zum Publishing in English Language Journals. Sie richten sich an (angehende und erfahrene) Wissenschafts- und Sachbuch-Autor*innen. Die Verlegerin selbst oder Expert*innen aus den unterschiedlichen Bereichen teilen ihr Wissen und ihre Erfahrungen in einem Impulsvortrag zum jeweiligen Spezialthema. Anschließend ist Zeit für Ihre Fragen und Austausch in einer Diskussionsrunde.

Unter https://budrich-training.de/publishing-insights-2021/ können Sie Termine sowie Themenbeschreibungen einsehen und sich anmelden. 


\section{Autor*innenportraits}

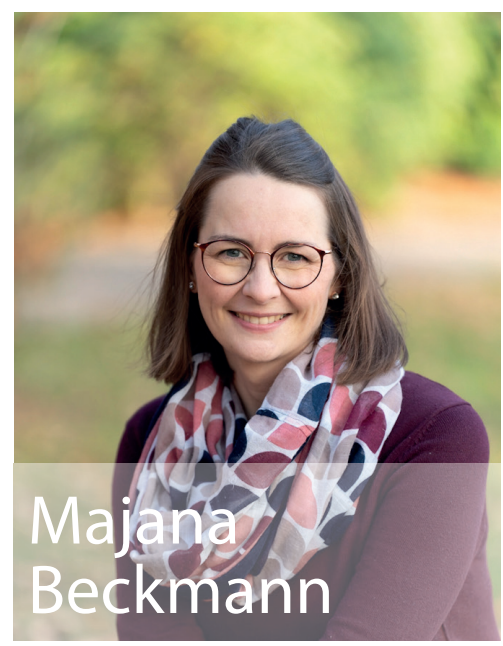

ist promovierte Linguistin, systemische Beraterin (SG), Mutter von zwei Kindern und Inhaberin von KLARwärts - Coaching für Promovierende. Über zehn Jahre lang hat sie Berufserfahrung in der akademischen Lehre, in der Erwachsenenbildung und in der medien- und hochschuldidaktischen Beratung gesammelt. Sie ist als Promotionscoach mit dem zusätzlichen Schwerpunkt „Promovieren mit Kind*ern" selbstständig.

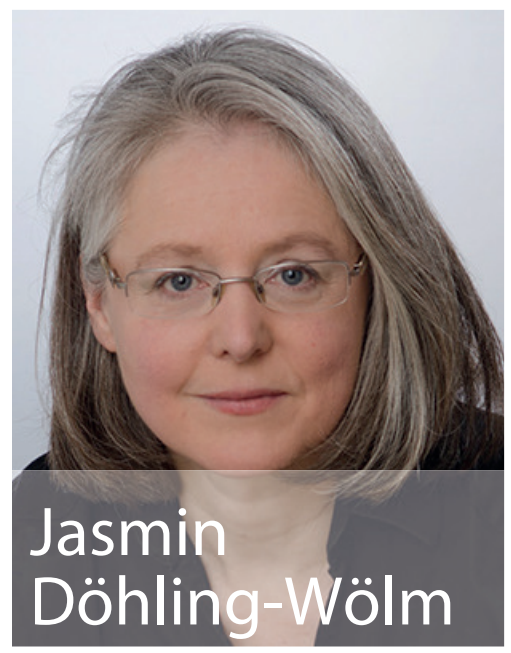

baute als Pädagogin und Wissenschaftsmanagerin an den Universitäten Hannover, Bremen und Oldenburg wissenschaftlich konzipierte Lehr- und Personalentwicklungsprogramme für Studierende, Forschende und Lehrende auf. 2001 gründete sie das Consulting-Institut für akademische Karriereentwicklung karrierekunst mit dem heutigen Sitz in Bremen. Mit ihrem Team ist sie in Deutschland, Österreich und der Schweiz tätig als Consultant und Coach für Fach- und Führungskräfte in inner- und außeruniversitären Karrieresystemen.

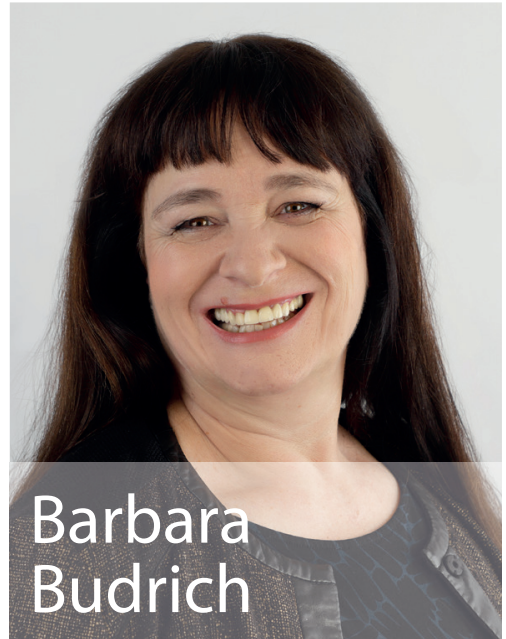

arbeitete über 10 Jahre im Verlag Leske + Budrich ihres Vaters, bevor sie 2004 den Verlag Barbara Budrich gründete. Sie hat zahlreiche Bücher und Aufsätze publiziert, übersetzt und geschrieben. Seit 2012 geben sie und ihr Team im von ihr etablierten Unternehmen budrich training ihr Know-how zum wissenschaftlichen Publizieren und Schreiben systematisch in Vorträgen, Workshops und Coachings weiter. Neuestes Projekt für den wissenschaftlichen Nachwuchs ist die Zeitschrift Exposé, deren Herausgeberin sie ist.

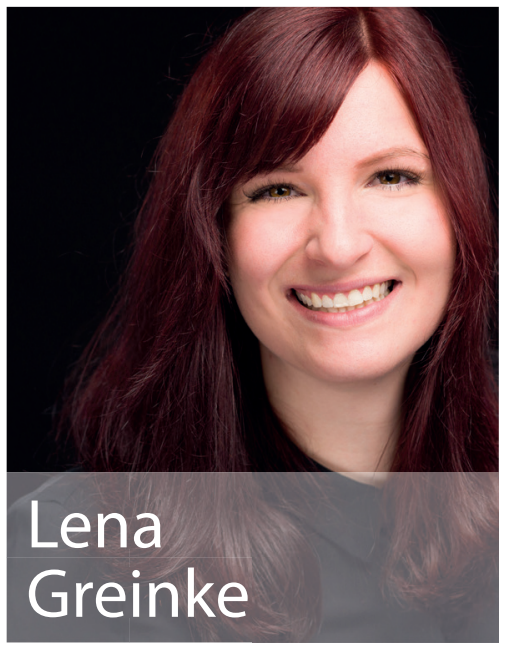

ist Umweltplanerin und wissenschaftliche Mitarbeiterin am Institut für Umweltplanung in der Abteilung Raumordnung und Regionalentwicklung an der Gottfried Wilhelm Leibniz Universität Hannover. Zu ihren Schwerpunkten in Forschung und Lehre zählen Untersuchungen zu Fragen der Regionalentwicklung, insbesondere der Partizipation sowie der Entwicklung urbaner und ländlicher Räume. 


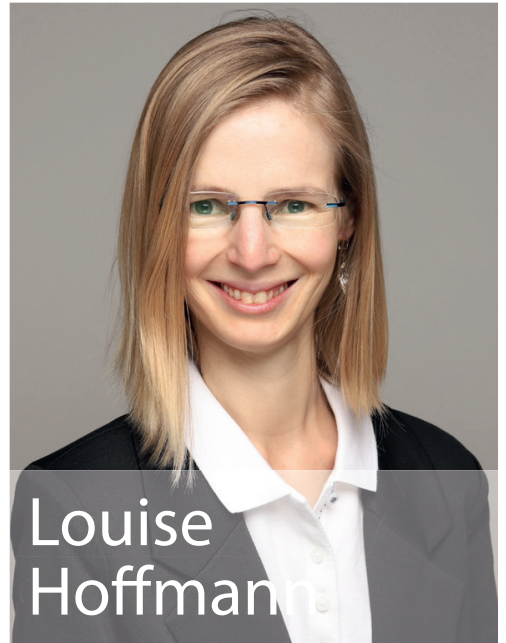

war fachlich im Bereich der wissenschaftlichen Schreibdidaktik angesiedelt. Sie war Mitglied der Gesellschaft für Schreibdidaktik und Schreibforschung e.V. Ihr Promotionsthema befasste sich mit der schreibdidaktischen, diversitätssensiblen Unterstützung von Studierenden in berufsbegleitenden Masterprogrammen an deutschen Hochschulen.

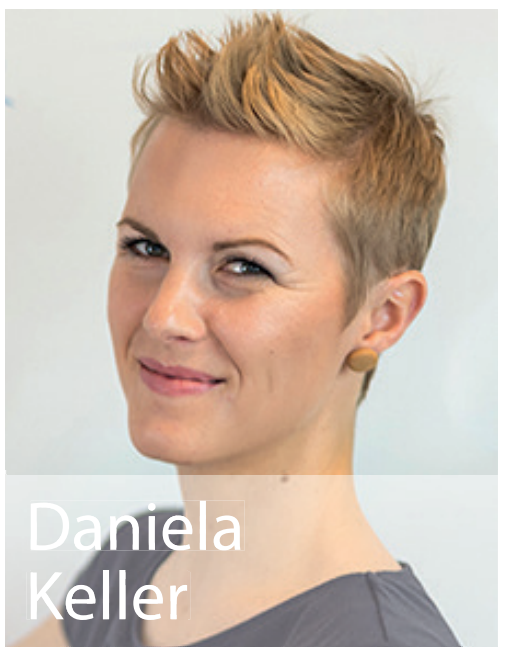

ist leidenschaftliche Statistik-Expertin und berät Studierende und Wissenschaftler*innen zu allen Themen der statistischen Datenanalyse. Während ihres Studiums der Diplom-Mathematik gründete sie mit Kommilitonen eine studentische statistische Beratung und arbeitete anschließend selbstständig in diesem Feld. Neben Einzelberatungen und Workshops unterstützt sie Ihre Kund*innen seit 2019 mit der Statistik-Akademie.

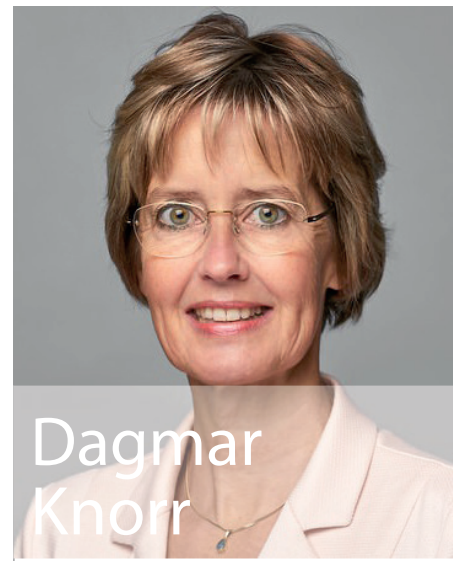

ist Schreibwissenschaftlerin und Linguistin. Sie forscht, lehrt und publiziert zum wissenschaftlichen Schreiben unter Bedingungen von Mehrsprachigkeit.

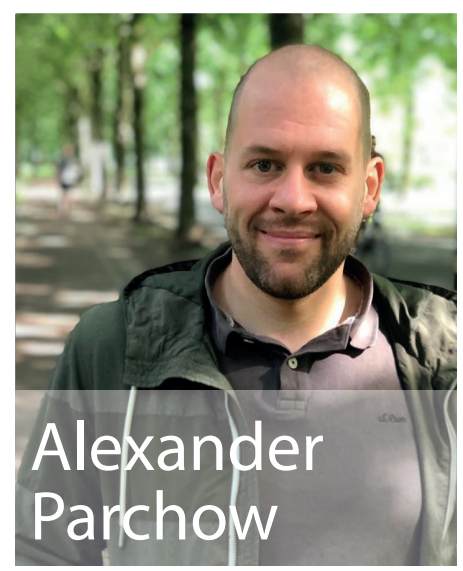

hat mehr als zehn Jahre Praxiserfahrung in verschiedenen Handlungsfeldern der Sozialen Arbeit. Seit 2019 ist er wissenschaftlicher Mitarbeiter an der Fachhochschule Münster im Fachbereich Sozialwesen mit dem Arbeits- und Forschungsschwerpunkt erzieherische Hilfen.

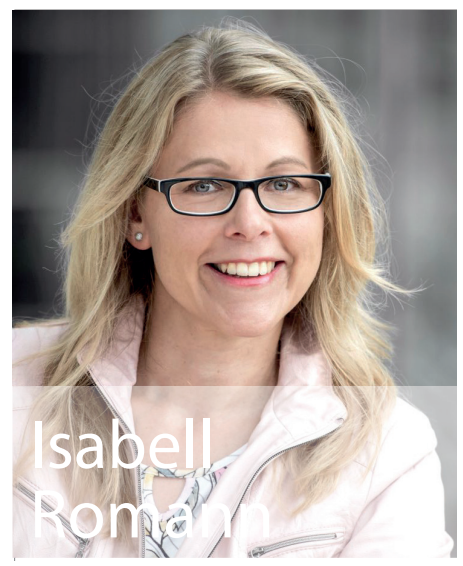

studierte Betriebswirtschaftslehre an der Berufsakademie Heidenheim (heute DHBW) sowie Romanistik und Orientalistik/lslamwissenschaft an der Ruhr-Universität Bochum. 


\section{Workshops}

Workshops zum wissenschaftlichen Schreiben

Schreiben ist die Schlüsselqualifikation in der Wissenschaft. Im Mittelpunkt steht üblicherweise das "Was", das "Wie" wird jedoch häufig vernachlässigt. Wir vermitteln, wie Sie Ihre Gedanken fachlich und stilistisch angemessen in Form bringen, und geben Ihnen Praxistipps und Werkzeuge an die Hand, mit deren Hilfe Sie sicher durch den Schreibprozess navigieren.

\section{Workshops zum wissenschaftlichen Publizieren}

Wer in den Wissenschaften nicht publiziert, verbreitet seine Erkenntnisse und Leistungen nicht und ist damit im Fachbereich nicht präsent. Auf Grundlage jahrzehntelanger Verlagserfahrung entwickeln wir mit Ihnen für Ihre Publikation die passende Strategie, finden geeignete Partner*innen zur Veröffentlichung und die angemessene Form für Ihren Text.

Alle Angebote in deutscher und englischer Sprache.

\section{Online-Schreibclub}

Der Schreibclub richtet sich an Autorinnen und Autoren, die Wissenschaftstexte oder fundierte Sachtexte verfassen (möchten). Jeden Monat treffen wir uns in einer kleinen Gruppe von maximal sechs Teilnehmerinnen und Teilnehmern online zum Austausch.

Einmal pro Monat reichen Sie einen Text ein, den Barbara Budrich Ihnen anredigiert zurückreicht. Sie erhalten eine Fülle an Praxismaterialien, die Sie beim Schreiben und Publizieren unterstützen.

Es ist nicht notwendig, bereits publiziert zu haben (aber es schadet auch nicht), um aus dem Coaching viel für Ihre Karriere mitzunehmen.

\section{Coaching-Angebote}

Wir unterstützen Sie rund um alle Belange der Wissenschaftskommunikation, von der Entwicklung Ihres Schreibstils und der Überwindung von Schreibblockaden bis hin zur Druckreife Ihres Manuskripts und dem Entwurf Ihres individuellen akademischen Kalenders.

Sie haben dabei die Wahl zwischen 1:1-Coachings im persönlichen Gespräch oder 1:1-Coachings per Telefon oder online über eine Meeting-Software.

Unser halbjähriges Online-Wissenschaftscoaching hilft Ihnen beim Aufbau Ihrer wissenschaftlichen Karriere. Zur Auswahl stehen eine Basis-, Profi- und Premiumvariante sowie eine unverbindliche Schnupperversion.

Unser Online-Kurs „Vom ersten „PUH!“ zur Publikation“ hilft Ihnen mit wöchentlichen Coaching-Mails in sieben Schritten zur Veröffentlichung. 


\section{Schlüsselkompetenzen für die Wissenschaft}

\section{Unsere Trainer*innen}

Als Lektor*innen, Berater*innen und Verlagsmenschen begleiten wir die Wissenschaft seit Jahrzehnten mit Schwerpunkten im Bereich des wissenschaftlichen Schreibens und Publizierens. Unsere persönlichen Erfahrungen haben wir systematisch aufbereitet und geben sie in Workshops, Vorträgen und Coachings weiter.

\section{Barbara Budrich}

Verlegerin, Autorin \& Übersetzerin, jahrzehntelang als Wissenschaftslektorin tätig

\section{Miriam von Maydell}

Programmleiterin im Verlag Barbara Budrich, Studium der Germanistik und Anglistik (Schwerpunkt: Gender Studies) in Bonn, Potsdam und Lancaster, ehem. freie Lektorin

\section{Jakob Horstmann}

Journalist und Lektor in Deutschland, Großbritannien und Osteuropa, ehem. Lektor bei Zed Books in London, nun selbstständig

\section{Feedback}

„Im Rahmen unseres Mentoring-Programms für Nachwuchswissenschaftler* innen ist Barbara Budrich jährlich zu Gast und gibt den Teilnehmer*innen wertvolle Einblicke hinter die Kulissen eines Verlags. Sie gibt Tipps zum Publizieren in der Wissenschaft und schafft es mit ihrer warmherzigen und nahbaren Art, den Teilnehmer*innen die Scheu vor der Ansprache von Verlagen zu nehmen." Julia Küchel, Koordinatorin der Veranstaltungen des Gleichstellungsbüros der Universität Siegen

"Eine super Referentin mit extrem viel Knowhow!"

Feedback zum Schreibworkshop von Barbara Budrich am 08.10.2020 an der

Universität Halle im Rahmen des MeCoSa-Mentoring- und Coachingprogramms Sachsen-Anhalt

„Die Trainerin war sehr kompetent und ist auf Fragen eingegangen. Es wurde viel Wert darauf gelegt, dass Vortrag mit Plenumsdiskussion und Einzelaufgaben abgewechselt wurden und somit die Zeit vor dem Bildschirm abwechslungsreich war, was wiederum der Konzentration dienlich war." Feedback zum Workshop „Publizieren der Dissertation“ von Barbara Budrich am 22.01.2021 im Rahmen von GRADE der Universität Frankfurt

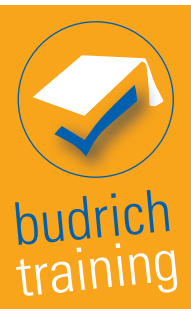

Kontakt

budrich training | Magdalena Gromada Stauffenbergstr. 7 | 51379 Leverkusen Tel.: (+49) (0)2171 7949150 | Fax: (+49) (0)2171 7949169 magdalena.gromada@budrich.de|www.budrich-training.de 


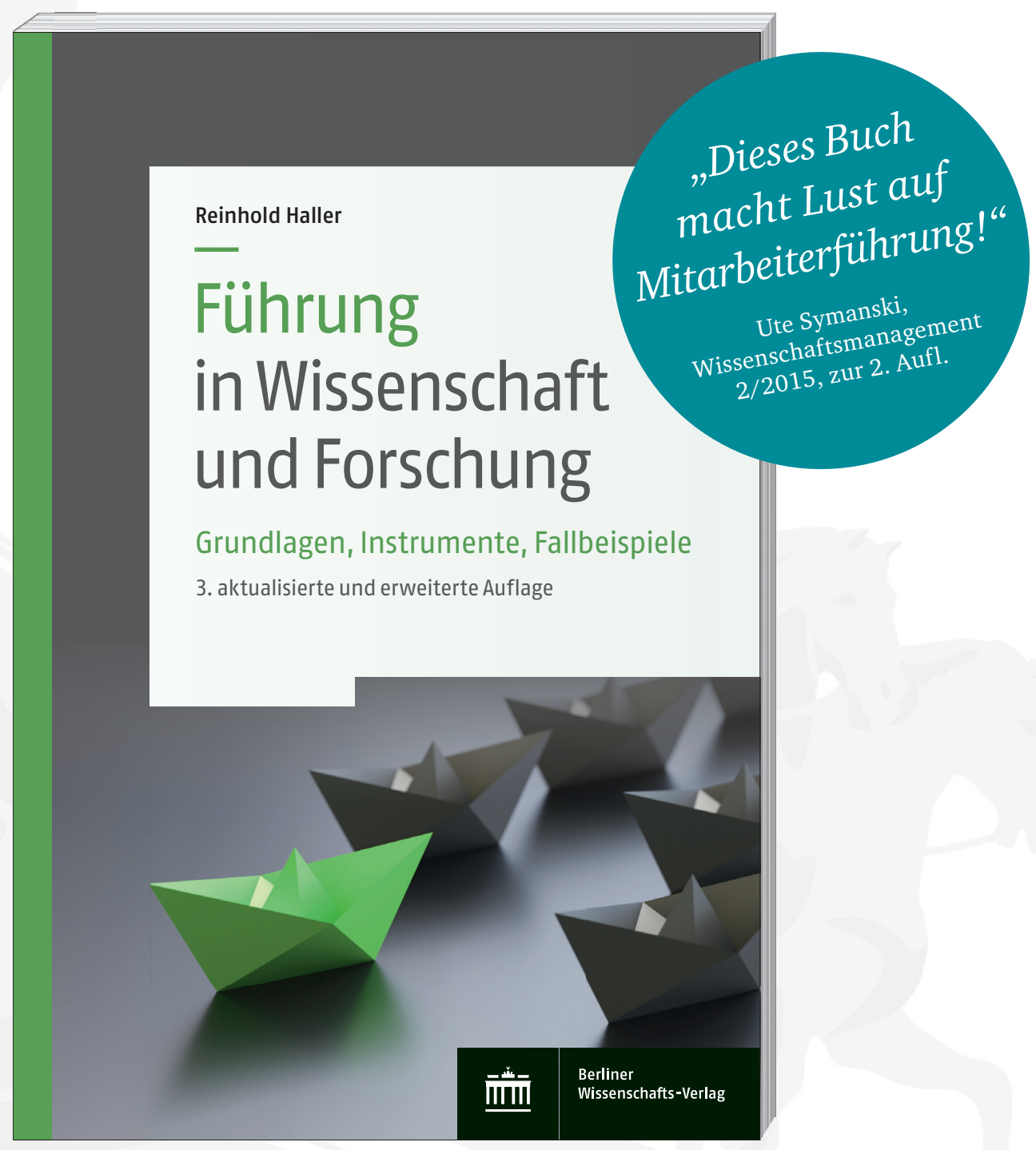

\section{Reinhold Haller}

\section{Führung in Wissenschaft und Forschung}

Grundlagen, Instrumente, Fallbeispiele

Unterscheidet sich die Führung im akademischen Bereich von der in öffentlicher Verwaltung oder freier Wirtschaft? Ja, sagt Reinhold Haller. Dieses Handbuch vermittelt Informationen, Fallbeispiele und Arbeitshilfen für eine nachhaltig motivierende und effiziente Personalführung speziell für den Bereich Wissenschaft und Forschung. Mit zahlreichen Modellen, Tools, Checklisten und Hilfsmitteln finden angehende und erfahrene Führungskräfte aus dem Wissenschaftsbereich ein praxisorientiertes und kompaktes Handbuch zur Personalführung.

Lernen Sie, wie Sie

- als Neuling in die Führungsrolle finden,

- methodisch bedachte Führungsstile einsetzen,

- strategisch planen,

- erfolgreich steuern durch laterale und agile Führung,

- Jahres-/Orientierungsgespräche führen,

- ziel- und lösungsorientiert kommunizieren,

- mit Performance-Improvement die Teamergebnisse steigern,
- Delegation als Schlüsselfaktor nutzen,

- mit Changemanagement Veränderungen gestalten,

- durch strategisches Selbstmanagement die LifeBalance bewahren,

- passende MitarbeiterInnen auswählen,

- sich selbst führen durch Selbstorganisation und LifeBalance sowie

- durch interkulturelle Führung und Diversität bestmögliche Chancengleichheit sicherstellen.

3. aktual. und erw. Aufl. 2020, 297 S., 46 s/w Abb., 47 s/w Tab., kart.,

39,90 €, 978-3-8305-5048-8 | EeBook PDF 978-3-8305-4214-8 